\title{
The role of neuroimaging phenotypes in ecogenetic studies of psychotic disorder
}

Citation for published version (APA):

Habets, P. A. M. (2011). The role of neuroimaging phenotypes in ecogenetic studies of psychotic disorder. [Doctoral Thesis, Maastricht University]. Maastricht University. https://doi.org/10.26481/dis.20110701ph

Document status and date:

Published: 01/01/2011

DOI:

10.26481/dis.20110701ph

Document Version:

Publisher's PDF, also known as Version of record

\section{Please check the document version of this publication:}

- A submitted manuscript is the version of the article upon submission and before peer-review. There can be important differences between the submitted version and the official published version of record.

People interested in the research are advised to contact the author for the final version of the publication, or visit the DOI to the publisher's website.

- The final author version and the galley proof are versions of the publication after peer review.

- The final published version features the final layout of the paper including the volume, issue and page numbers.

Link to publication

\footnotetext{
General rights rights.

- You may freely distribute the URL identifying the publication in the public portal. please follow below link for the End User Agreement:

www.umlib.nl/taverne-license

Take down policy

If you believe that this document breaches copyright please contact us at:

repository@maastrichtuniversity.nl

providing details and we will investigate your claim.
}

Copyright and moral rights for the publications made accessible in the public portal are retained by the authors and/or other copyright owners and it is a condition of accessing publications that users recognise and abide by the legal requirements associated with these

- Users may download and print one copy of any publication from the public portal for the purpose of private study or research.

- You may not further distribute the material or use it for any profit-making activity or commercial gain

If the publication is distributed under the terms of Article $25 \mathrm{fa}$ of the Dutch Copyright Act, indicated by the "Taverne" license above, 
The role of

neuroimaging phenotypes

in ecogenetic studies

of psychotic disorder

Petra Habets 
ISBN 978-90-8570-758-5

Cover design: David Baeyens

Printing: Wöhrmann Print Service

Lay out: Kim Habets

Copyright $\odot$ P. Habets, Maastricht 2011

All rights reserved. No part of this publication may be reproduced, stored in a retrieval system, or transmitted, in any form or by any means, electronic, mechanical, photocopying, recording, or otherwise, without the prior permission in writing from the proprietor. 


\section{The role of neuroimaging phenotypes in ecogenetic studies of psychotic disorder}

\section{PROEFSCHRIFT}

Ter verkrijging van de graad van doctor aan de Universiteit Maastricht,

$$
\text { op gezag van }
$$

de Rector Magnificus, Prof. mr. G.P.M.F. Mols,

volgens het besluit van het College van Decanen,

in het openbaar te verdedigen op vrijdag 1 juli 2011 om 12:00u

$$
\text { door }
$$

\section{Petra Habets}

Geboren op 10 mei 1981 te Maaseik, België 


\section{Promotor}

Prof. dr. J. van Os

\section{Co-Promotor}

Dr. M. Marcelis

\section{Beoordelingscommissie}

Prof. dr. M. de Vries (voorzitter)

Prof. dr. R. Kahn, UMC Utrecht

Prof. dr. I. Myin-Germeys,

Prof. dr. J. Suckling, Cambridge, England

Dr. R. van Winkel

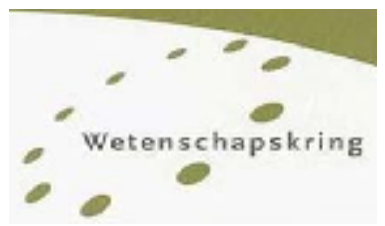

South Limburg Mental Health and Teaching Network PhD Series

The research presented in this thesis was conducted at the School for Mental health and Neuroscience, Department of Psychiatry and Neuropsychology of Maastricht University, Maastricht University Medical Centre and Mondriaan.

Publication of this thesis was financially supported by: Lilly Nederland 
To the key players in my memories 


\section{Paranimfen}

Ilse Pipeleers

Kim Habets 
CONTENTS

\section{Chapter 1}

General introduction

\section{Chapter 2}

Cortical thickness alterations and risk for psychotic disorder: evidence for an intermediate phenotype

\section{Chapter 3}

Reduced cortical thickness as an outcome of differential sensitivity to environmental risks in schizophrenia

\section{Chapter 4}

Pituitary volume, stress-reactivity and genetic risk for schizophrenia

\section{Chapter 5}

Hippocampal volume as marker of daily life emotional and cortisol stresssensitivity in psychosis

\section{Chapter 6}

General discussion

English summary

Nederlandse samenvatting

Dankwoord

Curriculum Vitae

List of publications 



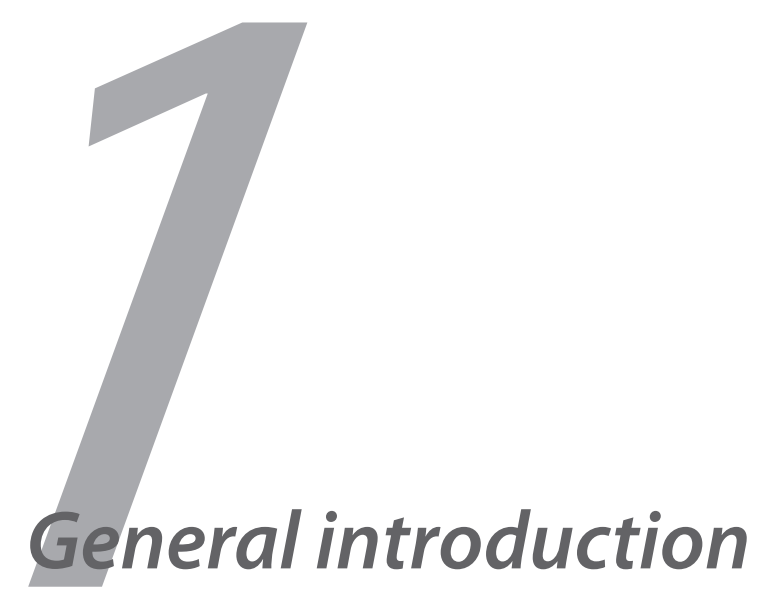




\section{PSYCHOTIC DISORDER}

"And then one voice says that I have an easy life, another that I complain too much, and again another voice says that I have a difficult life and they fight and scream to each other and it's like my body isn't my own anymore, like different persons are intertwining with my body and develop and rise against each other, it is dreadful. I do not know what I do at night, this is so scary. There is still fear. Even in my own room. The learning process of a person who does not know what he wants to learn.

My world. Fast. When you say one word, a thousand pass my mind.

So many worlds. Of which I am ashamed of. My body. A home for different people, whom each have a different identity and world. They all have different ways to deal with things. One is better with dealing and then that one will do the talking.

My mind,

A mind that is afraid to show what it feels."

(Scheeren, 2006, p. 23)(1)

Psychotic disorder is a collective term for a group of serious mental illnesses characterised by abnormalities in perception of reality and disruption of thought processes. The most known psychotic disorder is schizophrenia with a lifetime prevalence of $1 \%$ (2) and with the highest disability rating when compared to other mental illnesses (3). According to the Diagnostic and Statistical Manual of Mental Disorders IV (DSM-IV) classification system (4), a psychotic disorder is diagnosed when symptomatology is severe enough to cause social and occupational dysfunction over a period of at least six months (5).

Psychotic disorder is often characterised by both positive and negative symptoms in the long term; however, disorganised behaviour and affective symptoms may be present. Positive symptoms involve impaired reality testing and include delusions and hallucinations. A delusion is a fixed false belief, such as the incorrect belief that one is being followed by government organisations. A variety of delusions can occur, and the specific delusional content is influenced by the person's life and/or sociocultural setting. Hallucinations are sensory experiences without an external stimulus and can occur in any of the five sensory modalities although auditory hallucinations are the most common (6). Negative symptoms involve blunted affect, poverty of speech, anhedonia, and reduced motivational drive and will $(7,8)$.

Although psychotic disorder is still diagnosed in the DSM-IV (9) as a categorical 
defined set of symptoms, thus suggesting clear cut-off points between ill and healthy individuals, epidemiological research in the general population has shown that (subclinical) psychotic symptoms are present at a prevalence rate of $4 \%$, whereas an even larger proportion (8\%) report subclinical psychotic experiences (10). This finding suggests the existence of quantitative differences between "ill" and "healthy" individuals or a continuum of psychotic phenomena. Also, the marked heterogeneity of psychotic disorder and its pathophysiology and aetiology has become increasingly evident (11). In an attempt to reduce the heterogeneity, several dichotomous approaches have been developed. One of these dichotomous approaches distinguishes between type 1 and type 2 schizophrenia. Type 1 schizophrenia, also called the positive syndrome or non-developmental type, is characterised by high levels of positive symptoms, sudden onset, an episodic course with a good outcome and good response to antipsychotics. In contrast, type 2 schizophrenia, also called the negative syndrome or developmental type, is characterised by high levels of negative symptoms and cognitive impairments, a gradual onset, a chronic course with a poor outcome and resistance to drug treatment (12-17). However, the proposed dichotomous approaches have been found to be insufficient in explaining the heterogeneity of the disorder (18). More recently, the dimensional approach, in which psychopathology is rated on several symptom dimensions (i.e., groups of symptoms that occur together more often than would be expected by chance alone), has gained support (19-22). Using exploratory factor analyses, individuals can be defined by level scores on different dimensions that might co-exist. The initial work in this area examined the factor structure of the diagnostic category of schizophrenia and found evidence for three symptom dimensions: positive, negative and disorganised symptoms. When measures of affective symptomatology are considered, a five-factor model seems to apply with depressive and manic dimensions added to the list (19).

\section{AETIOLOGY: GENE-ENVIRONMENT INTERACTIONS}

Using family, adoption and twin studies, researchers have found that $80 \%$ of the liability to psychotic disorder has a genetic origin $(23,24)$. However, the search for candidate-risk genes for psychotic disorder is complicated due to the high phenotypic variability, diagnostic uncertainty, small effect of the identified genetic 
risk and gene-gene interactions (24-27). Moreover, gene-environment interaction (GxE), which is genetically mediated sensitivity to the environment or vice versa, genetic expression that is conditional on the environment is also implicated in psychotic disorder. The influence of genetic effects could be misinterpreted if environmental effects are not considered (28). For example, simulations have shown that, of the $80 \%$ of the genetic liability, a proportion can be attributed to GxE (29). Further support for the influence of environmental factors has come from the finding that concordance rates in genetically identical monozygotic twins are approximately $50 \%$.

The current view is that genetic, epigenetic and environmental factors combine via synergy or interaction in defining the risk for psychotic disorder (28). Research has identified several environmental risk factors for psychotic disorder such as living in an urban environment, social defeat, (childhood) trauma, daily life stress, cannabis use and obstetric complications. For the purpose of this thesis, we will focus on childhood trauma, cannabis use and daily life stress.

\section{Childhood trauma}

Studies have shown a relationship between the risk for developing a psychosis and exposure to traumatic events during childhood (30-33). A review by Read and colleagues (2005) found a $60.2 \%$ prevalence of sexual or physical abuse in patients with psychotic disorder. Moreover, there is evidence for a dose-response relationship between childhood trauma levels and psychotic symptoms, suggesting causality (34). More importantly, longitudinal $(31,35)$ population-based studies found that the risk of experiencing psychotic symptoms is increased in those exposed to early trauma compared to those not exposed.

During childhood, the brain is still fully developing and, therefore, is susceptible to changes. Childhood trauma may, consequently, cause neurodevelopmental abnormalities such as hippocampal volume reductions (36), contributing to an increased risk for psychotic disorder (37). However, whether brain alterations in psychotic disorder are associated with childhood trauma has not been investigated. 


\section{Cannabis}

Another environmental factor linked to the development of psychotic disorder is cannabis use (39). In 2007, approximately $24 \%$ of the general Dutch population had tried cannabis at least once in their life. This frequency is even higher in the psychotic disorder population (51\% in first-episode psychosis) (38). Patients who use cannabis have an earlier age of onset $(39-41)$, worse outcome $(42,43)$ and more positive symptoms (40) than patients who have never used cannabis. Furthermore, when healthy individuals with no history of cannabis abuse were injected with 5 $\mathrm{mg} \delta$-9-tetrohydrocannabinol $(\delta-9-\mathrm{THC})$, the active ingredient of cannabis, they experienced psychotic-like positive and negative symptoms (44). In contrast, a large case-register study investigated the effect of cannabis on the symptomatology in patients with and without cannabis use prior to first symptomatology and found no differences between groups (45).

The mechanisms underlying the association between cannabis use and psychotic symptoms have not yet been determined, but it has been proposed that Val allele carriers of the COMT Val ${ }^{158}$ Met gene are more prone to develop psychotic symptoms than carriers of the Met allele when using cannabis $(46,47)$. THC is thought to increase mesolimbic dopamine signalling, and its acute effects on the emergence of psychotic symptoms may be most prominent in individuals with the Val/Val genotype, as the COMT Val ${ }^{158}$ Met Val allele is associated with higher levels of mesolimbic dopamine signalling compared to the Met allele (48). Furthermore, a recent study found evidence for the AKT1 gene influencing the association between cannabis use and risk for psychosis: genetic variation in AKT1 moderated the relationship between recent cannabis use and the level of schizotypy in siblings of patients with psychotic disorder. In patients, increased risk allele loading was associated with increased sensitivity to lifetime cannabis use, influencing the risk for psychotic disorder.

Cannabis may have an effect on synaptic plasticity, which is believed to be impaired in psychotic disorder (49) and is found to influence brain maturation during adolescent development (50). Because important brain maturational events, such as synaptic pruning, elaboration of dendritic arborisation and increased myelination, continue into early adulthood, sensitive periods for exposure to environmental risk factors such as cannabis use are not confined to the period between gestation and childhood (51). Furthermore, frontal and temporal cortical abnormalities, which have been replicated many times in psychotic disorder, mature last and could thus be most vulnerable for environmental (and genetic) influences $(52,53)$. 
To date, only a few studies have investigated the effect of cannabis on brain structure in healthy individuals. These studies have been reviewed by Quickfall and coworkers (2006), who concluded that there is only minimal evidence for an effect of cannabis use on the human brain (54-56). With regard to psychotic disorder, studies investigating grey matter volume have produced mixed findings. Most studies did not find an effect of cannabis use in psychotic disorder (57), but there has been some suggestion for grey matter volume changes from cross-sectional (58) and longitudinal (59) studies. Clearly, more research is needed to further elucidate the relationship between brain changes in psychotic disorder and cannabis use.

\section{Stress-reactivity}

An important trait marker for psychosis is increased stress-reactivity. This marker does not only apply to the major stressors in one's life (60) but also to the more frequently occurring, small, daily-life events $(61,62)$. With the experience sampling method (ESM), a structured diary technique, current context, mood, and psychotic symptoms in daily life can be assessed. This method, applied to patients with psychotic disorder and first-degree relatives of patients with psychotic disorder, has yielded evidence for increased sensitivity to daily life stressors resulting in heightened negative emotions (62) and psychotic experiences (63). Furthermore, in a general population twin sample, increased psychometric risk for psychosis (i.e., high scores on a schizotypy questionnaire) was associated with increased emotional reactivity to stress (64). Additionally, a cross-trait, cross-twin association between stress-reactivity and subclinical psychosis was found, providing evidence for an unconfounded intermediate phenotype associated with genetic risk for psychosis (65). This increased stress-reactivity is associated with increased cortisol levels and has also been found in people at higher than average genetic risk for psychotic disorder with first-degree relatives displaying intermediate scores $(62,63)$. The underlying neural mechanisms of this augmented stress-sensitivity have not yet been identified. It has been hypothesised that this increased stress-sensitivity is associated with hyperactivity of the body's stress regulator: the hypothalamicpituitary-adrenal (HPA) axis. However, the association between sensitivity to stress and proxy measures for HPA axis functioning, such as pituitary volume, hippocampal volume and cortisol levels, has not been examined in relation to genetic risk for psychotic disorder. 
Even at the first description of schizophrenia by Kraeplin, he stated that the pathogenesis of schizophrenia, or "dementia praecox" as he named it, has a neurobiological underpinning (66). The technological advances of the last four decades have resulted in the development of non-invasive imaging tools, such as Magnetic Resonance Imaging (MRI), making it possible to investigate the brain in vivo. These tools have been used to discover and unravel the neural basis of psychotic disorder. Grey matter brain alterations in psychotic disorder have been extensively researched cross-sectionally $(67,68)$ and longitudinally $(69-71)$ and have been associated with clinical measures, such as outcome $(72,73)$, cognitive functioning $(74,75)$ and positive symptoms $(76,77)$. Numerous studies have found evidence for widespread brain alterations, suggesting that psychotic disorder may not be a disorder of a single brain area but rather a disorder of brain networks (78-83). Diffusion tensor imaging (DTI) and resting state functional imaging data studying the connectivity between brain regions lend additional support to this theory (84, 85). The most consistent regional grey matter changes in psychotic disorder are volume reductions in the superior temporal gyrus (STG) and the parahippocampal gyrus $(67,68)$. Although some of these brain alterations have been found to be present near disease onset (86-88), it is not clear when these changes occur and whether or not these changes have a progressive nature. Several studies have found evidence for progressive brain volume loss $(69,89,90)$ whereas other studies have not (91-93).

\section{Cortical thickness}

Measurements of grey matter volume may be too coarse to detect anatomical differences because volume is a combination of a region's surface area and cortical thickness, and changes in either measure can be missed unless they are measured independently. Furthermore, variations in regional folding patterns of the cortex may explain variations in grey matter volumes. Fornito and co-workers (2008) examined cortical thickness and grey matter volume of the anterior cingulate in firstepisode patients (FEP). They did not find differences in grey matter volume between patients and controls, but they did find a bilateral reduction in cortical thickness in the anterior cingulate (94). Their study demonstrated that microstructural changes in cortical thickness can be detected when macrostructural brain measurements, 
such as grey matter volume, do not indicate noticeable differences.

Cortical thickness is a proxy measure for cytoarchitectural integrity. Diffuse alteration in cortical thickness may be an index of differences in the number of dendrites, dendritic spines, synapses $(95,96)$ or in reduced neuropil $(97)$, which could result in disruptions of the neural circuits (98). Investigating cortical thickness may ultimately provide better insight into the causes and mechanisms contributing to the emergence and persistence of psychotic disorder.

Studies that have examined cortical thickness in psychotic disorder have made use of Region of Interest (ROI) and surface-based volumetry approaches. Because of the different ROIs that have been used, direct comparisons are difficult and findings are neither robust nor consistent. Main findings of ROI studies on chronic patients include reductions in frontal and temporal regions, in the cingulate (93, 99-102), in the parietal (93) and in the occipital regions (103). ROI studies on FEP suggest cortical thinning in the insula (101), cingulate (94), temporal and frontal regions (104-107) though some studies did not detect frontal alterations in this group (108, 109). Surface-based studies on FEP have reported reductions in cortical thickness in the frontal, temporal, parietal, occipital and cingulate regions $(105,106,110-113)$ with one study reporting no differences between groups (104). In chronic patients, frontal and temporal thinning $(93,100,103,114)$, together with some evidence for parietal (93) and occipital thinning (103), have been described.

\section{Intermediate phenotypes}

The concept endophenotype or, the more accurate term, intermediate phenotype, was first proposed by Gottesman and Gould (2003) and can be defined as a biological marker of illness with a genetic underpinning. A candidate intermediate phenotype may be of neurophysiological, biochemical, neuroanatomical, or cognitive origin. Gottesman and Gould also offered a set of definitions for such biological markers. The intermediate phenotype (1) is associated with psychotic disorder, (2) is heritable, (3) is present even when the illness is not active (e.g., is state independent), (4) cosegregates with psychotic disorder within families, (5) and is present at higher rates than in unaffected family members when compared to the general population (115).

The search for intermediate phenotypes, such as shared structural brain alterations in patients and siblings, provides a means to circumvent the problems related to genetic studies (115). Genes predisposing to the clinical phenotype may be 
transmitted without the expression of the clinical phenotype, thereby providing a more liable index of vulnerability than the illness itself. Furthermore, clinical heterogeneity can be further reduced by examining these quantitative biological markers as they are believed to be more proximal to the pathophysiological processes than the qualitative clinical diagnostic categories. Also, it is possible that several intermediate phenotypes contribute to the development of psychosis and that these are independent from each other. Identification of such intermediate phenotypes may, thus, lead to an improvement in diagnostic practices and to an increased knowledge on the causes of the illness.

Grey matter volume deficits as candidate intermediate phenotypes have been studied using family (116-118) and twin studies $(119,120)$. Overall, the studies investigating grey matter volume in non-psychotic relatives have provided mixed results, but a recent meta-analysis examining volumetric differences in total brain, intracranial ventricles, total grey matter, total white matter, amygdala, hippocampus and total cerebrospinal fluid concluded that reduced hippocampal volume appears to be the most affected area (121).

Only a few studies have examined cortical thickness in healthy relatives. Goghari and colleagues (2007) examined the relationship between cortical thickness/grey matter volume and genetic liability for psychotic disorder in 19 first-degree relatives of psychotic disorder patients and 22 controls $(122,123)$. They found bilaterally reduced cortical thickness in the cingulate gyrus and in the superior temporal sulcus. In another small study (28 patients, 28 siblings, 38 healthy controls), Calabrese and co-workers (2008) found that grey matter volume in the posterior cingulate gyrus in subjects with psychotic disorder and their non-psychotic siblings is reduced compared to healthy control subjects. Their analysis on cortical thickness and surface area reflect trend-level significant effects (102). In addition, a large study investigating 115 patients, 192 siblings and 196 controls found widespread cortical thinning in patients (predominantly in the frontal and temporal regions), but concluded that there were no significant differences in siblings compared to controls (82). This lack of clear evidence for cortical thickness alterations in siblings is consistent with other recent studies $(103,109,124)$.

In sum, volumetric imaging studies have provided some evidence for brain alterations in siblings compared to controls with the strongest evidence for hippocampal volume reductions. However, the few studies on cortical thickness to date have failed to support the existence of a structural intermediate phenotype. 
Importantly, MRI studies on psychotic disorder have rarely taken into account the effect of environmental factors which, in addition to presenting methodological issues, may well have affected the interpretation of some of the results from the neuroimaging literature.

Taken together, several environmental factors such as trauma, cannabis use and stress are thought to play a role in psychotic disorder. Hypotheses about underlying brain alterations and biological mechanisms through which environmental factors influence this risk are increasingly being put forward, but not many clinical studies in psychotic disorder have, as yet, tested these hypotheses. In other words, integrative studies wherein genetic-epidemiology is, for example, combined with the field of neuroimaging, are still scarce. Thus, a more translational view is needed to identify biological consequences of environmental risk factors that may impact the risk of psychosis (125). In this thesis, the association between brain alterations and environmental risk factors in psychotic disorder were investigated using a genetically sensitive sample, attempting to bridge neuroscientific and genetic-epidemiologic research on psychotic disorder.

\section{GROUP PROJECT}

Subjects were recruited from a multi-site longitudinal cohort study: Genetic Risk and Outcome of Psychosis (GROUP). This national study aimed at investigating risk and protective factors involved in the aetiology of psychotic disorder. The GROUP consortium consists of the academic psychiatric centres of Amsterdam, Groningen, Maastricht and Utrecht and their affiliated mental health care institutions (including some in Belgium). Data have been collected for a population-based cohort including 1120 patients with non-affective psychotic disorder, 1057 siblings of these 1120 patients, 919 parents of the patients and 590 unrelated controls. Assessments included symptomatology measures, various risk and protective factors, blood and urine samples for DNA analyses and drug screenings (126). In addition to the multicenter GROUP data, MRI scans were obtained locally at Maastricht University. The MRI study sample consisted of 89 patients with psychotic disorder, 98 nonpsychotic siblings of patients with psychotic disorder, and 87 controls. The studies described in this thesis were based on (subgroups of) this sample. 
The overall aim of this thesis was to examine potential determinants of structural brain alterations in psychotic disorder, using a family-based study design (as described above) and representing different levels of risk for psychotic disorder. First, it was examined whether cortical thickness may be a candidate intermediate phenotype for psychotic disorder. Secondly, it was tested whether there is evidence for GxE using two environmental exposures (childhood trauma and cannabis use) in models of cerebral cortical thickness. Finally, associations between specific brain volumes and stress-reactivity were investigated to provide more insight into the biological framework related to increased stress-reactivity in psychotic disorder.

\section{Structural intermediate phenotypes}

In chapter 2, cortical thickness was investigated as a function of the level of genetic risk for psychosis. Twin studies have provided evidence for a strong genetic component contributing to certain neuroanatomical phenotypes in psychotic disorder. Due to its sensitivity, cortical thickness measures may have greater potential than volumetric measures in identifying small anatomical differences in patients, especially in siblings at higher than average genetic risk for psychotic disorder. To test whether cortical thickness may be a marker of genetic risk, cortical thickness measurements were obtained from the patients with psychotic disorder, their nonaffected siblings and the controls. Group differences in cortical thickness were analysed. Based on previous literature, the hypothesis was that patients would have a pattern of decreased cortical alterations in frontal and temporal areas and that siblings would share this pattern of cortical decrements with their ill family member to a certain extent. Furthermore, it was expected that environmental factors, such as antipsychotic medication and cannabis use, would explain some of the variations in brain alterations in individuals at high genetic risk.

\section{Gene-environment interactions and cortical thickness}

As mentioned earlier, differences in genetic liability can be explained by differences in genetic make-up, occasioning differential sensitivity to environmental risk factors. This GxE phenomenon is thought to play an important role in schizophrenia. Examining GxE is difficult because risk factors for developing psychotic disorder, such as cannabis use and childhood trauma, are susceptible to bias and reverse 
causality. For example, patients may use cannabis and report more childhood trauma because of their illness. Experimental designs can overcome these issues, but this study design cannot always be conducted for ethical reasons. Alternatively, the illness phenotype (outcome variable) can be replaced with an objective biological measure that is only weakly associated with (risk for) psychotic disorder. In chapter 3, the aim was to examine whether cortical thickness alterations as an objective biological measure can be identified as an outcome of differential sensitivity to cannabis use and childhood trauma. Again, the family-based design was used in which patients and siblings represented the high genetic risk group and control subjects represented the low genetic risk group. The hypothesis was that a higher genetic risk would be associated with a greater impact of environmental exposures on the cortical phenotype.

\section{Stress-reactivity, genetic risk and regional brain volumes}

In chapters $\mathbf{4}$ and 5, the relationship between volumes of specific brain structures was investigated in relation to stress-reactivity and the genetic risk for psychosis. Patients with psychotic disorder and their siblings demonstrate increased stressreactivity, that is, they experience heightened negative emotions and psychotic symptoms in response to daily life stressors. In addition, this increased emotional stress-reactivity is associated with increased cortisol levels in people at higher than average genetic risk for psychotic disorder. Furthermore, previous studies have suggested that pituitary volume is associated with (the vulnerability for) psychotic disorder. It could thus be hypothesised that the increased stress-reactivity in psychotic disorder is associated with increased pituitary volume, the latter being a proxy measure for HPA axis dysfunction. The study described in chapter $\mathbf{4}$ tested this hypothesis by examining group (patients, siblings, controls) differences in the experience of negative emotions (emotional stress-reactivity) and cortisol levels (biological stress-reactivity) in the context of daily life stressors. Moreover, it was examined whether stress-reactivity is not only dependent on the level of genetic risk for psychotic disorder but also dependent on pituitary volume.

Reduced hippocampal size and increased sensitivity to stress are associated with a genetic risk for psychotic disorder. The role of hippocampal volume in daily life stressreactivity in psychotic disorder has never been examined. Hippocampal volume may be appraised as a proxy for HPA axis dysfunction because the hippocampus plays a role in the negative feedback mechanism of the HPA axis. The hypothesis would 
be that lower hippocampal volume would lead to diminished negative feedback, resulting in higher HPA axis functioning. In chapter 5, the association between hippocampal volume and the experience of negative emotions (emotional stressreactivity) and cortisol levels (biological stress-reactivity) was examined in the context of daily life stressors, and it was examined whether genetic risk for psychotic disorder moderated this association.

In chapter 6, the results are discussed and implications for clinical practice as well as directions for future research are given. In chapter 7, a summary of the presented studies is provided. 


\section{References}

1. Scheeren B, Vaessen G. Overleven met schizofrenie / Surviving with schizophrenia Apeldoorn: Garant-Uitgevers; 2006.

2. Jablensky A, Sartorius N, Ernberg G, et al.

Schizophrenia: manifestations, incidence and course in different cultures. A World Health Organization tencountry study. Psychol Med Monogr Suppl. 1992;20:1-97.

3. Eaton WW, Martins SS, Nestadt G, Bienvenu OJ, Clarke D, Alexandre P. The burden of mental disorders. Epidemiol Rev. 2008;30:1-14.

\section{APA. DSM-IV: Diagnostic} and Statistical Manual of Mental Disorders 4ed. Washington, DC: The Association; 1994.

\section{Association AP. Diagnostic} and Statistical Manual of Mental Disorders. .

Washington, DC: American

Psychiatric Association.; 1994.

6. Tandon R, Nasrallah HA, Keshavan MS. Schizophrenia, "just the facts" 4. Clinical features and conceptualization. Schizophr Res. May 2009;1 10(1-3):1-23.

7. Carpenter WT, Jr., Heinrichs DW, Wagman AM. Deficit and nondeficit forms of schizophrenia: the concept. Am J Psychiatry. May 1988;145(5):578-583.

8. Kirkpatrick B, Fenton WS, Carpenter WT, Jr., Marder SR. The NIMH-MATRICS consensus statement on negative symptoms. Schizophr Bull. Apr 2006;32(2):214-219.
9. APA. Diagnostic and statistical manual of mental disorders. 4th ed. Washington, DC: American Psychiatric Association; 2000.

10. van Os J, Linscott RJ, MyinGermeys I, Delespaul P, Krabbendam L. A systematic review and meta-analysis of the psychosis continuum: evidence for a psychosis proneness-persistenceimpairment model of psychotic disorder. Psychol Med. Jul 8 2009:1-17.

11. McCormick LM, Flaum M. Diagnosing schizophrenia circa 2005: how and why? Curr Psychiatry Rep. Aug 2005;7(4):311-315.

12. Andreasen NC. Positive vs. negative schizophrenia: a critical evaluation. Schizophr Bull. 1985;11(3):380-389.

13. Andreasen NC, Flaum $M$, Swayze VW, 2nd, Tyrrell G, Arndt S. Positive and negative symptoms in schizophrenia. A critical reappraisal. Arch Gen Psychiatry. Jul 1990;47(7):615621.

14. Murray RM, Lewis SW. Is schizophrenia a neurodevelopmental disorder? BrMed J (Clin Res Ed). Jan 2 1988;296(6614):63.

15. Murray RM, O'Callaghan E, Castle DJ, Lewis SW. A neurodevelopmental approach to the classification of schizophrenia. Schizophr Bull. 1992;18(2):319-332.

16. van Os J, Fahy TA, Jones $P$, et al. Psychopathological syndromes in the functional psychoses: associations with course and outcome. Psychol Med. Jan 1996;26(1):161-176.
17. Van Os J, Gilvarry C, Bale R, et al. A comparison of the utility of dimensional and categorical representations of psychosis. UK700 Group. Psychol Med. May 1999;29(3):595-606.

18. Roy MA, Merette C, Maziade M. Subtyping schizophrenia according to outcome or severity: a search for homogeneous subgroups. Schizophr Bull. 2001;27(1):115-138.

19. Allardyce J, Suppes T, Van Os J. Dimensions and the psychosis phenotype. Int $J$ Methods Psychiatr Res. 2007;16 Suppl 1:S34-40.

20. Linscott RJ, van Os J. Systematic reviews of categorical versus continuum models in psychosis: evidence for discontinuous subpopulations underlying a psychometric continuum. Implications for DSM-V, DSMVI, and DSM-VII. Annu Rev Clin Psychol. Apr 27;6:391-419.

21. McGorry PD, Bell RC, Dudgeon PL, Jackson HJ. The dimensional structure of first episode psychosis: an exploratory factor analysis. Psychol Med. Jul 1998;28(4):935-947.

22. Van Os J. Are psychiatric diagnoses of psychosis scientific and useful? The case of schizophrenia. JMent Health. Aug;19(4):305-317.

23. Gottesman I, Shields J. Schizophrenia: The Epigenetic Puzzle. New York: NY: Cambridge University Press 1982.

24. Sullivan PF, Kendler KS, Neale MC. Schizophrenia as a complex trait: evidence from a meta-analysis of twin studies. Arch Gen Psychiatry. Dec 2003;60(12):1187-1192. 
25. Kennedy JL, Farrer LA, Andreasen NC, Mayeux R, St George-Hyslop P. The genetics of adult-onset neuropsychiatric disease: complexities and conundra? Science. Oct 31 2003;302(5646):822-826.

26. Cannon TD, Kaprio J, Lonnqvist J, Huttunen M, Koskenvuo M. The genetic epidemiology of schizophrenia in a Finnish twin cohort. A populationbased modeling study. Arch Gen Psychiatry. Jan 1998;55(1):67-74.

27. van Os J, Marcelis M. The ecogenetics of schizophrenia: a review. Schizophr Res. Jul 27 1998;32(2):127-135.

28. van Os J, Kenis G, Rutten BP. The environment and schizophrenia. Nature. Nov 11 2010;468(7321):203-212.

29. van Os J, Sham P. Geneenvironment interactions. In: Murray RM, Jones, P.B., Susser, E., et al., ed. The Epidemiology of Schizophrenia. Cambridge: Cambridge University Press; 2003:235-254.

30. Bebbington PE, Bhugra D, Brugha T, et al. Psychosis, victimisation and childhood disadvantage: evidence from the second British National Survey of Psychiatric Morbidity. Br J Psychiatry. Sep 2004;185:220-226.

31. Janssen I, Krabbendam L, Bak M, et al. Childhood abuse as a risk factor for psychotic experiences. Acta Psychiatr Scand. Jan 2004;109(1):38-45.

32. Whitfield CL, Dube SR, Felitti VJ, Anda RF. Adverse childhood experiences and hallucinations. Child Abuse Negl. Jul 2005;29(7):797-810.
33. Bendall $\mathrm{S}$, Jackson $\mathrm{HJ}$, Hulbert CA, McGorry PD. Childhood trauma and psychotic disorders: a systematic, critical review of the evidence. Schizophr Bull. May 2008;34(3):568-579.

34. Read J, van Os J, Morrison AP, Ross CA. Childhood trauma, psychosis and schizophrenia: a literature review with theoretical and clinical implications. Acta

Psychiatr Scand. Nov 2005;112(5):330-350.

35. Spauwen J, Krabbendam L, Lieb R, Wittchen HU, van Os J. Impact of psychological trauma on the development of psychotic symptoms: relationship with psychosis proneness. Br J Psychiatry. Jun 2006;188:527-533.

36. Andersen SL, Tomada A, Vincow ES, Valente $E$, Polcari A, Teicher MH. Preliminary evidence for sensitive periods in the effect of childhood sexual abuse on regional brain development. $J$

Neuropsychiatry Clin

Neurosci. Summer 2008;20(3):292-301.

37. Nemeroff CB. Neurobiological consequences of childhood trauma. J Clin Psychiatry. 2004;65 Suppl 1:18-28.

38. Barnett JH, Werners U, Secher SM, et al. Substance use in a population-based clinic sample of people with first-episode psychosis. $\mathrm{Br} J$ Psychiatry. Jun 2007;190:515520.

39. Hambrecht M, Hafner $\mathrm{H}$. Substance abuse and the onset of schizophrenia. Biol Psychiatry. Dec 1 1996;40(11):1155-1163.
40. Hambrecht $M$, Hafner $H$. Cannabis, vulnerability, and the onset of schizophrenia: an epidemiological perspective. Aust N Z J Psychiatry. Jun 2000;34(3):468-475.

41. Veen ND, Selten JP, van der Tweel I, Feller WG, Hoek HW, Kahn RS. Cannabis use and age at onset of schizophrenia. Am J Psychiatry. Mar 2004;161(3):501-506.

42. Kovasznay B, Fleischer J, Tanenberg-Karant $M$, Jandorf $L$, Miller AD, Bromet E.

Substance use disorder and the early course of illness in schizophrenia and affective psychosis. Schizophr Bull. 1997;23(2):195-201.

43. Pencer $A$, Addington $J$, Addington D. Outcome of a first episode of psychosis in adolescence: a 2-year followup. Psychiatry Res. Jan 30 2005;133(1):35-43.

44. D'Souza DC, Perry E, MacDougall $L$, et al. The psychotomimetic effects of intravenous delta-9tetrahydrocannabinol in healthy individuals: implications for psychosis. Neuropsychopharmacology. Aug 2004;29(8):1558-1572.

45. Boydell J, Dean K, Dutta R, Giouroukou E, Fearon P, Murray R. A comparison of symptoms and family history in schizophrenia with and without prior cannabis use: implications for the concept of cannabis psychosis. Schizophr Res. Jul 2007;93(1-3):203-210. 
46. Caspi A, Moffitt TE, Cannon $M$, et al. Moderation of the effect of adolescent-onset cannabis use on adult psychosis by a functional polymorphism in the catechol-O-methyltransferase gene: longitudinal evidence of a gene $X$ environment interaction. Biol Psychiatry. May 15 2005;57(10):11171127.

47. Henquet $C$, Rosa $A$, Delespaul $\mathrm{P}$, et al. COMT ValMet moderation of cannabis-induced psychosis: a momentary assessment study of 'switching on'

hallucinations in the flow of daily life. Acta Psychiatr Scand. Feb 2009;119(2):156-160.

48. Bilder RM, Volavka J, Lachman HM, Grace AA. The catechol-O-methyltransferase polymorphism: relations to the tonic-phasic dopamine hypothesis and neuropsychiatric phenotypes. Neuropsychopharmacology. Nov 2004;29(11):1943-1961.

49. Keshavan MS, Anderson S, Pettegrew JW. Is schizophrenia due to excessive synaptic pruning in the prefrontal cortex? The Feinberg hypothesis revisited. $J$ Psychiatr Res. May-Jun 1994;28(3):239-265.

50. Robbe D, Alonso G, Manzoni OJ. Exogenous and endogenous cannabinoids control synaptic transmission in mice nucleus accumbens. Ann $N$ Y Acad Sci. Nov 2003;1003:212-225.

51. Luna B, Thulborn KR, Munoz DP, et al. Maturation of widely distributed brain function subserves cognitive development. Neuroimage. May 2001;13(5):786-793.
52. Gogtay N, Giedd JN, Lusk L, et al. Dynamic mapping of human cortical development during childhood through early adulthood. Proc Natl Acad Sci U S A. May 25 2004;101(21):8174-8179.

53. Sowell ER, Trauner DA, Gamst A, Jernigan TL. Development of cortical and subcortical brain structures in childhood and adolescence: a structural MRI study. Dev Med Child Neurol. Jan 2002;44(1):416.

54. Quickfall J, Crockford D. Brain neuroimaging in cannabis use: a review. $J$ Neuropsychiatry Clin Neurosci. Summer 2006;18(3):318-332.

55. Block RI, O'Leary DS, Ehrhardt JC, et al. Effects of frequent marijuana use on brain tissue volume and composition. Neuroreport. Feb 28 2000;11(3):491-496.

56. Matochik JA, Eldreth DA, Cadet JL, Bolla Kl. Altered brain tissue composition in heavy marijuana users. Drug Alcohol Depend. Jan 7 2005;77(1):23-30.

57. Cahn W, Hulshoff Pol HE, Caspers $\mathrm{E}$, van Haren NE, Schnack HG, Kahn RS. Cannabis and brain morphology in recent-onset schizophrenia. Schizophr Res. Apr 1 2004;67(2-3):305-307.

58. Szeszko PR, Robinson DG, Sevy S, et al. Anterior cingulate grey-matter deficits and cannabis use in firstepisode schizophrenia. $\mathrm{Br} J$ Psychiatry. Mar 2007;190:230236.

59. Rais M, Cahn W, Van Haren $\mathrm{N}$, et al. Excessive brain volume loss over time in cannabis-using first-episode schizophrenia patients. $\mathrm{Am} \mathrm{J}$ Psychiatry. Apr 2008;165(4):490-496.
60. Lardinois $M$, Lataster $T$, Mengelers R, van Os J, MyinGermeys I. Childhood trauma and increased stress sensitivity in psychosis. Acta Psychiatr Scand. Aug 152010.

61. Myin-Germeys I, Oorschot M, Collip D, Lataster J, Delespaul P, van Os J. Experience sampling research in psychopathology: opening the black box of daily life.

Psychol Med. Sep 2009;39(9):1533-1547.

62. Myin-Germeys I, van Os J, Schwartz JE, Stone AA, Delespaul PA. Emotional reactivity to daily life stress in psychosis. Arch Gen Psychiatry. Dec 2001;58(12):1137-1144.

63. Myin-Germeys I, Delespaul $P$, van Os J. Behavioural sensitization to daily life stress in psychosis. Psychol Med. May 2005;35(5):733-741.

64. Lataster $T$, Wichers $M$, Jacobs N, et al. Does reactivity to stress cosegregate with subclinical psychosis? A general population twin study. Acta Psychiatr Scand. Jan 2009;119(1):45-53.

65. Lataster T, Collip D, Lardinois M, van Os J, MyinGermeys I. Evidence for a familial correlation between increased reactivity to stress and positive psychotic symptoms. Acta Psychiatr Scand. May 112010.

\section{Kraeplin E. Dementia} Praecox and Paraphrenia. Edinburgh: E \& S Linvingstone; 1913.

67. Shenton ME, Dickey CC, Frumin M, McCarley RW. A review of MRI findings in schizophrenia. Schizophr Res. Apr 15 2001;49(1-2):1-52. 
68. Wright IC, Rabe-Hesketh S, Woodruff PW, David AS, Murray RM, Bullmore ET. Metaanalysis of regional brain volumes in schizophrenia. Am $J$ Psychiatry. Jan 2000;157(1):16-25.

69. Hulshoff Pol HE, Kahn RS. What happens after the first episode? A review of progressive brain changes in chronically ill patients with schizophrenia. Schizophr Bull. Mar 2008;34(2):354-366.

70. Koo MS, Levitt JJ, Salisbury DF, Nakamura M, Shenton ME, McCarley RW. A crosssectional and longitudinal magnetic resonance imaging study of cingulate gyrus gray matter volume abnormalities in first-episode schizophrenia and first-episode affective psychosis. Arch Gen Psychiatry. Jul 2008;65(7):746760.

71. Brans RG, van Haren NE, van Baal GC, et al. Longitudinal MRI study in schizophrenia patients and their healthy siblings. $\mathrm{Br} J$ Psychiatry. Nov

2008;193(5):422-423.

72. Cahn W, van Haren NE, Hulshoff Pol HE, et al. Brain volume changes in the first year of illness and 5-year outcome of schizophrenia. Br J Psychiatry. Oct 2006;189:381382.

73. Mitelman SA, Buchsbaum MS. Very poor outcome schizophrenia: clinical and neuroimaging aspects. Int Rev Psychiatry. Aug 2007;19(4):345-357.

74. Habets $P$, Krabbendam $L$, Hofman $P$, et al. Cognitive Performance and Grey Matter Density in Psychosis: Functional Relevance of a Structural Endophenotype. Neuropsychobiology. Dec 16 2008;58(3-4):128-137.
75. Antonova E, Sharma T, Morris R, Kumari V. The relationship between brain structure and neurocognition in schizophrenia: a selective review. Schizophr Res. Oct 1 2004;70(2-3):117-145.

76. Shapleske J, Rossell SL, Chitnis XA, et al. A computational morphometric MRI study of schizophrenia: effects of hallucinations.

Cereb Cortex. Dec 2002;12(12):1331-1341.

77. Shenton ME, Kikinis R, Jolesz FA, et al. Abnormalities of the left temporal lobe and thought disorder in schizophrenia. A quantitative magnetic resonance imaging study. N Eng/J Med. Aug 27 1992;327(9):604-612.

78. Goldman AL, Pezawas L, Mattay VS, et al. Heritability of brain morphology related to schizophrenia: a large-scale automated magnetic resonance imaging segmentation study. Biol

Psychiatry. Mar 1 2008;63(5):475-483.

79. Honea R, Crow TJ, Passingham D, Mackay CE. Regional deficits in brain volume in schizophrenia: a meta-analysis of voxel-based morphometry studies. Am J Psychiatry. Dec 2005;162(12):2233-2245.

80. Tanskanen P, Ridler K, Murray GK, et al. Morphometric Brain Abnormalities in Schizophrenia in a PopulationBased Sample: Relationship to Duration of Illness. Schizophr Bull. Nov 172008.

81. Vita A, De Peri L, Silenzi C, Dieci M. Brain morphology in first-episode schizophrenia: a meta-analysis of quantitative magnetic resonance imaging studies. Schizophr Res. Feb 15 2006;82(1):75-88.
82. Goldman AL, Pezawas L, Mattay VS, et al. Widespread reductions of cortical thickness in schizophrenia and spectrum disorders and evidence of heritability. Arch Gen Psychiatry. May 2009;66(5):467-477.

83. Glahn DC, Laird AR, EllisonWright I, et al. Meta-analysis of gray matter anomalies in schizophrenia: application of anatomic likelihood estimation and network analysis. Biol Psychiatry. Nov 1 2008;64(9):774-781.

84. Kyriakopoulos M, Frangou $\mathrm{S}$. Recent diffusion tensor imaging findings in early stages of schizophrenia. Curr Opin Psychiatry. Mar 2009;22(2):168-176.

85. Whitfield-Gabrieli S, Thermenos HW, Milanovic S, et al. Hyperactivity and hyperconnectivity of the default network in schizophrenia and in firstdegree relatives of persons with schizophrenia. Proc Natl Acad Sci U S A. Jan 27 2009;106(4):1279-1284.

86. Lawrie SM, McIntosh AM, Hall J, Owens DG, Johnstone EC. Brain structure and function changes during the development of schizophrenia: the evidence from studies of subjects at increased genetic risk. Schizophr Bull. Mar 2008;34(2):330-340.

87. Wood SJ, Pantelis C, Yung AR, Velakoulis D, McGorry PD. Brain changes during the onset of schizophrenia: implications for neurodevelopmental theories. Med J Aust. Feb 16 2009;190(4 Suppl):S10-13.

88. Ziermans TB, Schothorst $P F$, Schnack HG, et al. Progressive Structural Brain Changes During Development of Psychosis. Schizophr Bull. Oct 72010. 
89. Hulshoff Pol HE, Schnack HG, Bertens MG, et al. Volume changes in gray matter in patients with schizophrenia. Am J Psychiatry. Feb 2002;159(2):244-250.

90. Whitford TJ, Grieve SM, Farrow TF, et al. Progressive grey matter atrophy over the first 2-3 years of illness in firstepisode schizophrenia: a tensor-based morphometry study. Neuroimage. Aug 15 2006;32(2):511-519.

91. Bose SK, Mackinnon T, Mehta MA, et al. The effect of ageing on grey and white matter reductions in schizophrenia. Schizophr Res. Jul 2009;112(1-3):7-13.

92. DeLisi LE, Hoff AL. Failure to find progressive temporal lobe volume decreases 10 years subsequent to a first episode of schizophrenia. Psychiatry Res. Apr 30 2005;138(3):265-268.

93. Kubota M, Miyata J, Yoshida $\mathrm{H}$, et al. Age-related cortical thinning in schizophrenia. Schizophr Res. Oct 282010.

94. Fornito A, Yucel M, Wood SJ, et al. Surface-based morphometry of the anterior cingulate cortex in first episode schizophrenia. Hum Brain Mapp. Apr 2008;29(4):478-489.

95. Benes FM. Why does psychosis develop during adolescence and early adulthood? Curr Opin Psychiatry. 2003;16:317-319.

96. Harrison PJ. The neuropathology of schizophrenia. A critical review of the data and their interpretation. Brain. Apr 1999;122 ( Pt 4):593-624.
97. Glantz LA, Gilmore JH, Lieberman JA, Jarskog LF. Apoptotic mechanisms and the synaptic pathology of schizophrenia. Schizophr Res. Jan 1 2006;81(1):47-63.

98. Benes FM. Searching for unique endophenotypes for schizophrenia and bipolar disorder within neural circuits and their molecular regulatory mechanisms. Schizophr Bull. Jul 2007;33(4):932-936.

99. Kuperberg GR, Broome MR, McGuire PK, et al. Regionally localized thinning of the cerebral cortex in schizophrenia. Arch Gen Psychiatry. Sep 2003;60(9):878-888.

100. Nesvag R, Lawyer G, Varnas K, et al. Regional thinning of the cerebral cortex in schizophrenia: effects of diagnosis, age and antipsychotic medication. Schizophr Res. Jan 2008;98(13):16-28.

101. Roiz-Santianez R, PerezIglesias R, Quintero C, et al. Insular cortex thinning in first episode schizophrenia patients. Psychiatry Res. Jun 30 2010;182(3):216-222.

102. Calabrese DR, Wang $L$, Harms MP, et al. Cingulate gyrus neuroanatomy in schizophrenia subjects and their non-psychotic siblings. Schizophr Res. Sep 2008;104(1-3):61-70.

103. Yang $\mathrm{Y}$, Nuechterlein $\mathrm{KH}$, Phillips O, et al. The contributions of disease and genetic factors towards regional cortical thinning in schizophrenia: the UCLA family study. Schizophr Res. Nov 2010;123(2-3):116-125.
104. Gutierrez-Galve L, Wheeler-Kingshott CA, Altmann DR, et al. Changes in the frontotemporal cortex and cognitive correlates in firstepisode psychosis. Biol Psychiatry. Jul 1 2010;68(1):5160.

105. Schultz CC, Koch K, Wagner G, et al. Complex pattern of cortical thinning in schizophrenia: results from an automated surface based analysis of cortical thickness. Psychiatry Res. May 30 2010;182(2):134-140.

106. Schultz CC, Koch K, Wagner G, et al. Reduced cortical thickness in first episode schizophrenia. Schizophr Res. Feb 2010;116(2-3):204-209.

107. Crespo-Facorro B, RoizSantianez R, Perez-Iglesias R, et al. Global and regional cortical thinning in firstepisode psychosis patients: relationships with clinical and cognitive features. Psychol Med. Oct 14 2010:1-12.

108. Wiegand LC, Warfield SK, Levitt JJ, et al. Prefrontal cortical thickness in firstepisode psychosis: a magnetic resonance imaging study. Biol Psychiatry. Jan 15 2004;55(2):131-140.

109. Harms MP, Wang L, Campanella C, et al. Structural abnormalities in gyri of the prefrontal cortex in individuals with schizophrenia and their unaffected siblings.

Br J Psychiatry. Feb 2010;196(2):150-157.

110. Jung WH, Kim JS, Jang JH, et al. Cortical Thickness Reduction in Individuals at Ultra-High-Risk for Psychosis. Schizophr Bull. Dec 212009. 
111. Narr KL, Bilder RM, Toga AW, et al. Mapping cortical thickness and gray matter concentration in first episode schizophrenia. Cereb Cortex. Jun 2005;15(6):708-719.

112. Narr KL, Toga AW, Szeszko P, et al. Cortical thinning in cingulate and occipital cortices in first episode schizophrenia. Biol Psychiatry. Jul 1 2005;58(1):3240.

113. Rimol LM, Hartberg CB, Nesvag R, et al. Cortical thickness and subcortical volumes in schizophrenia and bipolar disorder. Biol Psychiatry. Jul 1 2010;68(1):4150.

114. Haukvik UK, Lawyer G, Bjerkan PS, et al. Cerebral cortical thickness and a history of obstetric complications in schizophrenia. J Psychiatr Res. Dec 2009;43(16):1287-1293.

115. Gottesman, II, Gould TD. The endophenotype concept in psychiatry: etymology and strategic intentions. $\mathrm{Am} \mathrm{J}$ Psychiatry. Apr 2003;160(4):636-645.

116. Marcelis M, Suckling J, Woodruff P, Hofman P, Bullmore $E$, van Os J. Searching for a structural endophenotype in psychosis using computational morphometry. Psychiatry Res. Apr 1 2003;122(3):153-167.

117. Staal WG, Hulshoff Pol HE, Schnack HG, Hoogendoorn ML, Jellema K, Kahn RS.

Structural brain abnormalities in patients with schizophrenia and their healthy siblings. $A m$ $J$ Psychiatry. Mar 2000;157(3):416-421.
118. Honea RA, MeyerLindenberg A, Hobbs KB, et al. Is gray matter volume an intermediate phenotype for schizophrenia? A voxel-based morphometry study of patients with schizophrenia and their healthy siblings. Biol Psychiatry. Mar 1 2008;63(5):465-474.

119. Cannon TD, van Erp TG, Huttunen $M$, et al. Regional gray matter, white matter, and cerebrospinal fluid distributions in schizophrenic patients, their siblings, and controls. Arch Gen Psychiatry. Dec 1998;55(12):1084-1091.

120. Wright IC, Sham $P$, Murray RM, Weinberger DR, Bullmore ET. Genetic contributions to regional variability in human brain structure: methods and preliminary results.

Neuroimage. Sep 2002;17(1):256-271.

121. Boos HB, Aleman A, Cahn W, Hulshoff Pol H, Kahn RS. Brain volumes in relatives of patients with schizophrenia: a meta-analysis. Arch Gen

Psychiatry. Mar

2007:64(3):297-304.

122. Goghari VM, Rehm K, Carter CS, MacDonald AW. Regionally specific cortical thinning and gray matter abnormalities in the healthy relatives of schizophrenia patients. Cereb Cortex. Feb 2007;17(2):415-424.

123. Goghari VM, Rehm K, Carter CS, MacDonald AW. Sulcal thickness as a vulnerability indicator for schizophrenia. Br J Psychiatry. Sep 2007;191:229-233.

124. Boos HB, Cahn W, van Haren NE, et al. Focal And Global Brain Measurements in Siblings of Patients With Schizophrenia. Schizophr Bull. Jan 172011.
125. Meyer-Lindenberg A. From maps to mechanisms through neuroimaging of schizophrenia. Nature. Nov 11 2010;468(7321):194-202.

126. Genetic Risk and Outcome in Psychosis (GROUP) Investigators. Evidence That Familial Liability for Psychosis Is Expressed as Differential Sensitivity to Cannabis: An Analysis of Patient-Sibling and Sibling-Control Pairs. Arch Gen Psychiatry. Oct 42010. 
1 Dept. of Psychiatry and Neuropsychology, School for Mental Health and Neuroscience, EURON, Maastricht University Medical Centre, PO Box 616 (Vijv1), 6200 MD Maastricht, The Netherlands

2 King's College London, King's Health Partners, Department of Psychosis Studies Institute of Psychiatry, London, United Kingdom 


\title{
ickness alterations and risk for psychotic disorder: \\ evidence for an intermediate phenotype
}

\author{
Submitted
}

Petra Habets ${ }^{1}$, Jim van Os ${ }^{1-2}$, Ed Gronenschild ${ }^{1}$, Irene Weltens', and Machteld Marcelis ${ }^{1}$ for G.R.O.U.P. 


\section{Abstract}

Background: Brain structures show high heritability rates. However, it remains unclear to what extent heritable factors are involved in cortical alterations associated with psychotic disorder. The present family study examined to what degree cortical thickness in psychotic disorder may be an indicator of genetic risk.

Methods: MRI scans were acquired in 89 patients with psychotic disorder (highest genetic risk), 98 healthy siblings of patients (higher than average genetic risk) and 87 controls (average genetic risk). Cortical thickness was compared between groups using a surface based General Linear Model (GLM) analysis in Freesurfer.

Results: Analysis showed significant clusters of cortical thinning in both patients and siblings in frontal, temporal, parietal and occipital regions, compared to controls. In addition, a widespread pattern of patient-specific widespread cortical thinning was found, as well as some sibling-specific cortical thinning. After controlling for cannabis use, the number of significant clusters was reduced in both patients and siblings, but some shared regions of cortical thinning in patients and siblings and some patient-specific thinning remained significant.

Conclusions: Patients with psychotic disorder showed a more extensive pattern of reduced cortical thickness than non-affected siblings. In frontal, temporal, parietal and occipital regions, there was evidence for a cortical thickness intermediate phenotype. Although cannabis use could explain some of the variation in cortical thickness, the majority of the intermediate phenotype regions held suggesting that alterations in these areas represent indicators of genetic risk. 


\section{Introduction}

In the general population, global brain measures such as total brain volume, cerebellar, gray and white matter volume have shown high heritability rates (70$95 \%)$, whereas regional volumes of the hippocampus or frontal lobe have shown moderate heritability rates (40-70\%) (1). In addition, there is evidence that cortical thickness (CT) is influenced by regionally specific genetic factors (2), suggesting that different genes are involved in different neural circuits. Twin studies have provided evidence for a strong genetic component contributing to neuroanatomical phenotypes in monozygotic twins discordant for psychotic disorder whereas for dizygotic twins compared with healthy control twins, genetic effects were less strong $(3,4)$. The advantage of measuring CT instead of volume is that the latter may be too coarse to identify subtle anatomical differences. Volume is a combination of cortical surface area and thickness, possibly influenced by different sets of genetic factors (3), and changes in either measure can be missed unless they are measured independently. Furthermore, variations in regional folding pattern of the cortex may explain variation in grey matter volumes. $\mathrm{CT}$ is a proxy measure for cytoarchitectural integrity. Thus, diffuse alteration in CT may be an index of differences in number of dendrites, dendritic spines, synapses $(5,6)$ or reduced neuropil $(7)$, which could result in disruptions in neural circuits (8).

To date, studies that have examined $C T$ in psychotic disorder have made use of Region of Interest (ROI) and surface based volumetry approaches. Because of the different ROI's that have been used, direct comparisons are difficult and findings are neither robust nor consistent. Main findings of ROI studies on chronic patients with psychotic disorder include reductions in frontal and temporal regions and in the cingulate (9-13), as well as some evidence for reductions in parietal (11) and occipital regions (14). Similar results have been reported in surface based studies: frontal and temporal cortical thinning $(10,11,14,15)$, and some evidence for parietal (11) and occipital thinning (14). With regard to first-episode patients (FEP), ROI studies have shown cortical thinning in the insula (12), cingulate (16) and temporal and frontal regions (17-20), although there are also negative findings with regard to frontal cortical alterations $(21,22)$. Surface-based studies in FEP patients have reported reductions in $\mathrm{CT}$ in the frontal, temporal, parietal, occipital and cingulate regions $(18,19,23-25)$ with one study reporting no differences between groups (17).

Only a few studies have examined CT in healthy relatives. The study by Goghari 
and co-workers (2007) reported bilaterally reduced CT in the cingulate gyrus and in the superior temporal sulcus in siblings (26). However, other studies failed to find differences in CT between siblings and controls $(14,22)$. Also, two large, recent, studies on patients and siblings reported widespread cortical thinning in patients (predominantly in the frontal and temporal regions), but not in siblings $(27,28)$.

Over recent years, evidence for the effects of environmental exposures such as antipsychotic medication and cannabis use on brain measures has been growing and, beside methodological issues, this may have contributed to inconsistencies in the findings on cortical alterations in psychotic disorder (29-32).

In search for a CT intermediate phenotype, the present study examined CT in a relatively large genetically sensitive sample of patients with psychotic disorder, nonpsychotic siblings and controls, while taking into account drug use and antipsychotic medication. It was expected that siblings would, to a certain extent, share a pattern of cortical decrements with their ill family member, but that environmental influence would also explain some of the brain alterations.

\section{Materials and methods}

\section{Subjects}

Data pertain to baseline measures of an ongoing longitudinal study in Maastricht, the Netherlands. In selected representative geographical areas in the Netherlands and Belgium, patients were identified through representative clinicians whose caseload was screened for inclusion criteria. Subsequently, a group of patients presenting consecutively at these services either as out- or in-patients were recruited for the study. First-degree relatives were sampled through participating patients. Control subjects were recruited from the same population as the patients using random mailings in the geographic region and through advertisements in newspapers. All interviews were conducted by trained psychology graduates. The resulting sample consisted of 89 patients with a diagnosis of psychotic disorder, 98 siblings of patients and 87 controls. The sample included 64 families, of which 40 families contributed one patient and one healthy sibling, 3 families contributed one patient and two healthy siblings and one family contributed one patient and three healthy siblings. Two families contributed two patients, 6 families contributed two healthy siblings, and 2 families contributed 3 healthy siblings. In the control group, 10 families contributed two siblings. In addition, 41 independent patients, 
31 independent siblings, and 67 independent controls were included. Inclusion criteria were age range 16 to 50 years, diagnosis of non-affective psychotic disorder and good command of Dutch language. Diagnosis was based on the Diagnostic and Statistical Manual of Mental Disorder-IV (DSM-IV) criteria (33), assessed with the Comprehensive Assessment of Symptoms and History (CASH) interview (34). Patient diagnoses were: schizophrenia $(n=65)$, schizophreniform disorder $(n=3)$, brief psychotic disorder $(n=2)$, psychotic disorder not otherwise specified $(n=10)$ and schizoaffective disorder $(n=9)$. In the sibling and control group, there were respectively 20 and 14 participants with a history of a major depressive disorder, but none presented with a current depressive episode.

Prior to MRI acquisition, participants were screened for the following exclusion criteria: (i) brain injury with unconsciousness for over 1 hour, (ii) meningitis or other neurological diseases that might have affected brain structure/function, (iii) cardiac arrhythmia requiring medical treatment (iv), severe claustrophobia. In addition, subjects with metal corpora aliena were excluded from the study, as well as women with intrauterine device status and (suspected) pregnancy. The study was approved by the standing ethics committee, and all the subjects gave written informed consent in accordance with the committee's guidelines.

\section{Measures}

The Positive and Negative Syndrome Scale (PANSS) (35) was used to measure psychotic symptoms over the last two weeks. Five subscales were computed: positive symptoms, negative symptoms, disorganization, excitement and emotional distress.

Educational level was defined as the highest accomplished level of education $(0=$ No education; $1=$ Primary school; $2=$ Secondary school, lower level; $3=$ Secondary school, higher level; $4=$ High school, lower level; $5=$ High school, higher level; $6=$ Vocational education, lower level; $7=$ Vocational education, higher level; 8= University).

Antipsychotic medication was determined using reports of the participant's psychiatrist. Best estimate lifetime (cumulative) AP medication use was determined by multiplying the number of days of AP use with the corresponding haloperidol equivalents and summing up these scores for all periods of AP use (36).

Substance use was assessed using the Composite International Diagnostic Interview (CIDI) sections B-J-L (37). Cannabis use and other drug use (stimulants, sedatives, 
opiates, cocaine, PCP, psychedelics, inhalants, or other (e.g. XTC, poppers)) was assessed as reported frequency of use (i) during the last 12 months, and (ii) lifetime. Alcohol intake was calculated as the average number of weekly consumptions over the last 12 months and tobacco use as the average number of daily cigarettes over the last 12 months.

\section{MRI acquisition and processing}

MRI scans were acquired using a 3T Siemens scanner. The following acquisition parameters were used for the anatomical scans: Modified Driven Equilibrium Fourier Transform (MDEFT) sequence: 176 slices, $1 \mathrm{~mm}$ isotropic voxel size, TE $2.4 \mathrm{~ms}$, TR 7.92 ms, total acquisition time: 12 min 51s, and for the Magnetization Prepared Rapid Acquisition Gradient Echo (MP-RAGE: Alzheimer's Disease Neuroimaging Initiation (ADNI) sequence): 192 slices, $1 \mathrm{~mm}$ isotropic voxel size, TE $2.6 \mathrm{~ms}$, TR $2250 \mathrm{~ms}$, total acquisition time $7 \mathrm{~min} 23 \mathrm{~s}$. The matrix size was $256 \times 256$ and field of view was $256 \times 256 \mathrm{~mm}$. Two sequences were used because of a scanner update during data collection, precluding temporary use of the MDEFT sequence. The ADNI and MDEFT sequences are very similar, but in order to prevent any systematic bias, the total proportion of ADNI scans (around 1/3) was balanced between the groups.

\section{MRI preprocessing}

Scans were analyzed using Freesurfer stable release version 5.0.0. The technical details of these procedures are described in prior publications (38-49) and here only a brief description will be presented.

\section{Cortex-based alignment}

Variation between participants in regional folding pattern of the cortex may produce unreliable results. To improve inter-subject mapping, the reconstructed cortices were aligned using curvature information reflecting the individual cortical folding patterns to match cortical geometry across subjects (45). It has been shown that a cortical matching approach substantially improves statistical analysis across subjects by reducing anatomical variability (44). First, the reconstructed cortices of each subject of each hemisphere were morphed into a sphere. Each vertex on the sphere (spherical coordinate system) has a corresponding vertex of the folded cortex (Cartesian coordinate system). These spheres were aligned to a spherical atlas. 
The cerebral cortex was parcellated into units based on gyral and sulcal structure $(46,50)$. Furthermore, a variety of surface-based data was created including maps of curvature and sulcal depth. This method uses both intensity and continuity information from the entire three-dimensional MR volume in segmentation and deformation procedures to produce representations of $\mathrm{CT}$, calculated as the closest distance from the grey/white boundary to the grey/CSF boundary at each vertex on the tessellated surface (40). The maps are created using spatial intensity gradients across tissue classes and are therefore not simply reliant on absolute signal intensity. The maps produced are not restricted to the voxel resolution of the original data thus are capable of detecting sub-millimeter differences between groups. Procedures have been validated against histological analysis (51) and manual measurements (9, 52). Freesurfer morphometric procedures have been demonstrated to show good test-retest reliability across scanner manufacturers and across field strengths (47).

\section{Statistical analyses}

\section{Main effects on total cortical thickness}

The CT surface map was loaded, for each individual and for each hemisphere, in a group file, where individual CT values averaged over each predefined Region of Interest (ROI) (adapted from the Desikan atlas (50), 34 regions per hemisphere) were calculated and exported to STATA version 11 (53). Thus, for each individual $68 \mathrm{CT}$ measurements were derived. Total CT was calculated by summing up the CT values of the 68 ROI's. Because patients and siblings were from the same family, compromising statistical independence of the observations, multilevel random regression models were fitted (54).

In order to investigate whether total CT differed between groups, multilevel regression analyses were conducted using the XTREG command in STATA with the variable "group" (patients, siblings, controls) as the independent variable, and total $\mathrm{CT}$ as the dependent variable. Age, gender, educational level, handedness and scan type were used as covariates in the models, based on their a priori hypothesized confounding effects. Effect sizes of explanatory variables were expressed as regression coefficients (B) from the multilevel models. In order to examine whether the effect of group on total CT was modified by gender, a gender $x$ group interaction was incorporated in the model of CT and evaluated by Wald test. 


\section{Surface based regional cortical thickness analyses}

The regional CT value at each vertex for each subject was mapped to the surface of the sphere. The cortical map of each subject was smoothed with a Gaussian kernel of 20-mm full-width at half-maximum (FWHM) for the entire cortex analyses.

A general linear model was estimated at each vertex across the cortical surface, with $\mathrm{CT}$ as dependent variable and group as the independent variable. Age, gender, educational level, handedness and scan type were used as covariates in the models, based on their a priori hypothesized confounding effects.

This procedure allows for generation of statistical parametric maps that were thresholded at $P$-values $<0.05$ and $<0.01$. The left and right hemisphere cortical surfaces were analyzed separately. The maps show the distribution of $-\log _{10} P$-values for pairwise comparisons between the groups, as defined by the following contrasts: patients versus controls and siblings versus controls. Neighboring significant vertices were grouped and presented as maps of clustered vertices.

\section{Antipsychotic medication and drug use: associations with cortical thickness}

In the model of total CT, main effects of alcohol and cannabis use on the one hand were assessed using multilevel regression and, when appropriate, additionally used as covariates in the surface based regional CT analyses.

In patients, the association between antipsychotic medication (present and lifetime exposure) and total CT was also evaluated.

\section{Results}

\section{Demographic characteristics}

Patients were younger than controls and had, on average, a lower educational level than controls and siblings. There were more men than women in the patient group, whereas the opposite held for the control group.

At the moment of the scan, 74 patients were receiving AP medication (second generation: $n=71$; first generation: $n=3$ ). The mean current dosage of AP medication in terms of standard haloperidol equivalents was 2.9 milligrams $(\mathrm{mg})(\mathrm{SD}=2.7)$. Lifetime AP use (total days of use times haloperidol equivalents) was 2331.6 (SD=4352.5). Furthermore, 17 patients used an antidepressant (selective serotonin reuptake inhibitor (SSRI)), 6 a benzodiazepine, 5 an anti-epileptic drug, and 2 lithium. In the control group, 3 participants received an SSRI and 1 also used a benzodiazepine. In 
the sibling group, 3 participants received an SSRI. Siblings used more alcohol than controls. Patients displayed more drug use than controls and siblings, regardless of the type of drug (Table 1).

\section{Main effects on total cortical thickness}

Total CT did not differ between groups $(B=-0.3, C l=-1.0-0.39, P=0.38)$. In the combined group of patients, siblings and controls, CT was negatively associated with lifetime cannabis use indicating that drug use was associated with lower CT. This was not the case for alcohol use in the past 12 months. Neither current dose nor lifetime exposure to AP medication was significantly associated with CT. There was no significant association between gender and total $C T$, and no interaction between group and gender in the model of total $C T\left(X^{2}=3.13, P=0.21\right)$, indicating that the association between group and CT was not modified by gender (Table 2 ).

\section{Surface based regional cortical thickness alterations}

In comparison to controls, both patients and siblings displayed a significant decrease in CT in the following regions: superior frontal gyrus bilaterally, right fusiform, right superior parietal, right postcentral, right supramarginal gyrus and right lateral occipital cortex.

At a more conservative threshold $(P<0.01)$, the right supramarginal gyrus remained significant in both patients and siblings. The right superior parietal and the postcentral gyrus remained significant in patients, but not in siblings (Table 3; Figure $1 \mathrm{~A}$ and $1 \mathrm{~B})$.

Decreases in $\mathrm{CT}$, uniquely present in patients, were found in the following regions: left precentral gyrus, right rostral middle frontal gyrus, right caudal middle frontal gyrus, right inferior frontal gyrus, right lateral orbitofrontal cortex, right temporal pole, superior temporal gyrus bilaterally, left fusiform, middle temporal gyrus bilaterally, left superior parietal, precuneus bilaterally, left supramarginal gyrus, left lateral occipital, left pericalcarine and left posterior cingulate. In the left inferior parietal gyrus, patients showed an increase in CT compared to controls.

At the $P<0.01$ threshold, the left precentral gyrus and left posterior cingulate remained significant (Table 4; Figure 1A).

Sibling-specific decreases were found in the right medial orbitofrontal gyrus, right pars orbitalis, inferior parietal bilaterally, left lingual and right cuneus. A siblingspecific increase in CT was found in the right precentral gyrus. 
At the $P<0.01$ threshold the right medial orbitofrontal gyrus and the right inferior parietal gyrus remained significant (Table 4; Figure 1B).

\section{Surface based regional cortical thickness alterations controlled for cannabis use}

The number of significant clusters in patients and siblings was reduced after controlling for lifetime cannabis use, though most clusters with cortical thinning that were present in both patients and siblings remained significant: the right superior frontal gyrus, right fusiform, right superior parietal gyrus. At the $P<0.01$ threshold, the right supramarginal remained significant for both patients and siblings, whereas for the left precentral, right superior parietal and left precuneus, clusters were significant at $P<0.01$ and in siblings at $P<0.05$. The left precentral gyrus and the right precuneus became significant in both patients and siblings at $P<0.05$.

In the patients versus control comparison, the clusters in the right rostral middle frontal gyrus, right precentral gyrus, left fusiform gyrus, left superior parietal cortex and left supramarginal gyrus, lateral occipital cortex bilaterally and left posterior cingulate remained significant. At the $P<0.01$ threshold, the right caudal middle frontal gyrus right postcentral gyrus, remained significant.

In the siblings versus control comparison, the left superior frontal gyrus and right inferior parietal gyrus remained significant (Figure 1C and 1D).

\section{Discussion}

Using a family study design to examine the influence of different levels of genetic risk for psychotic disorder on surface based CT measures, some decreases in overlapping regions were found in patients with psychotic disorder and their healthy siblings. Shared cortical decrements were found in frontal, temporal, parietal and occipital regions in the two groups at higher than average genetic risk for psychosis. In addition, widespread patient-specific cortical thinning was found and some siblingspecific cortical thinning. In addition, cannabis use was associated with CT and explained some, but not all, of the variations. 


\section{Cortical thickness alterations in the higher than average genetic risk-groups}

Because structural brain traits are under substantial genetic control $(2,55)$, investigating its potential as an intermediate phenotype for psychotic disorder may provide structural brain phenotypes that could narrow the search for genes influencing brain structure (1) and risk of psychotic disorder. The present study showed CT reductions in both patients and siblings in frontal, temporal, parietal and occipital regions, suggesting that regional cortical alterations can potentially be considered as intermediate phenotypes. This is not in accordance with two recent studies of large sample sizes, which did not find strong evidence for CT intermediate phenotypes $(27,28)$. It should be noted, however, that Goldman and colleagues (2009) did find CT alterations in siblings, but their finding did not survive the stringent False Discovery Rate (FDR) correction for multiple comparisons. In addition, using the Risch $\lambda$ as an index for heritability, they found evidence for widespread regions under genetic control.

The most obvious reductions in both patients and siblings were the temporal and occipital regions and the regions that are part of the heteromodal association cortex (i.e., superior frontal gyrus, superior parietal, supramarginal gyrus). The heteromodal association cortex is a highly organised and interconnected neocortical brain network involving the superior and middle temporal gyrus, the dorsolateral prefrontal cortex, Broca's area and the inferior parietal lobe (56). Furthermore, the heteromodal association cortex has extensive connections with the cingulate gyrus (57). Studies have indicated that the heteromodal association cortex is disrupted in patients with schizophrenia $(58,59)$ and in their siblings $(60)$. In addition, some of the clusters that were found (e.g., superior frontal gyrus, postcentral gyrus and superior parietal) are involved in sensory gating (61). Moreover, the P50 gating deficit has been described as the most robust physiological finding in schizophrenia research $(62,63)$. Sensory gating is thought to reflect the filtering of redundant and/or distracting sensory information, to protect from the processing of the first stimulus. Delusions and hallucinations could consequently arise from an individual's response to erroneous attribution of salience to external and internal stimuli (64). 


\section{Group-specific cortical alterations}

The present study found widespread patient-specific cortical thinning as well as some sibling-specific alterations. The results in patients have face validity as they are consistent with findings in several other studies $(18,19,23-25)$. The siblingspecific alterations that were found in the present study are not in accordance with the studies of Boos and co-workers (28) and Goldman and colleagues (27), although extensive correction in these studies could have led to false negatives. Nevertheless, a smaller study did find some evidence of cortical thinning in siblings of patients with psychotic disorder in frontal and temporal regions (14).

The brain alterations of schizophrenia are not well understood in relation to the clinical phenotype (65). Psychotic disorder may not be a disorder of a single brain area but rather a disorder of brain networks $(27,66)$. Diffusion tensor imaging (DTI) and resting state functional imaging data addressing the connectivity between brain regions have lent some support to this theory $(67,68)$, as do the present findings. In the group at highest genetic risk, alterations were much more pronounced and widespread than in the sibling group, which may be associated with more severe dysfunctional brain networks. Siblings shared some of the CT decrements with their ill family members and additionally showed some specific alterations while not expressing the clinical phenotype. It could be hypothesised that brain networks are flexible and able to compensate for certain failures until a certain threshold is reached. When the threshold is exceeded, the dysfunction of the network could result in the expression of overt psychotic symptoms. However, small failures in the network might contribute to the development of symptoms at a subclinical level. Therefore, future research should investigate whether the cortical alterations found in siblings are related to schizotypal traits.

In summary, the genetic vulnerability for psychotic disorder may be associated with cortical thinning in regions of the heteromodal association cortex. Environmental factors, specific (epi)genetic effects or gene-environment interactions may contribute to additional patient or sibling-specific cortical thinning.

\section{Cannabis use}

Total CT was associated with cannabis, and cannabis use explained some of the variation in cortical thickness as the number of cortical thickness clusters was reduced after adjustment for cannabis use in the surface based analyses. Moreover, in a previous publication on the same study sample, we were able to show that 
cannabis use partly mediated the association between risk for psychotic disorder and cortical alterations (32).

Although evidence suggests that cannabis use is implicated in the aetiology of psychotic disorder (69-77), most studies investigating the association of cannabis use and brain structure in psychotic disorder have failed to find an association between cannabis use and brain alterations. However, the majority of these studies used global brain measures such as total brain volume; therefore, regional differences could have remained undetected. For example, Cahn et al. (2004) investigated the association between cannabis use and total brain volume and total grey and white matter volume in FEP, and they did not find differences between cannabisnaïve FEP and cannabis-using FEP. Studies investigating specific ROls, on the other hand, have found grey matter volume reductions in the posterior cingulate gyrus (78) and in the anterior cingulate (79) in cannabis using patients. Additionally, two longitudinal studies indicated evidence for additional brain alterations in cannabis-using patients compared to cannabis-naïve patients with regard to lateral and third ventricle volumes (80) and CT (29). Most studies investigating CT excluded subjects with a history of alcohol or other drug dependence $(9,10,12$ $17,20-22,28)$ whereas other studies did not exclude subjects based on substance use. The studies, however, did not control for substance use either $(18,23-25,27)$. Patients with a psychotic disorder have a high rate of co-morbid drug use (81), and therefore, exclusion of these subjects could have led to a selection bias influencing the representativeness of the study population and the type of brain alterations. In addition, previous research has shown that any use of cannabis is associated with clinical and subclinical psychosis outcomes (75). Thus, it is possible that drug use not meeting the criteria for drug dependence can still be associated with some of the brain alterations found in psychotic disorder. Therefore, environmental factors such as cannabis use should be considered when conducting neuroimaging studies in psychotic disorder.

\section{Antipsychotic medication}

Current and cumulative AP medication dose does not show a significant association with total CT, which is in accordance with earlier reports $(10,24,28)$. Recent reviews $(30,82)$ concluded that antipsychotics may act regionally rather than globally on grey matter volume with a possible differential association according to the type of medication (first vs. second generation AP). Although an association between 
AP medication and cortical alterations cannot be completely ruled out, the present findings suggest that AP medication use cannot explain the total variation in CT, which is consistent with the results of other studies in medication-naïve patients $(24,83)$ and in healthy, non-medicated siblings $(13,26)$.

\section{Conclusion}

In addition to group-specific alterations, patients with psychotic disorder and their non-psychotic relatives were found to have a similar pattern of CT alterations compared to controls, suggesting a genetic influence. These structural abnormalities may underlie the formation of symptoms (e.g., language problems, attention problems, hallucinations) that are seen in patients with schizophrenia and, in a more subsyndromal form, in siblings. In addition, cannabis use appeared to be associated with the CT outcome measure and explained some of the variation in cortical thickness.

\section{Methodological considerations}

There is a lot of debate as to which method is most appropriate to correct for multiple comparisons in surface-based analyses, as currently available methods are often too conservative. In the present study, only the right superior parietal lobe remained significant in the patient-control comparison after FDR correction and the significant findings in relatives (like in the study by Goldman and colleagues (27)) did not survive the correction (results available on request). As FDR-corrected studies often use a $\mathrm{P}<0.05$ threshold, the current (not FDR-corrected) results were not only presented using the $\mathrm{P}<0.05$ threshold, but also with a more conservative threshold (i.e., $\mathrm{P}<0.01$ ). Using this method, the number of significant clusters was reduced at this latter threshold but not nullified. In addition, a comparative ROI analysis on this data yielded 20 significant regions out of 68 regions in patients and siblings compared to controls, which is far above the number of expected (7) significant regions based on chance alone. This indeed suggests that the FDR correction may be a too stringent correction. Previous studies using high smoothing levels did not correct for multiple comparisons for this reason $(52,84)$.

The significant clusters presented in this study may have somewhat higher $P$ values than other studies investigating surface-based cortical thickness, which 
could be explained by the larger number of covariates that were used in the model, resulting in a reduction of statistical power. Indeed, when only age and gender were incorporated in the model, similar to most cortical thickness studies to date, $P$-values were lower (results available upon request).

The surface-based GLM analyses that were used to investigate group differences in cortical thickness precluded the possibility to consider the fact that some subjects (siblings) were part of the same family. To examine whether genetic relatedness of the subjects (violation of independence) had any large or significant effect on the results, multilevel regression analyses were conducted using the XTREG command in STATA investigating group differences in regional cortical thickness (34 regions per hemisphere). Controlling for familial relationships did not influence the results (results available upon request).

In the controls and siblings, some participants had a DSM-IV diagnosis of past major depressive disorder. These participants were not excluded from the study, as exclusion would result in an extremely healthy comparison group, compromising the representativeness of the population under study. It is unlikely that differences between siblings and controls can be fully explained by the (small) group of siblings and controls with a history of depression.

There were more men than women in the patient group, whereas the opposite was the case in the controls. Sowell et al. (2007) investigated differences in CT in healthy subjects for 90 men and 86 women, and concluded that women had increased thickness in the right inferior parietal lobe and in the posterior temporal cortex (85), compared to men. The present study did not reveal confounding or effect modification by gender, suggesting that the differences in CT between the study groups are not likely the result of gender effects. 
Table 1. Subject demographics

Patients ( $n=89)$ Siblings $(n=98)$ Controls $(n=87)$

$\begin{array}{lccc}\text { Age at scan (yrs) } & 28.1(6.9)^{*} & 29.5(8.7) & 30.6(10.9) \\ \text { Level of education } & 4.3(2.0)^{* \dagger} & 5.1(2.1) & 5.4(1.8) \\ \text { Gender } n(\%) \text { male } & 60(67 \%) & 50(51 \%) & 33(38 \%) \\ \text { Mean number of times cannabis use lifetime } & 49.6(46.0)^{*} \dagger & 22.3(4.2) & 14.0(28.3) \\ \text { Mean number of times hard drug use lifetime } & 53.7(99.4)^{* \dagger} & 12.8(52.8) & 3.3(14.1) \\ \text { Alcohol use last year } & 4.7(8.9)^{\dagger} & 9.5(16.9)^{*} & 4.6(6.9) \\ \text { PANSS Positive } & 12.3(6.1)^{* \dagger} & 7.6(1.2) & 7.4(1.4) \\ \text { PANSS negative } & 12.0(5.6)^{* \dagger} & 8.4(2.1) & 8.2(1.0) \\ \text { PANSS Disorganization } & 13.3(4.4)^{*} \dagger & 10.3(0.7) & 10.3(1.2) \\ \text { PANSS Excitement } & 10.3(2.8)^{* \dagger} & 8.6(1.4) & 8.3(1.1) \\ \text { PANSS Emotional distress } & 13.9(5.3)^{*}+ & 10.1(2.7) & 9.4(2.3) \\ \text { Age of onset (yrs) } & 22.6(6.4) & & \\ \text { Illness duration (yrs) } & 5.5(3.6) & & \\ \text { Lifetime exposure to AP } & 2331.6(4352.5) & & \\ \end{array}$

Means \pm SDs are reported

Abbreviations: PANSS, Positive and Negative Syndrome Scale; Yrs, years

$A P$, antipsychotics (haloperidol equivalents)

${ }^{(*)}$ Significantly different from controls

${ }^{(\dagger)}$ Significantly different from siblings 


\section{Table 2. Main effects on total cortical thickness}

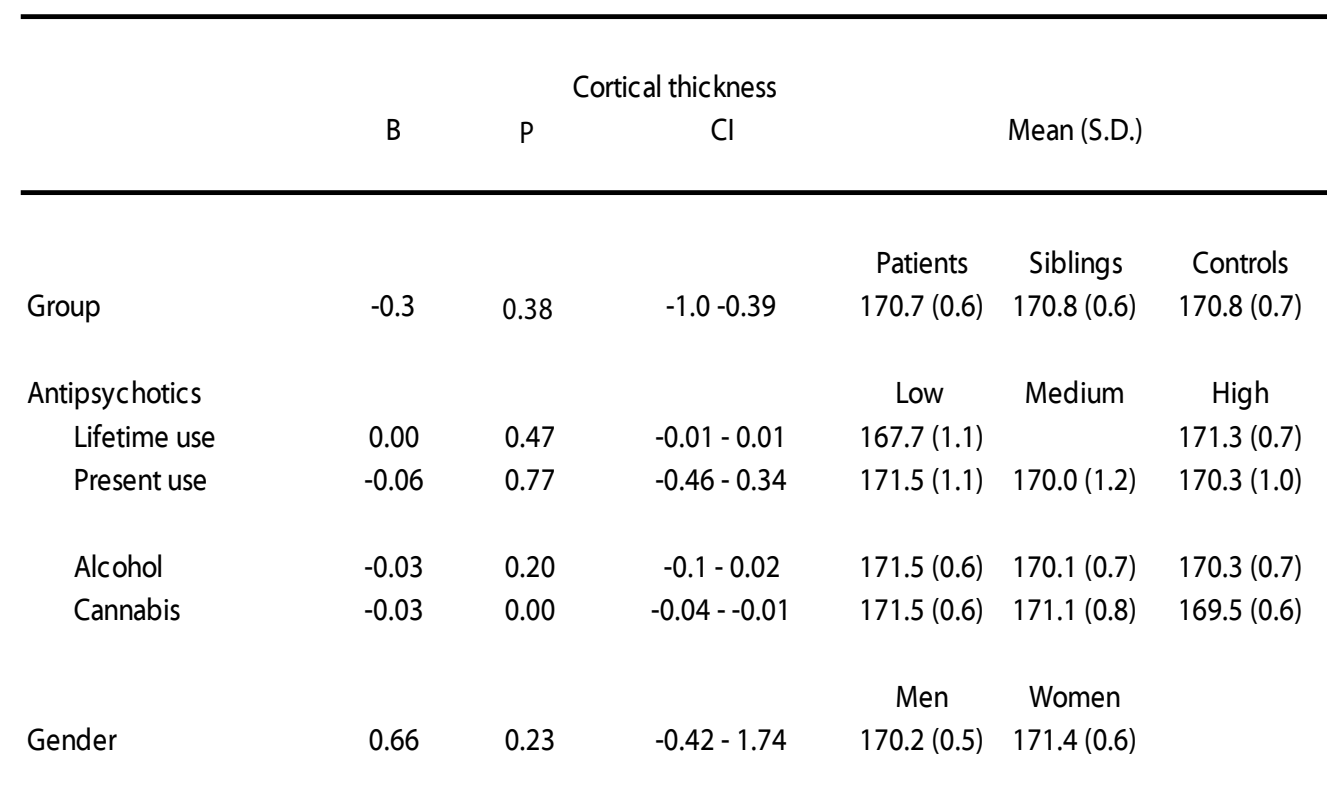

B's represent the effect sizes from the regression analyses investigating the association between cortical thickness and use of antipsychotics, drugs and the association with gender

Antipsychotics, alcohol and cannabis use have been divided into tertiles in order to report descriptive cortical thickness values per group

For lifetime antipsychotic use only two groups could be created 
Table 3. Regional decreases in cortical thickness in patients and siblings compared to controls

Patients vs. controls Siblings vs. controls

\begin{tabular}{lcccccc}
\hline & $\begin{array}{c}\text { Number of } \\
\text { clusters }\end{array}$ & $\begin{array}{c}\text { Max. } \\
\text { log value }\end{array}$ & Weight & $\begin{array}{c}\text { Number of } \\
\text { clusters }\end{array}$ & $\begin{array}{c}\text { Max. } \\
\text { log value }\end{array}$ & Weight \\
Right superior frontal gyrus & 332 & 1.70 & 563.80 & 103 & 1.44 & 148.60 \\
Left superior frontal gyrus & 270 & 1.50 & 406.11 & 71 & 1.36 & 96.26 \\
Right fusiform & 564 & 1.95 & 1101.16 & 139 & 1.43 & 198.60 \\
Right superior parietal & 2993 & $\mathbf{2 . 6 3}$ & 7866.60 & 985 & 1.76 & 1731.90 \\
Right postcentral gyrus & 2307 & $\mathbf{2 . 7 2}$ & 6280.83 & 902 & 1.95 & 1754.58 \\
Right supramarginal gyrus & 1403 & $\mathbf{2 . 6 4}$ & 3708.04 & 1175 & $\mathbf{3 . 1 7}$ & 3730.21 \\
Right supramarginal gyrus & & & & 570 & $\mathbf{2 . 1 0}$ & 1198.62 \\
Right lateral occipital cortex & 22 & 1.33 & 29.35 & 306 & 1.86 & 567.67 \\
& & & & & & \\
\hline
\end{tabular}

Weighting was calculated as the product of the number of vertices and the maximum log-value (expressed as 10-x).

Regional definitions were based on proximity to neural labels (Desikan et al., 2006; Fischl et al., 2002).

Positive log values represent decreases in cortical thickness when compared to controls and negative log values increases in cortical thickness

All regions are significant at $p<0.05$; regions in bold are significant at $p<0.01$ 


\begin{tabular}{|c|c|c|c|}
\hline Region of interest & $\begin{array}{c}\text { Number of } \\
\text { clusters }\end{array}$ & $\begin{array}{c}\text { Max. } \\
\text { log value }\end{array}$ & Weight \\
\hline \multicolumn{4}{|l|}{ Patients compared to controls } \\
\hline Left precentral gyrus & 521 & 2.05 & 1067.22 \\
\hline Right rostral middle frontal gyrus & 488 & 1.99 & 972.18 \\
\hline Right caudal middle frontal gyrus & 458 & 1.99 & 909.57 \\
\hline Left precentral gyrus & 298 & 1.81 & 538.31 \\
\hline Right inferior frontal gyrus & 242 & 1.65 & 400.11 \\
\hline Right lateral orbitofrontal cortex & 192 & 1.55 & 297.59 \\
\hline Right temporal pole & 690 & 1.80 & 1239.05 \\
\hline Left superior temporal gyrus & 668 & 1.79 & 1198.53 \\
\hline Right superior temporal gyrus & 338 & 1.64 & 554.08 \\
\hline Left fusiform & 250 & 1.62 & 405.33 \\
\hline Left middle temporal gyrus & 173 & 1.45 & 251.51 \\
\hline Right middle temporal gyrus & 23 & 1.32 & 30.43 \\
\hline Left superior parietal & 1266 & 1.97 & 2496.43 \\
\hline Right precuneus & 240 & 1.66 & 399.25 \\
\hline Left Precuneus & 164 & 1.62 & 265.42 \\
\hline Left supramarginal gyrus & 171 & 1.48 & 252.23 \\
\hline Left superior parietal & 140 & 1.50 & 209.58 \\
\hline Right precuneus cortex & 125 & 1.44 & 180.25 \\
\hline Left inferior parietal & 66 & -1.35 & -89.36 \\
\hline Left supramarginal gyrus & 19 & 1.32 & 25.01 \\
\hline Left lateral occipital cortex & 566 & 1.66 & 940.24 \\
\hline Left peric alcarine cortex & 30 & 1.33 & 40.02 \\
\hline Left posterior cingulate & 627 & 2.14 & 1340.46 \\
\hline \multicolumn{4}{|l|}{ Siblings compared to controls } \\
\hline Right medial orbitofrontal gyrus & 572 & 2.07 & 1183.88 \\
\hline Right pars orbitalis & 323 & 1.72 & 554.74 \\
\hline Right precentral gyrus & 201 & -1.49 & -300.49 \\
\hline Right inferior parietal & 1055 & 2.18 & 2296.68 \\
\hline Left inferior parietal & 128 & 1.44 & 183.70 \\
\hline Right inferior parietal & 87 & 1.40 & 122.09 \\
\hline Left lingual & 277 & 1.61 & 444.62 \\
\hline Left lingual & 189 & 1.57 & 296.82 \\
\hline Right cuneus & 86 & 1.42 & 122.37 \\
\hline
\end{tabular}

Note: Regions were ordered by region and by weighting, calculated as the product of the number of vertices and the maximum log-value (expressed as 10-x). Regional definitions were based on proximity to neural labels (Desikan et al., 2006). Positive log values represent decreases in cortical thickness when compared to controls and negative log values increases in cortical thickness All regions are significant at $p<0.05$; regions in bold are significant at $p<0.01$ 
Patients vs. controls
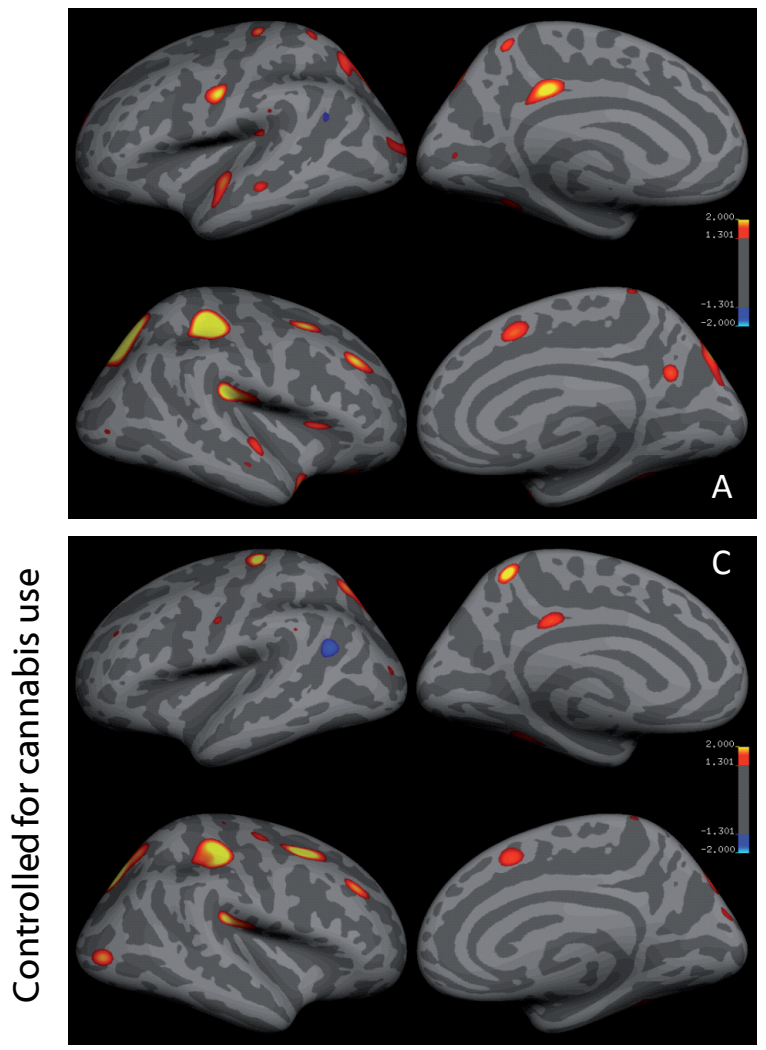

Siblings vs. controls
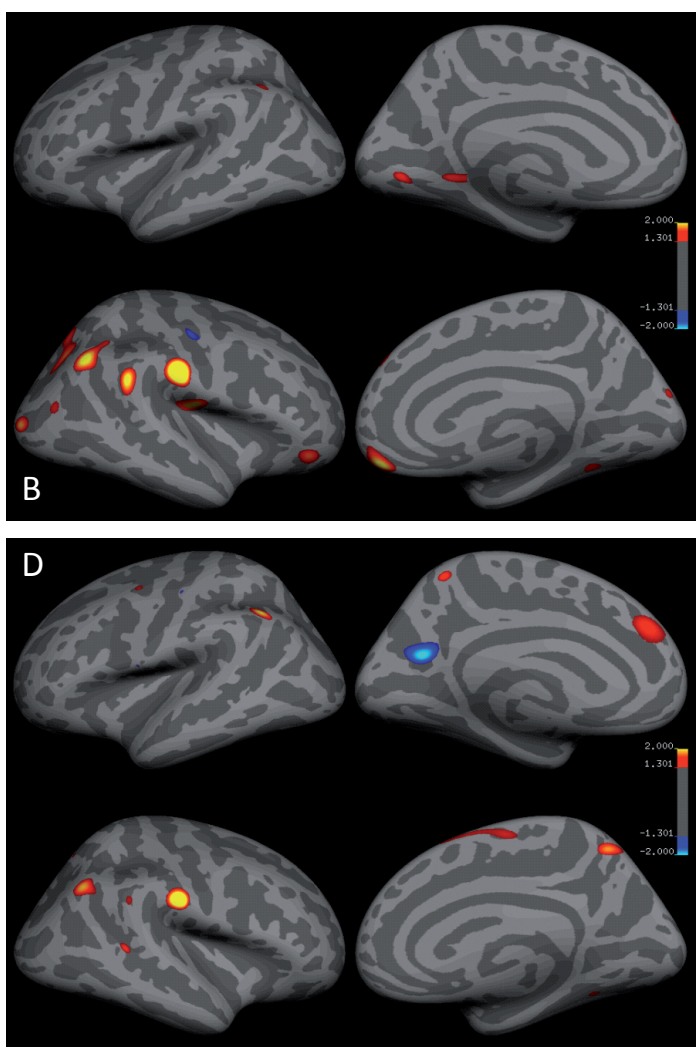

Figure 1. Group differences in cortical thickness. Thickness values for each subject were mapped to an average surface and smoothed using a 20-mm FWHM Gaussian filter. Group contrasts were performed, covarying for age and gender, level of education, handedness and scan type. Results were thresholded at $\mathrm{P}<0.05$ : A) Patients versus controls; $\mathrm{B}$ ) siblings versus controls; C) Patients versus controls, with additional covariate cannabis use; D) siblings versus controls with additional covariate cannabis use. 


\section{References}

1. Kaymaz $\mathrm{N}$ and van Os $J$ (2009): Heritability of structural brain traits an endophenotype approach to deconstruct schizophrenia. Int Rev Neurobio/89:85-130.

2. Rimol LM, Panizzon MS, Fennema-Notestine $C$, Eyler LT, Fischl B, Franz CE, et al. (2009): Cortical Thickness Is Influenced by Regionally Specific Genetic Factors. Biol Psychiatry.

3. Baare WF, van Oel CJ, Hulshoff Pol HE, Schnack HG, Durston S, Sitskoorn MM, et al. (2001): Volumes of brain structures in twins discordant for schizophrenia. Arch Gen Psychiatry 58:33-40.

4. Hulshoff Pol HE, Schnack HG, Mandl RC, Brans RG, van Haren NE, Baare WF, et al. (2006): Gray and white matter density changes in monozygotic and samesex dizygotic twins discordant for schizophrenia using voxelbased morphometry. Neuroimage 31:482-8.

5. Benes FM (2003): Why does psychosis develop during adolescence and early adulthood? Curr Opin Psychiatry 16:317-319.

6. Harrison PJ (1999): The neuropathology of schizophrenia. A critical review of the data and their interpretation. Brain 122 ( Pt 4):593-624.
7. Glantz LA, Gilmore JH, Lieberman JA, and Jarskog LF (2006): Apoptotic mechanisms and the synaptic pathology of schizophrenia. Schizophr Res 81:47-63.

8. Benes FM (2007): Searching for unique endophenotypes for schizophrenia and bipolar disorder within neural circuits and their molecular regulatory mechanisms. Schizophr Bul/33:932-6.

9. Kuperberg GR, Broome MR, McGuire PK, David AS, Eddy M, Ozawa F, et al. (2003): Regionally localized thinning of the cerebral cortex in schizophrenia. Arch Gen Psychiatry 60:878-88.

10. Nesvag R, Lawyer G, Varnas K, Fjell AM, Walhovd KB, Frigessi A, et al. (2008): Regional thinning of the cerebral cortex in schizophrenia: effects of diagnosis, age and antipsychotic medication. Schizophr Res 98:16-28.

11. Kubota M, Miyata J, Yoshida H, Hirao K, Fujiwara H, Kawada R, et al. (2010): Age-related cortical thinning in schizophrenia. Schizophr Res.
12. Roiz-Santianez R, PerezIglesias R, Quintero C, Tordesillas-Gutierrez D, Mata I, Ayesa R, et al. (2010): Insular cortex thinning in first episode schizophrenia patients. Psychiatry Res 182:216-22.

13. Calabrese DR, Wang $L$, Harms MP, Ratnanather JT, Barch DM, Cloninger CR, et al. (2008): Cingulate gyrus neuroanatomy in schizophrenia subjects and their non-psychotic siblings. Schizophr Res 104:61-70.

14. Yang $Y$, Nuechterlein $\mathrm{KH}$, Phillips O, Hamilton LS, Subotnik KL, Asarnow RF, et al. (2010): The contributions of disease and genetic factors towards regional cortical thinning in schizophrenia: the UCLA family study. Schizophr Res 123:1 16-25.

15. Haukvik UK, Lawyer G, Bjerkan PS, Hartberg CB, Jonsson EG, McNeil T, et al. (2009): Cerebral cortical thickness and a history of obstetric complications in schizophrenia. J Psychiatr Res 43:1287-93.

16. Fornito A, Yucel $M$, Wood SJ, Adamson C, Velakoulis D, Saling MM, et al. (2008): Surface-based morphometry of the anterior cingulate cortex in first episode schizophrenia. Hum Brain Mapp 29:478-89. 
17. Gutierrez-Galve L, Wheeler-Kingshott CA, Altmann DR, Price G, Chu $E M$, Leeson VC, et al. (2010): Changes in the frontotemporal cortex and cognitive correlates in firstepisode psychosis. Biol Psychiatry 68:51-60.

18. Schultz CC, Koch K, Wagner G, Roebel M, Nenadic I, Schachtzabel C, et al. (2010): Complex pattern of cortical thinning in schizophrenia: results from an automated surface based analysis of cortical thickness. Psychiatry Res 182:134-40.

19. Schultz CC, Koch K, Wagner G, Roebel M, Schachtzabel C, Gaser C, et al. (2010): Reduced cortical thickness in first episode schizophrenia. Schizophr Res 116:204-9.

20. Crespo-Facorro B, RoizSantianez R, Perez-Iglesias $\mathrm{R}$, Rodriguez-Sanchez JM, Mata I, TordesillasGutierrez D, et al. (2010): Global and regional cortical thinning in firstepisode psychosis patients: relationships with clinical and cognitive features. Psychol Med1-12.

21. Wiegand LC, Warfield SK, Levitt JJ, Hirayasu Y, Salisbury DF, Heckers $S$, et al. (2004): Prefrontal cortical thickness in firstepisode psychosis: a magnetic resonance imaging study. Biol Psychiatry 55:131-40.
22. Harms MP, Wang $L$, Campanella C, Aldridge $\mathrm{K}$, Moffitt AJ, Kuelper J, et al. (2010): Structural abnormalities in gyri of the prefrontal cortex in individuals with schizophrenia and their unaffected siblings. $\mathrm{Br} \mathrm{J}$ Psychiatry 196:150-7.

23. Narr KL, Bilder RM, Toga AW, Woods RP, Rex DE, Szeszko PR, et al. (2005): Mapping cortical thickness and gray matter concentration in first episode schizophrenia. Cereb Cortex 15:708-19.

24. Narr KL, Toga AW, Szeszko P, Thompson PM, Woods RP, Robinson D, et al. (2005): Cortical thinning in cingulate and occipital cortices in first episode schizophrenia. Biol Psychiatry 58:32-40.

25. Rimol LM, Hartberg CB, Nesvag R, FennemaNotestine C, Hagler DJ, Jr., Pung CJ, et al. (2010): Cortical thickness and subcortical volumes in schizophrenia and bipolar disorder. Biol Psychiatry 68:41-50.

26. Goghari VM, Rehm K, Carter CS, and MacDonald AW (2007): Regionally specific cortical thinning and gray matter abnormalities in the healthy relatives of schizophrenia patients. Cereb Cortex 17:415-24.
27. Goldman AL, Pezawas L, Mattay VS, Fischl B, Verchinski BA, Chen Q, et al. (2009): Widespread reductions of cortical thickness in schizophrenia and spectrum disorders and evidence of heritability. Arch Gen Psychiatry 66:467-77.

28. Boos HB, Cahn W, van Haren NE, Derks EM, Brouwer RM, Schnack HG, et al. (2011): Focal And Global Brain Measurements in Siblings of Patients With

Schizophrenia. Schizophr Bull. Jan 17. [Epub ahead of print]

29. Rais $M$, van Haren $N E$, Cahn W, Schnack HG, Lepage C, Collins L, et al. (2010): Cannabis use and progressive cortical thickness loss in areas rich in $\mathrm{CB} 1$ receptors during the first five years of schizophrenia. Eur Neuropsychopharmacol 20:855-65.

30. Navari $S$ and Dazzan $P$ (2009): Do antipsychotic drugs affect brain structure? A systematic and critical review of MRI findings. Psychol Med 39:1763-77.

31. Moncrieff $\mathrm{J}$ and Leo $\mathrm{J}$ (2010): A systematic review of the effects of antipsychotic drugs on brain volume. Psychol Med 40:1409-22. 
32. Habets $P$, Marcelis $M$, Gronenschild E, Drukker M, and Os JV (2011): Reduced Cortical Thickness as an Outcome of Differential Sensitivity to

Environmental Risks in Schizophrenia. Biol Psychiatry. 69: 487-494

33. APA (2000): Diagnostic and statistical manual of mental disorders, 4th ed. Washington, DC: American Psychiatric Association.

34. Andreasen NC, Flaum $M$, and Arndt S (1992): The Comprehensive

Assessment of Symptoms and History (CASH). An instrument for assessing diagnosis and psychopathology. Arch Gen Psychiatry 49:615-23.

35. Kay SR, Fiszbein A, and Opler LA (1987): The positive and negative syndrome scale (PANSS) for schizophrenia. Schizophr Bull 13:261-76.

36. Cahn W, Hulshoff Pol $\mathrm{HE}$, Lems EB, van Haren NE, Schnack HG, van der Linden JA, et al. (2002): Brain volume changes in first-episode schizophrenia: a 1-year follow-up study. Arch Gen Psychiatry 59:1002-10.

37. WHO (1990): Composite International Diagnostic Interview (CIDI) Geneva: World Health Organization.
38. Dale AM, Fischl $B$, and Sereno MI (1999): Cortical surface-based analysis. I. Segmentation and surface reconstruction.

Neuroimage 9:179-94.

39. Dale AM and Sereno MI (1993): Improved localization of cortical activity by combining EEG and MEG with MRI cortical surface reconstruction: a linear approach. J Cogn Neurosci162-176.

40. Fischl $B$ and Dale AM (2000): Measuring the thickness of the human cerebral cortex from magnetic resonance images. Proc Natl Acad Sci USA 97:11050-5.

41. Fischl $B$, Liu $A$, and Dale AM (2001): Automated manifold surgery: constructing geometrically accurate and topologically correct models of the human cerebral cortex. IEEE Trans Med Imaging 20:70-80.

42. Fischl $B$, Salat $D H$, Busa E, Albert M, Dieterich M, Haselgrove C, et al. (2002): Whole brain segmentation: automated labeling of neuroanatomical structures in the human brain. Neuron 33:341-55.

43. Fischl $B$, Salat $D H$, van der Kouwe AJ, Makris N, Segonne F, Quinn BT, et al. (2004): Sequenceindependent segmentation of magnetic resonance images. Neuroimage 23 Suppl 1:S69-84.
44. Fischl B, Sereno MI, and Dale AM (1999): Cortical surface-based analysis. II: Inflation, flattening, and a surface-based coordinate system. Neuroimage 9:195207.

45. Fischl B, Sereno MI, Tootell RB, and Dale AM (1999): High-resolution intersubject averaging and a coordinate system for the cortical surface. Hum Brain Mapp 8:272-84.

46. Fischl $B$, van der Kouwe A, Destrieux C, Halgren E, Segonne F, Salat DH, et al. (2004): Automatically parcellating the human cerebral cortex. Cereb Cortex 14:11-22.

47. Han X, Jovicich J, Salat $D$, van der Kouwe $A$, Quinn B, Czanner S, et al. (2006): Reliability of MRI-derived measurements of human cerebral cortical thickness: the effects of field strength, scanner upgrade and manufacturer. Neuroimage 32:180-94.

48. Jovicich J, Czanner $S$, Greve D, Haley E, van der Kouwe A, Gollub R, et al. (2006): Reliability in multisite structural MRI studies: effects of gradient nonlinearity correction on phantom and human data. Neuroimage 30:436-43.

49. Segonne F, Dale AM, Busa E, Glessner M, Salat D, Hahn HK, et al. (2004): A hybrid approach to the skull stripping problem in MRI. Neuroimage 22:106075. 
50. Desikan RS, Segonne F, Fischl B, Quinn BT, Dickerson BC, Blacker D, et al. (2006): An automated labeling system for subdividing the human cerebral cortex on MRI scans into gyral based regions of interest.

Neuroimage 31:968-80.

51. Rosas HD, Liu AK, Hersch S, Glessner M, Ferrante RJ, Salat DH, et al. (2002): Regional and progressive thinning of the cortical ribbon in Huntington's disease. Neurology 58:695-701.

52. Salat DH, Buckner RL, Snyder AZ, Greve DN, Desikan RS, Busa E, et al. (2004): Thinning of the cerebral cortex in aging. Cereb Cortex 14:721-30.

53. StataCorp (2009): Stata Statistical Software: Release 11. College Station, TX: StataCorp LP.

54. Goldstein H (1987): Multilevel Models in Educational and Social Research London: Griffin.

55. Panizzon MS, FennemaNotestine C, Eyler LT, Jernigan TL, PromWormley E, Neale M, et al. (2009): Distinct genetic influences on cortical surface area and cortical thickness. Cereb Cortex 19:2728-35.

56. Green R (2004): Heteromodal association cortex in schizophrenia. Am J Psychiatry 161:17234; author reply 1724.
57. Ross CA and Pearlson GD (1996): Schizophrenia, the heteromodal association neocortex and development: potential for a neurogenetic approach. Trends Neurosci 19:171-6.

58. Buchanan RW, Francis A, Arango C, Miller K, Lefkowitz DM, McMahon $\mathrm{RP}$, et al. (2004):

Morphometric assessment of the heteromodal association cortex in schizophrenia. Am J Psychiatry 161:322-31.

59. Pearlson GD, Petty RG, Ross CA, and Tien AY (1996): Schizophrenia: a disease of heteromodal association cortex? Neuropsychopharmacolog y14:1-17.

60. Cannon TD, Thompson PM, van Erp TG, Toga AW, Poutanen VP, Huttunen $M$, et al. (2002): Cortex mapping reveals regionally specific patterns of genetic and disease-specific graymatter deficits in twins discordant for schizophrenia. Proc Natl Acad Sci U S A 99:3228-33.

61. Grunwald T, Boutros NN, Pezer N, von Oertzen J, Fernandez G, Schaller C, et al. (2003): Neuronal substrates of sensory gating within the human brain. Biol Psychiatry 53:511-9.
62. Bramon E, RabeHesketh S, Sham P, Murray RM, and Frangou S (2004): Meta-analysis of the P300 and P50 waveforms in schizophrenia. Schizophr Res 70:315-29.

63. Heinrichs RW (2004): Meta-analysis and the science of schizophrenia: variant evidence or evidence of variants? Neurosci Biobehav Rev 28:379-94.

64. Howes OD and Kapur S (2009): The dopamine hypothesis of schizophrenia: version III-the final common pathway. Schizophr Bull 35:549-62.

65. van Os J, Kenis G, and Rutten BP (2010): The environment and schizophrenia. Nature 468:203-12.

66. Glahn DC, Laird AR, Ellison-Wright I, Thelen SM, Robinson JL, Lancaster JL, et al. (2008): Meta-analysis of gray matter anomalies in schizophrenia: application of anatomic likelihood estimation and network analysis. Biol Psychiatry 64:774-81.

67. Kyriakopoulos $M$ and Frangou S (2009): Recent diffusion tensor imaging findings in early stages of schizophrenia. Curr Opin Psychiatry 22:168-76. 
68. Whitfield-Gabrieli S, Thermenos HW, Milanovic S, Tsuang MT, Faraone SV, McCarley RW, et al. (2009): Hyperactivity and hyperconnectivity of the default network in schizophrenia and in firstdegree relatives of persons with schizophrenia. Proc

Natl Acad Sci U S A

106:1279-84.

69. Bersani G, Orlandi V, Kotzalidis GD, and Pancheri P (2002):

Cannabis and schizophrenia: impact on onset, course, psychopathology and outcomes. Eur Arch Psychiatry Clin Neurosci 252:86-92.

70. D'Souza DC, Sewell RA, and Ranganathan $\mathrm{M}$ (2009): Cannabis and psychosis/schizophrenia: human studies. Eur Arch Psychiatry Clin Neurosci 259:413-31.

71. Hall W and Degenhardt $L$ (2008): Cannabis use and the risk of developing a psychotic disorder. World Psychiatry 7:68-71.

72. Henquet $C, D i$ Forti $\mathrm{M}$, Morrison $\mathrm{P}$, Kuepper R, and Murray RM (2008): Gene-environment interplay between cannabis and psychosis. Schizophr Bull34:1111-21.
73. Henquet $C$,

Krabbendam L, Spauwen J, Kaplan C, Lieb R, Wittchen $\mathrm{HU}$, et al. (2005):

Prospective cohort study

of cannabis use,

predisposition for

psychosis, and psychotic

symptoms in young

people. Bmj330:11.

74. Henquet $C$, Murray R, Linszen $D$, and van Os J (2005): The environment and schizophrenia: the role of cannabis use. Schizophr Bull31:608-12.

75. van Os J, Bak M, Hanssen M, Bijl RV, de Graaf $\mathrm{R}$, and Verdoux $\mathrm{H}$ (2002): Cannabis use and psychosis: a longitudinal population-based study. Am J Epidemio/156:31927.

76. Verdoux H, Gindre C, Sorbara F, Tournier $M$, and Swendsen JD (2003): Effects of cannabis and psychosis vulnerability in daily life: an experience sampling test study. Psychol Med 33:23-32.

77. Verdoux $\mathrm{H}$ and Tournier M (2004): Cannabis use and risk of psychosis: an etiological link? Epidemiol Psichiatr Soc 13:113-9.

78. Bangalore SS, Prasad KM, Montrose DM, Goradia DD, Diwadkar VA, and Keshavan MS (2008): Cannabis use and brain structural alterations in first episode schizophrenia--a region of interest, voxel based morphometric study. Schizophr Res 99:1-6.
79. Szeszko PR, Robinson DG, Sevy S, Kumra S, Rupp $\mathrm{Cl}$, Betensky JD, et al. (2007): Anterior cingulate grey-matter deficits and cannabis use in firstepisode schizophrenia. $\mathrm{Br} J$ Psychiatry 190:230-6.

80. Rais M, Cahn W, Van Haren N, Schnack H, Caspers E, Hulshoff Pol $\mathrm{H}$, et al. (2008): Excessive brain volume loss over time in cannabis-using first-episode schizophrenia patients. Am J Psychiatry 165:490-6.

81. Lammertink $M$, Lohrer F, Kaiser R, Hambrecht M, and Pukrop R (2001): Differences in substance abuse patterns: multiple drug abuse alone versus schizophrenia with multiple drug abuse. Acta Psychiatr Scand 104:361-6.

82. Smieskova R, Fusar-Poli $P$, Allen $P$, Bendfeldt $K$, Stieglitz RD, Drewe J, et al. (2009): The effects of antipsychotics on the brain: what have we learnt from structural imaging of schizophrenia?--a systematic review. Curr Pharm Des 15:2535-49.

83. Jayakumar PN, Venkatasubramanian G, Gangadhar BN, Janakiramaiah $\mathrm{N}$, and Keshavan MS (2005): Optimized voxel-based morphometry of gray matter volume in firstepisode, antipsychoticnaive schizophrenia. Prog Neuropsychopharmacol Biol Psychiatry 29:587-91. 
84. Dickerson BC, Bakkour A, Salat DH, Feczko E, Pacheco J, Greve DN, et al. (2009): The cortical signature of Alzheimer's disease: regionally specific cortical thinning relates to symptom severity in very mild to mild AD dementia and is detectable in asymptomatic amyloidpositive individuals. Cereb Cortex 19:497-510.

85. Sowell ER, Peterson BS, Kan E, Woods RP, Yoshii J, Bansal R, et al. (2007): Sex differences in cortical thickness mapped in 176 healthy individuals between 7 and 87 years of age. Cereb Cortex 17:155060. 

1 Dept. of Psychiatry and Neuropsychology, School for Mental Health and Neuroscience, EURON, Maastricht University Medical Centre, PO Box 616 (Vijv1), 6200 MD Maastricht, The Netherlands

2 King's College London, King's Health Partners, Department of Psychosis Studies Institute of Psychiatry, London, United Kingdom 


\title{
Reduced Cortical Thickness as an Outcome of Differential Sensitivity to Environmental Risks in Schizophrenia
}

\author{
Biological Psychiatry, 69: 487-494
}

Petra Habets' ${ }^{1}$, Machteld Marcelis' ${ }^{1}$, Ed Gronenschild', Marjan Drukker', and Jim van Os ${ }^{1-2}$ for G.R.O.U.P. 


\begin{abstract}
Background. The aetiology of schizophrenia is thought to involve differential - likely genetically mediated - sensitivity to environmental exposures. However, examination of differential sensitivity in models of psychopathological constructs is subject to bias as psychopathology itself may distort exposure assessment. The use of neuroimaging phenotypes, conversely, may provide unbiased evidence for differential sensitivity to environmental exposures. The present study examined the impact of two environmental exposures associated with both schizophrenia and MRI cerebral alterations, in models of cerebral cortical thickness.
\end{abstract}

Methods. T1-weighted MRI scans were acquired from 88 patients with schizophrenia, 98 healthy siblings at higher than average genetic risk for schizophrenia and 87 controls. Freesurfer was used to measure cortical thickness for 68 brain regions. Associations between cortical thickness on the one hand, and cannabis use and developmental trauma on the other were examined.

Results. A significant group $x$ developmental trauma interaction $(x 2=9.65, p=0.01)$, as well as a significant group $x$ cannabis interaction $(x 2=6.04, p=0.05)$ was apparent, indicating differential sensitivity of the patient group who displayed stronger reductions of cortical thickness for both exposures. A similar pattern was found in the sibling-control comparison for cannabis. For developmental trauma, siblings did not differ from controls, displaying an increase in cortical thickness with higher levels of trauma.

Conclusions. The findings suggest that schizophrenia and its genetic liability are associated with differential cerebral cortical sensitivity to developmental environmental exposures such as cannabis. Gene-environment interactions may underlie some of the brain alterations observed in patients with schizophrenia and their relatives. 


\section{Introduction}

It is thought that most of the differences in liability to schizophrenia can be explained by genetic variation (1-3) occasioning differential sensitivity to environmental risk factors impacting during critical phases of development (4-7), a phenomenon known as gene-environment interaction (GxE) (8-10). Examining GxE is difficult because for ethical reasons people cannot be assigned randomly to, for example, heavy cannabis use or childhood trauma. The problems related to GxE research can be circumvented to a degree by (i) replacing the dependent variable in GxE analyses with an objective biological measure that is only weakly associated with (risk for) schizophrenia and (ii) by including siblings of patients as a group at high genetic risk but without the illness phenotype (Fig. 1). This method was pioneered by Cannon and colleagues (2002), who showed that obstetric complications (an environmental risk factor for schizophrenia (11)) was related to grey matter reductions and increased cerebrospinal fluid in patients and siblings (12). Thus, patients may overreport childhood trauma and start using cannabis because of their illness (reverse causality). However, such over-reporting cannot readily explain, for example, why a difference in cortical grey volume matter between exposed and unexposed patients and particularly siblings is greater than between exposed and non-exposed controls. Thus, although only random assignment can overcome reporting bias and reverse causality, several alternatives exist in observational research that, in combination, have complementary value in the interpretation of GxE.

As schizophrenia is associated with cortical grey matter alterations that to a lesser degree are also observed in healthy siblings $(13,14)$, and two environmental exposures associated with schizophrenia, cannabis use (15-18) and developmental trauma (19-21), are also associated with cerebral alterations (22-30), the environmentally sensitive (31) measure of cortical thickness (CT) was used in the analyses. The analyses focused on differential sensitivity to two environmental risk factors as a function of risk for schizophrenia, comparing patients (high genetic risk), their siblings (intermediate genetic risk) and controls (low genetic risk) and using measures of $\mathrm{CT}$ as the outcome. The hypothesis was that higher genetic risk would be associated with greater impact of environmental exposures on the cortical phenotype. 


\section{Methods and analyses}

\section{Subjects}

Data pertain to baseline measures of an ongoing longitudinal MRI study in Maastricht, the Netherlands. In selected representative geographical areas in the Netherlands and Belgium, patients were identified through representative clinicians whose caseload was screened for inclusion criteria. Subsequently, a group of patients presenting consecutively at these services either as out-or in-patients were recruited for the study. First-degree relatives were sampled through participating patients. Control subjects were recruited from the same population as the cases using random mailings in nearby municipalities and through advertisement in newspapers. All interviews were conducted by trained psychology graduates. The sample consisted of 88 schizophrenia patients, 98 siblings of schizophrenia patients and 87 controls. The sample included 62 families, of which 39 families contributed one patient and one discordant sibling, 3 families contributed one patient and two discordant siblings, one family contributed one patient and three discordant siblings. Two families contributed two patients, 7 families contributed two discordant siblings, and one family contributed 3 discordant siblings. In the control group, 9 families contributed two siblings. In addition, 41 independent patients, 33 independent siblings, and 69 independent controls were included. Inclusion criteria were: (i) age: 16 to 50 years, (ii) diagnosis of non-affective psychotic disorder and (iii) good command of Dutch language. In a few instances, the patient refused whereas the sibling wished to participate, in which case the sibling was included; the majority represented sib-pairs with at least one ill relative. Siblings had to be free of any lifetime non-affective psychotic disorder. For the control subjects, the occurrence of any psychotic disorder in either the subject or any first-degree family member, assessed using the Family Interview for Genetic Studies (FIGS) (32), constituted an exclusion criterion.

Diagnosis was based on the Diagnostic and Statistical Manual of Mental Disorder-IV (DSM-IV) criteria (33), assessed with the Comprehensive Assessment of Symptoms and History (CASH) interview (34). Patients were diagnosed with: schizophrenia $(n=62)$, schizoaffective disorder $(n=9)$, schizophreniform disorder $(n=4)$, brief psychotic disorder $(n=2)$, and psychotic disorder not otherwise specified $(n=11)$. The CASH was also used to confirm the absence of a diagnosis of non-affective psychosis in the siblings, and absence of a lifetime diagnosis of any psychotic disorder or 
any current affective disorder in the healthy controls. Twenty-one siblings and 14 controls had a history of major depressive disorder, but none presented in a current depressive episode.

Prior to MRI acquisition, participants were screened for exclusion criteria: (i) brain injury with unconsciousness of $>1$ hour, (ii) meningitis or other neurological diseases that might have affected brain structure/function, (iii) cardiac arrhythmia requiring medical treatment and (iv) severe claustrophobia. In addition, subjects with metal corpora aliena were excluded from the study, as well as women with IUD status and (suspected) pregnancy.

The study was approved by the standing ethics committee, and all the subjects gave written informed consent in accordance with the committee's guidelines.

\section{Measures}

The Positive and Negative Syndrome Scale (PANSS) (35) was used to measure psychotic symptoms over the last two weeks.

Educational level was defined as highest accomplished level of education. Antipsychotic medication (AP) was determined using the reports of the participant's psychiatrist.

Best estimate lifetime (cumulative) AP use was determined by multiplying the number of days of AP use with the corresponding haloperidol equivalents and summing up these scores for all periods of AP use (36).

\section{Substance use}

Substance use was assessed using the Composite International Diagnostic Interview (CIDI) sections B-J-L (37).

Cannabis use was assessed as the reported lifetime number of instances of cannabis use, ranging from 1-5, 6-9, 10-19, 20-39, 40-59, 60-79, 80-99 or 100 times or more. In the analyses, three groups were created, allowing for the assessment of doseresponse: (i) subjects who had never used cannabis, (ii) subjects who used cannabis between 1 and 39 times and (iii) subjects who used cannabis at least 40 times in their life, as previous research in the Dutch and German general populations has shown that severity of exposure, defined in terms of frequency of use, represents an excellent tradeoff between sensitivity and specificity with regard to clinical and subclinical psychosis outcomes $(16,38)$. CIDI cannabis lifetime frequency data was available for 235 subjects (14\% missing data). 
Hard drug use, such as stimulants, sedatives, opiates, cocaine, PCP, psychedelics, inhalants, or other (e.g. XTC, poppers) was assessed as reported frequency of use (i) during the last 12 months, and (ii) lifetime.

Alcohol use was defined as the reported number of weekly consumptions during the last 12 months.

Developmental trauma

Developmental trauma was assessed with the Dutch version of the Childhood Trauma Questionnaire Short Form (CTQ). The short CTQ consists of 25 items rated on a 5-point Likert scale ( $1=$ never true to $5=$ very often true) enquiring about traumatic experiences in childhood. Five types of childhood maltreatment were assessed: emotional, physical and sexual abuse, and emotional and physical neglect, with five questions covering each type of trauma (39). A general measure of developmental trauma was created by calculating the mean of the 25 items. CTQ data was missing for one person.

\section{MRI acquisition and processing}

MRI scans were acquired using a 3T Siemens scanner and the following acquisition parameters: MDEFT sequence: 176 slices, 1 mm, TE 2.4 ms, TR 7.92 ms, TI 910 ms, flip angle $15^{\circ}$, total acquisition time: $12 \mathrm{~min} 51 \mathrm{~s}$, and for the MP-RAGE (ADNI) sequence: 192 slices, $1 \mathrm{~mm}$, TE $2.6 \mathrm{~ms}$, TR $2250 \mathrm{~ms}$, TI $900 \mathrm{~ms}$, flip angle $9^{\circ}$, total acquisition time: $7 \mathrm{~min} 23 \mathrm{~s}$. The matrix size and field of view was $256 \times 256$. The number of excitations was 1. Two sequences were used because of a scanner update during data collection. The MP-RAGE and MDEFT are very similar, but to prevent any systematic bias, the total proportion of MP-RAGE scans (around 1/3) was balanced between the groups.

\section{MRI preprocessing}

Scans were processed and analyzed using Freesurfer stable release v4.5.0. Technical details of these procedures are described in prior publications (40-46). Data was automatically transformed into Talairach standard space.

\section{Cortical thickness measurement}

Before CT measurement, the cerebral cortex was parcellated into units based on gyral and sulcal structure $(47,48)$. Furthermore, a variety of surface-based data was created including maps of curvature and sulcal depth. This method uses both intensity and continuity information from the entire three dimensional MR volume 
in segmentation and deformation procedures to produce representations of CT, calculated as the closest distance from the grey/white boundary to the grey/CSF boundary at each vertex on the tessellated surface (41). The maps are created using spatial intensity gradients across tissue classes and are not restricted to the voxel resolution of the original data, thus are capable of detecting sub-millimeter differences between groups. CT measurement procedures have been validated against histological analysis (49) and manual measurements $(50,51)$.

\section{Statistical analyses}

The CT surface map was loaded, for each individual and for each hemisphere, in a group file, where individual CT values for each predefined region of interest (hereafter: region; adapted from the Desikan atlas (47), 34 regions per hemisphere) were calculated and exported to STATA version 11 (52). The dataset was transformed from a wide format to a long format, resulting in a hierarchically structured dataset, with 68 regional CT measures (level 1) nested in subjects (level 2) who were part of the same families (level 3). Because of the three-level grouping structure of the data, compromising statistical independence of the observations, multilevel random regression models were fitted (53) using the XTMIXED command in STATA with $\mathrm{CT}$ measures as the dependent variable and subject number and family number modeled as random effects. Mixed models contain both fixed and random effects, the fixed effects being analogous to standard regression coefficients $(\beta)$.

In order to test the hypothesis that groups differed in their sensitivity to developmental trauma, analyses were conducted with trauma and group (patients, siblings and controls) as well as their interaction term as independent variables and $C T$ as the dependent variable $\left(C T=\beta_{0}+\beta_{1}\right.$ (trauma) $+\beta_{2}$ (group) $+\beta_{3}$ (trauma $\times$ group). The trauma $\times$ group interaction was fitted with the control group as the reference category. The trauma exposure was entered both as a linear variable and as dummy variables representing the distribution of the trauma score divided by its quartiles, allowing visualization of dose-response $(0=$ no trauma, $1=$ low trauma, 2=medium trauma, $3=$ high trauma).

Interaction terms were evaluated by Wald test (54). Stratified effect sizes for all trauma levels were assessed by calculating the appropriate linear combinations from the model containing the interaction, using the LINCOM procedure in STATA. Analyses were adjusted for the a priori hypothesized confounders age, sex and level 
of education.

Similar multilevel random regression analyses were conducted with the cannabis exposure as independent variable $\left(\mathrm{CT}=\beta_{0}+\beta_{1}\right.$ (cannabis use) $+\beta_{2}$ (group) $+\beta_{3}$ (cannabis use $\times$ group), cannabis exposure entered both as a linear variable and as dummy variables $(0=$ no cannabis use, $1=$ moderate cannabis use, $2=$ heavy cannabis use).

\section{Power analysis}

The power of the 2-way and 3-way interaction analyses was calculated by empirical statistical simulation in STATA (www.stata.com/support/faqs/stat/power.html), as described previously (55). Effect sizes used were based on published work in this area. These power simulations showed that the 2-way interactions in the study had a power of $75 \%$ to find a significant effect at an alpha of 0.05 .

The study was not powered to examine whether the differential impact of trauma and cannabis varied not only with group status, but also with brain region. Thus, the three-way interaction (trauma/cannabis $x$ group $x$ region) modeling these effects had only $10 \%$ power. Therefore, results of these three-way interactions will only be described exploratively in order to generate hypotheses for future research.

\section{Results}

\section{Descriptive analyses}

Patients had lower educational level than controls and siblings (Table 1). There were more men than women in the patient group, whereas the opposite held for the control group. Siblings used more alcohol than controls and patients. Patients reported more cannabis use than siblings and controls, and more lifetime and present (last 12 months) hard drug use than siblings and controls, with no large or significant differences between the latter two groups. For all groups, the age of first cannabis use was in adolescence, with a mean age of 16.9 years in patients, 16.8 years in siblings and 16.5 years in controls (d.f. $(2,106), F=0.10, P=0.90)$. Patients reported more developmental trauma than siblings and controls, the latter groups having similar levels of reported trauma.

Seventy-three patients were receiving AP (second generation: $n=70$; first generation: $\mathrm{n}=3$ ). Furthermore, 17 patients used antidepressants, 6 benzodiazepines, 5 antiepileptic drugs and 2 lithium. Three siblings and 3 controls used antidepressants, 
and 1 control used benzodiazepines. Lifetime AP use was associated with neither CT $(\beta=0.00, P=0.39)$ nor cannabis use $(\beta=0.00, P=0.50)$ (Table 1$)$.

\section{Main and interaction effects}

Main effects of environmental exposure and group on cortical thickness In the model without interaction terms, there was no significant association between developmental trauma and CT in the total group of patients, siblings and controls ( $\beta=-0.001, P=0.78$ ). Heavy cannabis use was significantly associated with $C T$ ( $\beta=-$ $0.05, P=0.00$ ) indicating that heavy cannabis users had lower $C T$ values. There was no significant association between group and CT (Table 2).

\section{Interaction between group status and developmental trauma}

There was a significant group $x$ trauma (linear variable) interaction $\left(x^{2}=9.65, p=0.01\right.$ ), indicating that the effect of trauma on CT differed between groups. Stratified analyses revealed that patients had significantly lower $C T$ values when exposed to higher levels of developmental trauma $(\beta=-0.02, P=0.03)$, which was not found in controls $(\beta=0.003, P=0.72)$. The opposite pattern was found in siblings $(\beta=0.02$, $P=0.05$ ), indicating higher $C T$ values when exposed to higher levels of developmental trauma. Visualizing the effect over the four quartile groups of trauma exposure revealed progressively lower values of $C T$ with progressively higher levels of trauma in exposed patients and exposed controls, whereas an opposite trend was apparent in the sibling group (Table 3, Fig. 2A).

\section{Interaction between group status and cannabis}

There was a significant group $x$ cannabis interaction (linear variable) $\left(x^{2}=6.04\right.$, $P=0.05)$, indicating that the effect of using cannabis on $C T$ varied as a function of group. Stratified analyses showed that patients with heavy cannabis use had significantly lower CT values compared to patients with no cannabis use $(\beta=-0.07$, $P=0.002)$ and a similar pattern of results was found for siblings $(\beta=-0.06, P=0.01)$, but not for controls $(\beta=0.01, P=0.65$ ) (Table 3, Fig. $2 B$ ). The $p$-values were only marginally affected after adjustment for hard drug use in patients $(\beta=-0.06, P=0.01)$ and siblings ( $\beta=-0.06, P=0.01$ ). Patients with moderate cannabis exposure had CT values that were intermediate to those with no or heavy use, whereas for siblings the effect on CT was confined mainly to the group of heavy use (Table 3, Fig. 2B). 
Explorative group $x$ exposure $x$ region interactions

Explorative analyses of three-way interactions examining regional variation of differential sensitivity revealed no significant interactions for trauma. There was some suggestion for regional group interactions with cannabis in that in patients (compared to controls), cortical thinning in relation to heavy cannabis use, compared to non users, was apparent in the left frontal pole $\left(x^{2}=3.75, p=0.05\right)$ and left $\left(x^{2}=4.65\right.$, $\mathrm{p}=0.03)$ and right $\left(x^{2}=9.67, \mathrm{p}=0.00\right)$ parahippocampal gyrus. In siblings, findings were partly similar in that cortical thinning for heavy cannabis users compared to non users was apparent in the left frontal pole $\left(x^{2}=5.32, p=0.02\right)$, right entorhinal cortex $\left(x^{2}=3.72, p=0.05\right)$ and the right parahippocampal gyrus $\left(x^{2}=3.70, p=0.05\right)$.

\section{Discussion}

The results showed that exposure to cannabis, as well as exposure to trauma in childhood, was associated with cerebral cortical thinning in individuals at high genetic risk for schizophrenia (patients), whereas this was not the case in those at low genetic risk (controls). For the cannabis exposure, the pattern of results in individuals with intermediate genetic risk (siblings) was similar to that of the patient group. Furthermore, there was a suggestion of a similar pattern of regional thinning in patient and sibling cannabis users in frontal and parahippocampal regions. For the developmental trauma exposure, siblings revealed CT increases with higher trauma levels, although this pattern was not significantly different from controls.

\section{Differential impact of environmental exposures on the brain}

No previous studies on the relationship between trauma and brain alterations in schizophrenia are available. However, childhood trauma has been associated with structural brain changes, such as volume loss in the hippocampus, corpus callosum, and prefrontal cortex $(22,24,29,30,56,57)$.

The finding that cannabis use had a differential impact on CT in not only patients but also siblings, extend earlier findings indicating that gene-environment interactions may underlie the association between cannabis and psychosis (5, 58-60). Furthermore, the findings are suggestive of a dose-response relationship (higher cannabis exposure associated with more severe CT alteration) in the group most at risk (patients). Studies investigating the effect of cannabis on the brain in healthy subjects have reported only minimal evidence for cannabis-induced brain 
alterations $(23,25,26,61)$. In schizophrenia, studies are scarce and have produced inconsistent findings ranging from no effect of cannabis on brain morphology (62), to decreased grey matter volume (27). The fact that similar findings were apparent in the sibling-control comparison for the cannabis exposure is in line with the initial hypothesis: siblings, at higher than average genetic risk, also displayed differential sensitivity.

For the trauma exposure, there was evidence for an opposite effect in patients and siblings, whereas the pattern of results in siblings did not significantly differ from the pattern in controls. The directionally opposite finding in the siblings may represent chance or noise. Alternatively, siblings and controls may differ from patients in that the effect of exposure to traumatic experiences may be neutral (controls) or even trophic (siblings). To the degree that the effects of trauma on the brain are mediated by long-term psychological adaptation, resilience and coping may moderate the outcome of traumatic experiences over time, possibly mitigating the risk for later psychotic outcomes. In other words, not only sensitivity may be an important moderator determining the psychiatric outcome, but also individuals' resilience and coping. An individual's resilience is thought to be mediated by adaptive functioning of distinct molecular machineries and brain circuits that allow the individual to experience positive emotions rather than negative, and search positive ways to reframe stressful events (63). Given the fact that siblings only share some of their genes and environments with patients, the opposite effect in patients and siblings observed for childhood trauma may be explained by (i) genetic variants not shared between the sibs, (ii) non-shared environmental exposures, (iii) illness effects. In addition, evidence has emerged that this type of contrast in the findings may be indicative of genetic plasticity (64): the same gene may confer positive sensitivity to an exposure in some environments, but negative sensitivity in others. To the degree that differential negative sensitivity to childhood trauma may be contingent on illness expression, underlying illness-related brain changes or treatment factors such as antipsychotic medication may play a role. For the cannabis exposure, however, genes contributing to differential sensitivity to the environment may be shared between patients and their siblings and not be illness-dependent. 


\section{Final common pathway}

The effects of cannabis or traumatic stress may impact along a final common pathway. Prefrontal cortical alterations could have an impact on the stress-buffering system, resulting in mesolimbic hyperdopaminergia. Repeated exposure to stress or cannabis may lead to prolonged changes in dopaminergic signaling, and eventually to dopamine sensitization (65-68). There was some evidence that cannabis-related regional thinning in patients and siblings was anatomically congruent with the hypothesis of impact on dopamine projections, as there was a suggestion of differential impact of cannabis on the frontal pole, the entorhinal cortex and the parahippocampal gyrus.

\section{Possible underlying mechanisms}

During childhood, the brain is still in full development and thus vulnerable to environmental exposures. Studies suggest that developmental trauma alters hypothalamic-pituitary-adrenal (HPA) axis functioning (69). These neurobiological abnormalities (70) could, in concert with an already existing genetic liability contribute to an increased risk for schizophrenia. The changes in the HPA axis could be the result of a hypersensitive glucocorticoid release or abnormalities in glucocorticoid receptors consequently upon (chronic) stress exposure (71). Due to synergism between the activity of the HPA axis and the dopaminergic circuits, glucocorticoid secretion may increase dopamine activity in the mesolimbic system (71). Some brain regions, such as the hippocampus or the prefrontal lobe, may be particularly sensitive to stressors $(57,72)$.

Delta-9-tetrahydrocannabinol $(\delta-9-T H C)$, the active psychotropic ingredient of cannabis, activates the cannabinoid-1 (CB1) receptor, the primary binding site of endogenous cannabinoids. THC may influence dopamine firing in the ventral tegmental area (VTA), resulting in increased striatal DA levels; in addition, THC is also believed to impact synaptic plasticity, which is thought to be impaired in schizophrenia (73). Furthermore, THC-related glutamatergic effects may affect grey matter volume $(78)$, and possibly $C T$, through a mechanism of neurotoxicity $(74,75)$. However, the exact influence of THC on endocannabinoid, dopamine, GABA and glutamate signaling remains to be elucidated, as is the relationship with neuronal network alterations and psychosis. 


\section{Limitations}

Gene-environment interaction studies assume that the interacting variables are independent. In some instances, this assumption did not hold as patients reported more cannabis use and trauma than both controls and siblings. The consequence of this is that the interpretation of interaction cannot distinguish between moderation (genetic risk influences sensitivity to the environment) and mediation (genetic risk influences exposure to the environment). The fact that the violation of independence in the case of the cannabis exposure does not apply to the siblings, suggests that moderation rather than mediation is the underlying mechanism, as siblings displayed similar differences with the controls as the patients. Although for the trauma exposure we cannot exclude mediation in the case-control comparison, it is unlikely that mediation is the only underlying mechanism as for most exposures in psychiatry both moderation and mediation usually apply (76).

Assessments of childhood trauma in patients with psychotic disorder may be biased. However, recent work suggests that patient reports of environmental exposures such as childhood trauma have good reliability and validity and are not subject to reverse causality (77).

Although our design including a biological measure as dependent variable reduces the risk of reporting bias, and thus represents an alternative to previous studies using this paradigm, it cannot be ruled out that brain alterations, that are weakly associated with the illness, still have a minor impact on the reporting of childhood trauma or cannabis use. This, of course, applies to all neuroimaging studies that are observational in nature and cannot experimentally assign individuals to cannabis use or childhood trauma.

Although the effect of heavy cannabis use on mean CT was larger in patients (standardized effect size: -0.18 ) relative to controls (standardized effect size 0.03 ), giving rise to the reported significant two-way interaction, absolute effect sizes were small and difficult to interpret in terms of biological and clinical relevance. Effects were analyzed across 68 CT measures, hierarchically clustered within persons, so that larger effect sizes (as for example hypothesized in frontal areas and temporal areas) were averaged with smaller effect sizes. Future studies with larger sample sizes may provide more precise estimates of regional CT effect sizes associated with cannabis use.

Patients more often used cannabis than controls, which may distort interaction analysis given more precise estimates of cannabis effects on gray matter in the 
patients; however, siblings and controls did not differ in cannabis exposure and a similar interaction was apparent in these groups.

Freesurfer CT measurements appear to be relatively robust to differences in MRI protocols and scanners (41). Thus, in our data, no large or significant interaction was found between scan type and group on $C T\left(x^{2}=0.99 p=0.61\right)$. Similarly, adjusting for scanning sequence did not affect direction or significance of the results (results available upon request). 
Table 1. Subject demographics

\begin{tabular}{|c|c|c|c|c|c|}
\hline & Patients $(n=88)$ & Siblings $(n=98)$ & Controls $(n=87)$ & $\mathrm{F} / \mathrm{chi}^{2}$ & $\mathrm{P}$ \\
\hline Age at scan & $28.2 \pm 6.9$ & $29.5 \pm 8.7$ & $30.7 \pm 10.8$ & 1.8 & 0.17 \\
\hline Level of education & $4.3 \pm 2.0^{*}$ & $5.1 \pm 2.1$ & $5.4 \pm 1.8$ & 7.8 & 0.00 \\
\hline Sex n (\%) male & $59(67 \%)$ & $50(51 \%)$ & $33(38 \%)$ & 14.9 & 0.00 \\
\hline \multicolumn{6}{|l|}{ Cannabis use $\mathrm{n}(\%)$} \\
\hline None & $28(35 \%)$ & $53(62 \%)$ & $48(70 \%)$ & & \\
\hline Moderate & $14(17.5 \%)$ & $15(17 \%)$ & $11(16 \%)$ & & \\
\hline Heavy & $38(47.5 \%)$ & $18(21 \%)$ & $10(14 \%)$ & 26.1 & 0.00 \\
\hline Mean number of times harddrug use last year & $10.9 \pm 30.4^{*+}$ & $0.90 \pm 8.3$ & $1.2 \pm 7.8$ & 8.6 & 0.00 \\
\hline Mean number of times harddrug use lifetime & $54.2 \pm 99.9^{*+}$ & $12.8 \pm 42.8$ & $3.3 \pm 14.1$ & 13.9 & 0.00 \\
\hline Alcohol use & $4.8 \pm 9.0^{\dagger}$ & $9.5 \pm 16.9^{*}$ & $4.6 \pm 6.9$ & 4.5 & 0.01 \\
\hline PANSS Positive & $12.3 \pm 6.1^{*+}$ & $7.6 \pm 1.2$ & $7.4 \pm 1.4$ & 45.4 & 0.00 \\
\hline PANSS negative & $12.1 \pm 5.8^{* \dagger}$ & $8.4 \pm 2.1$ & $8.2 \pm 1.0$ & 29.2 & 0.00 \\
\hline PANSS Disorganization & $13.3 \pm 4.5^{*+}$ & $10.3 \pm 0.7$ & $10.3 \pm 1.2$ & 31.7 & 0.00 \\
\hline PANSS Excitement & $10.3 \pm 2.8^{* \dagger}$ & $8.6 \pm 1.4$ & $8.3 \pm 1.1$ & 25.9 & 0.00 \\
\hline PANSS Emotional distress & $13.9 \pm 5.4^{* \dagger}$ & $10.1 \pm 2.7$ & $9.4 \pm 2.3$ & 33.7 & 0.00 \\
\hline Emotional abuse & $1.9 \pm 0.9^{* \dagger}$ & $1.4 \pm 0.6$ & $1.5 \pm 0.7$ & 11.3 & 0.00 \\
\hline Physical abuse & $1.3 \pm 0.7^{*}$ & $1.1 \pm 0.4$ & $1.1 \pm 0.3$ & 3.9 & 0.02 \\
\hline Sexual abuse & $1.3 \pm 0.7^{*+}$ & $1.1 \pm 0.2$ & $1.1 \pm 0.3$ & 9.6 & 0.00 \\
\hline Emotional neglect & $2.3 \pm 0.9^{*}$ & $2.0 \pm 0.8$ & $1.9 \pm 0.8$ & 5.5 & 0.00 \\
\hline Physical neglect & $1.5 \pm 0.6^{*+}$ & $1.2 \pm 0.3$ & $1.2 \pm 0.4$ & 12.2 & 0.00 \\
\hline CTQ total & $7.2 \pm 2.9^{*+}$ & $5.9 \pm 1.6$ & $5.7 \pm 1.8$ & 12.3 & 0.00 \\
\hline Age of onset & $22.7 \pm 6.4$ & & & & \\
\hline Illness duration & $5.5 \pm 3.7$ & & & & \\
\hline Lifetime exposure to AP & $2743.4 \pm 4625.7$ & & & & \\
\hline
\end{tabular}

Means \pm SDs are reported

Abbreviations: PANSS, Positive and Negative Syndrome Scale; CTQ, Childhood trauma questionnaire; AP, antipsychotics

$\mathrm{F} / \mathrm{Chi}^{2}$ and $\mathrm{P}$-values refer to between-group differences

${ }^{*}$ Significantly different from controls

${ }^{(+)}$Significantly different from siblings 
Table 2. Comparisons of cortical thickness by group and environmental exposure

No. of observations ${ }^{\dagger} \quad$ Cortical thickness

$(\mathrm{n})^{\ddagger} \quad$ Mean \pm SD $\quad \beta^{\#} \quad P$

\begin{tabular}{lllll}
\hline Controls $^{*}$ & $5916(87)$ & $2.59 \pm 0.37$ & & \\
Siblings & $6664(98)$ & $2.58 \pm 0.37$ & 0.00 & 0.94 \\
Patients & $5984(88)$ & $2.57 \pm 0.37$ & -0.02 & 0.17
\end{tabular}

\begin{tabular}{lcccc} 
No cannabis users $^{*}$ & $8772(129)$ & $2.59 \pm 0.37$ & & \\
Medium cannabis users & $2720(40)$ & $2.59 \pm 0.37$ & -0.01 & 0.36 \\
High cannabis users & $4488(66)$ & $2.56 \pm 0.36$ & -0.05 & 0.00 \\
& & & & \\
No childhood trauma & & $2.57 \pm 0.37$ & & 0.29 \\
Low childhood trauma & $4624(68)$ & $2.59 \pm 0.36$ & 0.02 & 0.29 \\
Medium childhood trauma & $4760(70)$ & $2.59 \pm 0.37$ & 0.02 & 0.71 \\
High childhood trauma & $4692(69)$ & $2.57 \pm 0.37$ & -0.01 & \\
\hline
\end{tabular}

* reference level

${ }^{\dagger}$ no. of observations $=$ number of subjects* ${ }^{*}$ umber of region's \pm 68

${ }^{\ddagger}(\mathrm{n})=$ number of subjects

\# the $\beta$ 's represent the regression coefficients from multilevel linear regression analyses, adjusted for age, gender and level of education 


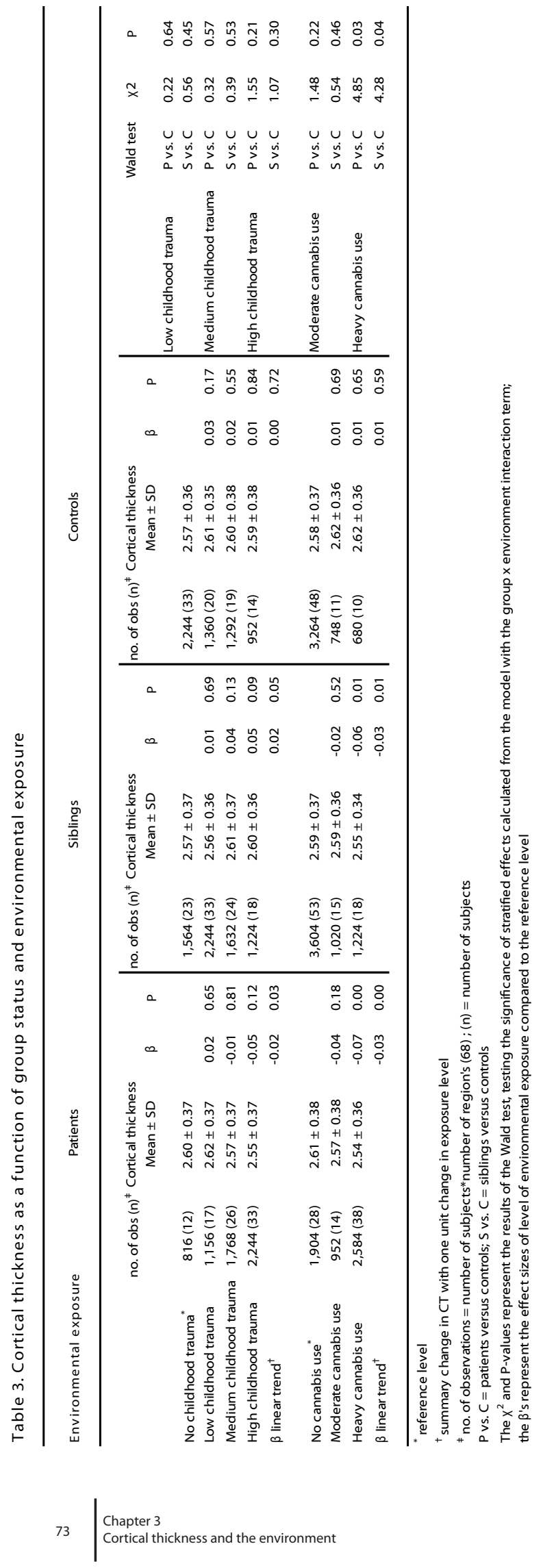


Figure 1. Environment to genotype design using biological alterations

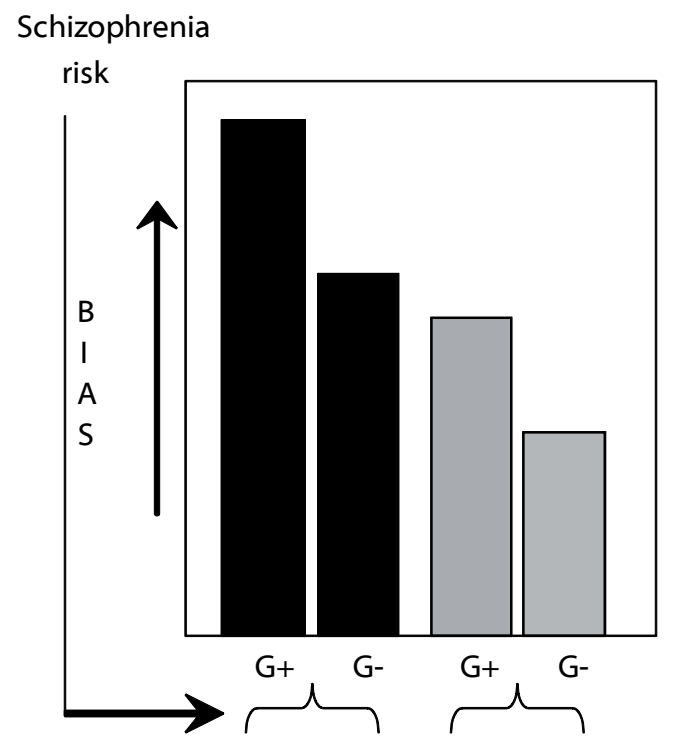

$\mathrm{E}+$

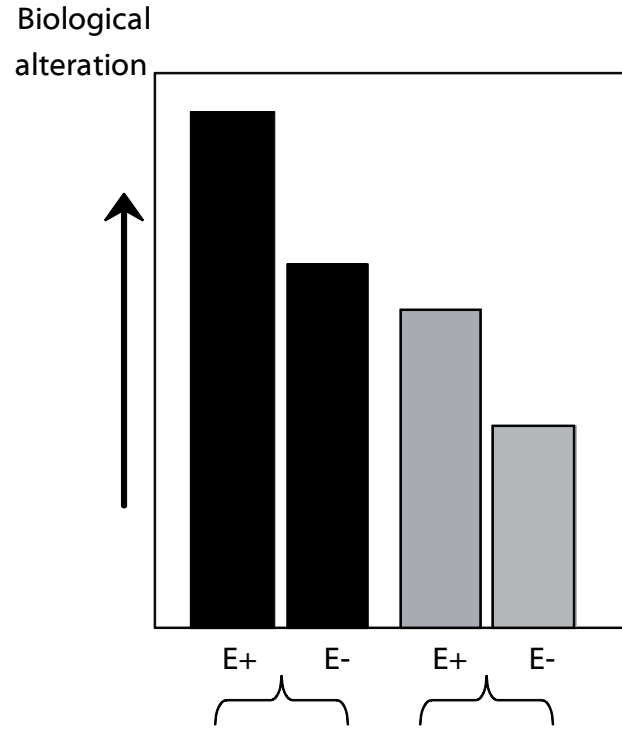

$\mathrm{G}+$
G-

Figure 1. Environment to genotype design using biological alterations.G+, high genetic risk; G-, low genetic risk; $\mathrm{E}+$, exposed to environmental risk; $\mathrm{E}-$, nonexposed to environmental risk. A common problem in gene-environment interaction (GE) studies is that the illness phenotype under investigation, and the dependent variable in the statistical model, influences assessment of the environmental exposure, giving rise to risk of bias (left-side figure of case-control study of GE). Although only experimental designs can overcome this issue, an alternative that reduces the risk of bias is to replace the outcome under investigation by a biological phenotype that is weakly associated with (risk of) the disease and examine differential impact of the environmental exposure in groups at high and low genetic risk with and without the illness phenotype (right-side figure). This study used a family-based design in which cases and siblings represent high genetic risk groups (with and without the illness phenotype respectively) and control subjects the low genetic risk group. 
Figure 2. Interaction between environmental risk factors and group on cortical thickness
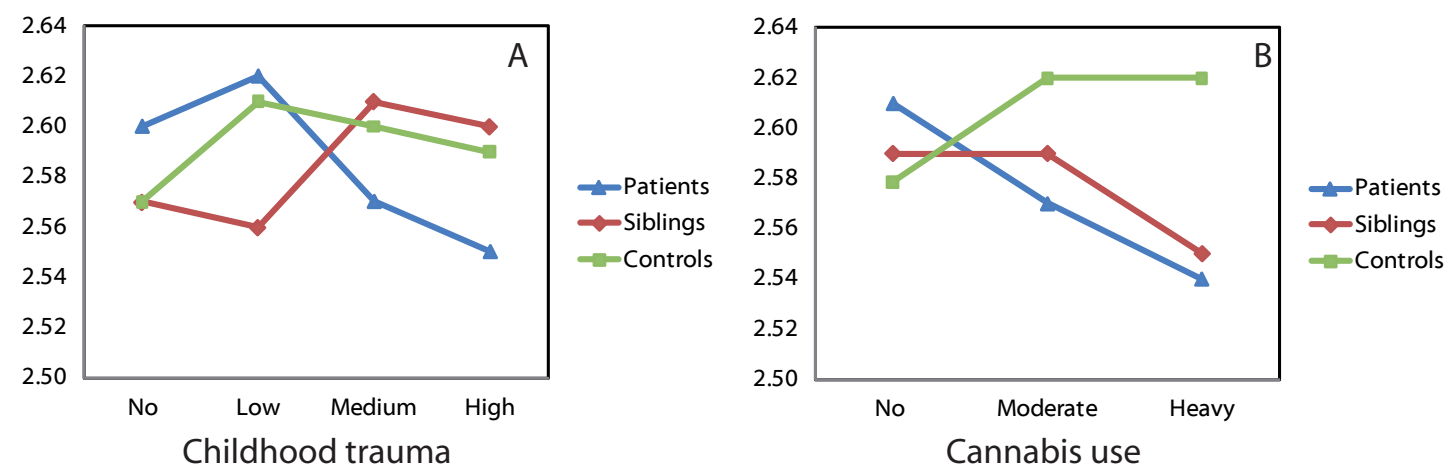

Figure 2. (A) Interaction between childhood trauma and group (linear trauma group interaction, $p$ .01). (B) Interaction between cannabis use and group (cannabis $x$ group interaction, $p$.05). 


\section{References}

1. Kennedy JL, Farrer LA, Andreasen NC, Mayeux R, and St George-Hyslop P (2003): The genetics of adult-onset neuropsychiatric disease: complexities and conundra? Science 302:822-6.

2. Cannon TD, Kaprio J, Lonnqvist J, Huttunen M, and Koskenvuo M (1998): The genetic epidemiology of schizophrenia in a Finnish twin cohort. A population-based modeling study. Arch Gen Psychiatry 55:67-74.

3. Sullivan PF, Kendler KS, and Neale MC (2003):

Schizophrenia as a complex trait: evidence from a meta-analysis of twin studies. Arch Gen Psychiatry60:1187-92.

4. Nicodemus KK, Marenco S, Batten AJ, Vakkalanka R, Egan MF, Straub RE, et al. (2008): Serious obstetric complications interact with hypoxiaregulated/vascularexpression genes to influence schizophrenia risk. Mol Psychiatry.
5. Caspi A, Moffitt TE, Cannon M, McClay J, Murray R, Harrington $\mathrm{H}$, et al. (2005): Moderation of the effect of adolescentonset cannabis use on adult psychosis by a functional polymorphism in the catechol-Omethyltransferase gene: longitudinal evidence of a gene $X$ environment interaction. Biol Psychiatry 57:1117-27.

6. Spauwen J, Krabbendam $\mathrm{L}$, Lieb R, Wittchen HU, and van Os J (2006): Impact of psychological trauma on the development of psychotic symptoms: relationship with psychosis proneness. Br J Psychiatry 188:527-33.

7. van Os J and Marcelis M (1998): The ecogenetics of schizophrenia: a review. Schizophr Res 32:127-35.

8. van Os J and Kapur S (2009): Schizophrenia. Lancet 374:635-45.

9. van Os J and Rutten BP (2009): Gene-environmentwide interaction studies in psychiatry. Am J Psychiatry 166:964-6.

10. van Os J, Rutten BP, and Poulton R (2008):

Gene-environment interactions in schizophrenia: review of epidemiological findings and future directions. Schizophr Bull34:1066-82.
11. Marcelis $M$, van Os J, Sham $\mathrm{P}$, Jones $\mathrm{P}$, Gilvarry $\mathrm{C}$, Cannon M, et al. (1998): Obstetric complications and familial morbid risk of psychiatric disorders. $\mathrm{Am} \mathrm{J}$ Med Genet 81:29-36.

12. Cannon TD, van Erp TG, Rosso IM, Huttunen $M$, Lonnqvist J, Pirkola T, et al. (2002): Fetal hypoxia and structural brain abnormalities in schizophrenic patients, their siblings, and controls. Arch Gen Psychiatry 59:3541.

13. Whitfield-Gabrieli $S$, Thermenos HW, Milanovic S, Tsuang MT, Faraone SV, McCarley RW, et al. (2009): Hyperactivity and hyperconnectivity of the default network in schizophrenia and in firstdegree relatives of persons with schizophrenia. Proc Natl Acad Sci U S A 106:1279-84.

14. Boos HB, Aleman $A$, Cahn W, Pol HH, and Kahn RS (2007): Brain volumes in relatives of patients with schizophrenia: a metaanalysis. Arch Gen Psychiatry64:297-304.

15. Moore TH, Zammit $S$, Lingford-Hughes $A$, Barnes TR, Jones PB, Burke $M$, et al. (2007): Cannabis use and risk of psychotic or affective mental health outcomes: a systematic review. Lancet 370:319-28. 
16. Henquet $C$,

Krabbendam L, Spauwen J,

Kaplan C, Lieb R, Wittchen

$\mathrm{HU}$, et al. (2005):

Prospective cohort study

of cannabis use,

predisposition for

psychosis, and psychotic

symptoms in young

people. Bmj330:11.

17. Verdoux $H$, Tournier $M$, and Cougnard A (2005):

Impact of substance use

on the onset and course of early psychosis. Schizophr

Res 79:69-75.

18. Ongur $D$, Lin $L$, and Cohen BM (2009): Clinical characteristics influencing age at onset in psychotic disorders. Compr

Psychiatry 50:13-9.

19. Morgan $\mathrm{C}$ and Fisher $\mathrm{H}$ (2007): Environment and schizophrenia:

environmental factors in schizophrenia: childhood trauma--a critical review. Schizophr Bull33:3-10.

20. Read J, van Os J, Morrison AP, and Ross CA (2005): Childhood trauma, psychosis and schizophrenia: a literature review with theoretical and clinical implications. Acta Psychiatr Scand 112:33050.

21. Janssen I, Krabbendam L, Bak M, Hanssen M, Vollebergh W, de Graaf R, et al. (2004): Childhood abuse as a risk factor for psychotic experiences. Acta Psychiatr Scand 109:38-45.
22. Andersen SL, Tomada $A$, Vincow ES, Valente $E$, Polcari $\mathrm{A}$, and Teicher $\mathrm{MH}$ (2008): Preliminary evidence for sensitive periods in the effect of childhood sexual abuse on regional brain development. $J$

Neuropsychiatry Clin Neurosci 20:292-301.

23. Block RI, O'Leary DS, Ehrhardt JC, Augustinack JC, Ghoneim MM, Arndt S, et al. (2000): Effects of frequent marijuana use on brain tissue volume and composition. Neuroreport 11:491-6.

24. Bremner JD (2005): Effects of traumatic stress on brain structure and function: relevance to early responses to trauma. $J$ Trauma Dissociation 6:5168.

25. Matochik JA, Eldreth DA, Cadet JL, and Bolla KI (2005): Altered brain tissue composition in heavy marijuana users. Drug Alcohol Depend 77:23-30.

26. Quickfall J and Crockford D (2006): Brain neuroimaging in cannabis use: a review. $J$ Neuropsychiatry Clin Neurosci 18:318-32.

27. Rais M, Cahn W, Van Haren N, Schnack H, Caspers E, Hulshoff Pol H, et al. (2008): Excessive brain volume loss over time in cannabis-using first-episode schizophrenia patients. Am J Psychiatry 165:490-6.
28. Szeszko PR, Robinson DG, Sevy S, Kumra S, Rupp $\mathrm{Cl}$, Betensky JD, et al. (2007): Anterior cingulate grey-matter deficits and cannabis use in firstepisode schizophrenia. $\mathrm{Br} J$ Psychiatry 190:230-6.

29. Teicher $M H$, Dumont NL, Ito Y, Vaituzis C, Giedd $\mathrm{JN}$, and Andersen SL (2004): Childhood neglect is associated with reduced corpus callosum area. Biol Psychiatry 56:80-5.

30. Tomoda A, Suzuki H, Rabi K, Sheu YS, Polcari A, and Teicher MH (2009): Reduced prefrontal cortical gray matter volume in young adults exposed to harsh corporal punishment. Neuroimage 47 Suppl 2:T66-71.

31. Kaymaz $\mathrm{N}$ and van Os J (2009): Heritability of structural brain traits an endophenotype approach to deconstruct schizophrenia. Int Rev Neurobio/89:85-130.

32. Maxwell ME (1992): Family Interview for Genetic Studies (FIGS): Manual For FIGSClinical Neurogenetics Branch, Intramural Research Program, National Institute of Mental Health, Bethesda, MD.

33. APA (2000): Diagnostic and statistical manual of mental disorders, 4th ed. Washington, DC: American Psychiatric Association. 
34. Andreasen NC, Flaum $\mathrm{M}$, and Arndt S

(1992): The

Comprehensive

Assessment of Symptoms

and History (CASH). An

instrument for assessing

diagnosis and

psychopathology. Arch

Gen Psychiatry 49:615-23.

35. Kay SR, Fiszbein A, and Opler LA (1987): The positive and negative syndrome scale (PANSS) for schizophrenia. Schizophr Bull 13:261-76.

36. Cahn W, Hulshoff Pol HE, Lems EB, van Haren $\mathrm{NE}$, Schnack HG, van der Linden JA, et al. (2002): Brain volume changes in first-episode schizophrenia: a 1-year follow-up study. Arch Gen Psychiatry 59:1002-10.

37. WHO (1990): Composite International Diagnostic Interview (CIDI) Geneva: World Health Organization.

38. Van Os J, Bak M, Hanssen M, Bijl RV, de Graaf R, and Verdoux H (2002): Cannabis use and psychosis: a longitudinal population-based study. Am J Epidemiol 156:31927.

39. Bernstein DP, Ahluvalia T, Pogge D, and Handelsman L (1997): Validity of the Childhood Trauma Questionnaire in an adolescent psychiatric population. J Am Acad Child Adolesc Psychiatry 36:340-8.
40. Dale AM, Fischl B, and Sereno MI (1999): Cortical surface-based analysis. I. Segmentation and surface reconstruction. Neuroimage 9:179-94.

41. Fischl $B$ and Dale AM (2000): Measuring the thickness of the human cerebral cortex from magnetic resonance images. Proc Natl Acad Sci USA 97:11050-5.

42. Fischl B, Salat DH, Busa E, Albert M, Dieterich $M$, Haselgrove $C$, et al. (2002): Whole brain segmentation: automated labeling of neuroanatomical structures in the human brain. Neuron 33:341-55.

43. Fischl B, Sereno MI, and Dale AM (1999): Cortical surface-based analysis. II: Inflation, flattening, and a surfacebased coordinate system. Neuroimage 9:195-207.

44. Han $X$, Jovicich J, Salat $D$, van der Kouwe $A$, Quinn B, Czanner S, et al. (2006): Reliability of MRIderived measurements of human cerebral cortical thickness: the effects of field strength, scanner upgrade and manufacturer. Neuroimage 32:180-94.

45. Jovicich J, Czanner S, Greve D, Haley E, van der Kouwe A, Gollub R, et al. (2006): Reliability in multisite structural MRI studies: effects of gradient nonlinearity correction on phantom and human data. Neuroimage 30:436-43.
46. Segonne F, Dale AM, Busa E, Glessner M, Salat D, Hahn HK, et al. (2004): A hybrid approach to the skull stripping problem in MRI.

Neuroimage 22:1060-75.

47. Desikan RS, Segonne F, Fischl B, Quinn BT, Dickerson BC, Blacker $D$, et al. (2006): An automated labeling system for subdividing the human cerebral cortex on MRI scans into gyral based regions of interest.

Neuroimage 31:968-80.

48. Fischl $B$, van der Kouwe A, Destrieux $C$, Halgren E, Segonne F, Salat DH, et al. (2004): Automatically parcellating the human cerebral cortex. Cereb Cortex 14:11-22.

49. Rosas HD, Liu AK, Hersch S, Glessner M, Ferrante RJ, Salat DH, et al. (2002): Regional and progressive thinning of the cortical ribbon in Huntington's disease. Neurology 58:695-701.

50. Kuperberg GR, Broome MR, McGuire PK, David AS, Eddy M, Ozawa F, et al. (2003): Regionally localized thinning of the cerebral cortex in schizophrenia. Arch Gen Psychiatry 60:878-88.

51. Salat DH, Buckner RL, Snyder AZ, Greve DN, Desikan RS, Busa E, et al. (2004): Thinning of the cerebral cortex in aging. Cereb Cortex 14:721-30. 
52. StataCorp (2009):

Stata Statistical Software:

Release 11. College

Station, TX: StataCorp LP.

53. Snijders T and

Bosker R (1999): Multilevel

Analysis: An Introduction

to Basic and Advanced

Modeling London: Sage

Publications.

54. Clayton D and Hills M (1993): Statistical Models in Epidemiology Oxford:

Oxford University Press.

55. Versmissen $D$, Janssen I, Johns L, McGuire P, Drukker M, a Campo J, et al. (2007): Verbal selfmonitoring in psychosis: a non-replication. Psychol Med37:569-76.

56. Bremner JD (2003): Long-term effects of childhood abuse on brain and neurobiology. Child Adolesc Psychiatr Clin N Am 12:271-92.

57. Teicher $\mathrm{MH}$, Andersen SL, Polcari A, Anderson $C M$, and Navalta CP (2002): Developmental neurobiology of childhood stress and trauma.

Psychiatr Clin North Am 25:397-426, vii-viii.

58. Henquet $C$, Murray $R$, Linszen $D$, and van Os J (2005): The environment and schizophrenia: the role of cannabis use. Schizophr Bull31:608-12.
59. Henquet $C$, Rosa $A$, Delespaul P, Papiol S, Fananas L, van Os J, et al. (2009): COMT ValMet moderation of cannabisinduced psychosis: a momentary assessment study of 'switching on' hallucinations in the flow of daily life. Acta Psychiatr Scand 119:156-60.

60. Verdoux $H$, Gindre C, Sorbara F, Tournier M, and Swendsen JD (2003): Effects of cannabis and psychosis vulnerability in daily life: an experience sampling test study.

Psychol Med 33:23-32.

61. Yucel M, Solowij N, Respondek C, Whittle S, Fornito A, Pantelis C, et al. (2008): Regional brain abnormalities associated with long-term heavy cannabis use. Arch Gen Psychiatry65:694-701.

62. Cahn W, Hulshoff Pol HE, Caspers E, van Haren NE, Schnack HG, and Kahn RS (2004): Cannabis and brain morphology in recent-onset schizophrenia. Schizophr Res 67:305-7.

63. Feder A, Nestler EJ, and Charney DS (2009): Psychobiology and molecular genetics of resilience. Nat Rev Neurosci 10:446-57.

64. Belsky J, Jonassaint $C$, Pluess $M$, Stanton M, Brummett B, and Williams R (2009): Vulnerability genes or plasticity genes? Mol Psychiatry 14:746-54.
65. Ujike H (2002):

Stimulant-induced psychosis and schizophrenia: the role of sensitization. Curr Psychiatry Rep 4:177-84.

66. Howes OD, McDonald C, Cannon M, Arseneault L, Boydell J, and Murray RM (2004):

Pathways to schizophrenia: the impact of environmental factors. Int $J$ Neuropsychopharmacol7 Suppl 1:S7-S13.

67. Laruelle M (2000): The role of endogenous sensitization in the pathophysiology of schizophrenia: implications from recent brain imaging studies. Brain Res Brain Res Rev31:371-84.

68. Lieberman JA, Sheitman BB, and Kinon BJ (1997): Neurochemical sensitization in the pathophysiology of schizophrenia: deficits and dysfunction in neuronal regulation and plasticity. Neuropsychopharmacolog y17:205-29.

69. Heim C, Newport DJ, Heit S, Graham YP, Wilcox M, Bonsall R, et al. (2000): Pituitary-adrenal and autonomic responses to stress in women after sexual and physical abuse in childhood. JAMA

284:592-7.

70. Nemeroff CB (2004): Neurobiological consequences of childhood trauma. J Clin Psychiatry65 Suppl 1:1828. 
71. Walker EF and

Diforio D (1997):

Schizophrenia: a neural diathesis-stress model. Psychol Rev 104:667-85.

72. Sowell ER, Thompson PM, Holmes CJ, Batth R, Jernigan $T L$, and Toga AW (1999): Localizing age-related changes in brain structure between childhood and adolescence using statistical parametric mapping. Neuroimage 9:587-97.

73. Kuepper R, Morrison PD, Van Os J, Murray RM, Kenis G, and Henquet C (2010): Does dopamine mediate the psychosis-inducing effects of cannabis? A review and integration of findings across disciplines. Schizophr Res In press.

74. Gaspar PA,

Bustamante ML, Silva H, and Aboitiz F (2009):

Molecular mechanisms underlying glutamatergic dysfunction in schizophrenia: therapeutic implications. J Neurochem 111:891-900.

75. Stone JM, Day F, Tsagaraki $\mathrm{H}$, Valli I, McLean MA, Lythgoe DJ, et al. (2009): Glutamate dysfunction in people with prodromal symptoms of psychosis: relationship to gray matter volume. Biol Psychiatry 66:533-9.
76. van Os J, Henquet C, and Stefanis N (2005): Cannabis-related psychosis and the gene-environment interaction: comments on Ferdinand et Al. 2005. Addiction 100:874-5.

77. Fisher HL, Craig TK, Fearon $\mathrm{P}$, Morgan $\mathrm{K}$, Dazzan P, Lappin J, et al. (2009): Reliability and Comparability of Psychosis Patients' Retrospective Reports of Childhood Abuse. Schizophr Bull. 

1 Dept. of Psychiatry and Psychology, School for Mental Health and Neuroscience, EURON, Maastricht University Medical Center, Maastricht, The Netherlands

2 Dept. of Radiology, Maastricht University Medical Center, Maastricht, The Netherlands

3 King's College London, King's Health Partners, Department of Psychosis Studies Institute of Psychiatry, London, United Kingdom 


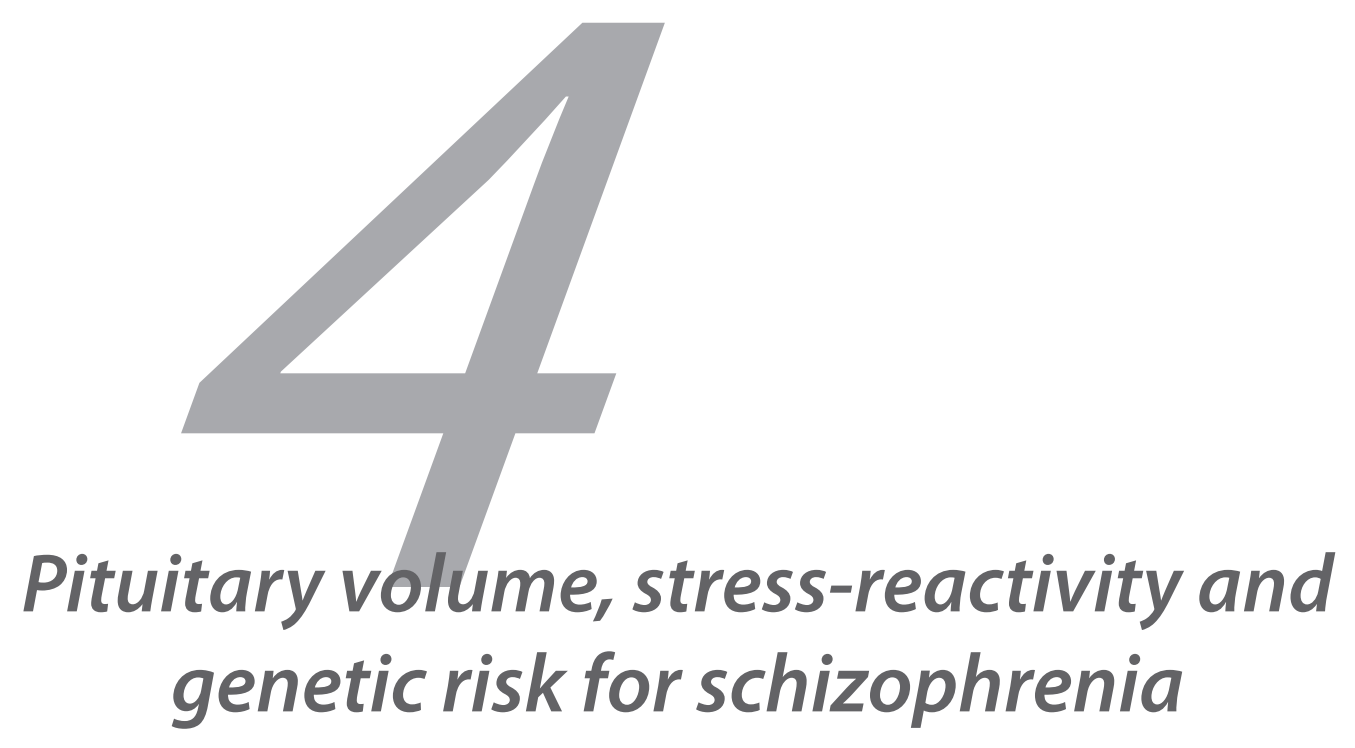

Submitted

Petra Habets ${ }^{1 *}$, Dina Collip ${ }^{1 *}$, Inez Myin-Germeys ${ }^{1}$, Ed Gronenschild ${ }^{1}$, Suzanne van Bronswijk ${ }^{1}$, Paul Hofman ${ }^{2}$, Tineke Lataster ${ }^{1}$, Mariëlle Lardinois ${ }^{1}$, Nancy A. Nicolson ${ }^{1}$, Jim van Os ${ }^{1,3}$, Machteld Marcelis ${ }^{1}$ for G.R.O.U.P.

* Contributed equally 


\section{Abstract}

Background: HPA axis hyperactivity, associated with increased pituitary volume, may mediate observed alterations in stress-sensitivity in patients with schizophrenia. We examined, for the first time, the association between pituitary volume, reallife stress-reactivity and genetic liability for schizophrenia.

Methods: Pituitary volumes were derived from MRI scans of 20 patients with schizophrenia, 37 non-psychotic siblings of these patients, and 32 controls. The Experience Sampling Method (ESM) was used to measure stress-reactivity (changes in negative affect [NA] and in cortisol levels associated with daily life stress). Associations between group status and pituitary volume were investigated, as were interactions between group, stress and pituitary volume in models of NA and cortisol.

Results: Groups did not differ in pituitary volume. There was a significant group $x$ stress interaction in the model of NA, in that patients showed significantly higher stress-reactivity than both siblings and controls. In addition, there was a significant group $x$ stress $x$ pituitary volume interaction in the model of NA, indicating that stress-reactivity increased with increasing pituitary volume to a greater degree in patients than in controls and in siblings, whereas the latter two groups did not differ. Siblings had higher cortisol levels than controls, but showed no increased cortisol reactivity to stress. There was no interaction between pituitary volume, cortisol reactivity and group status.

Conclusion: Higher pituitary volume was associated with increased stress-reactivity in patients with schizophrenia, siblings and controls. The association was significantly stronger in the patient group, suggesting a process of progressive sensitization mediating clinical outcome. 


\section{Introduction}

Altered volumes of the pituitary gland have been associated with increased vulnerability for schizophrenia (1). Patients with a first episode (FE) of schizophrenia display increased pituitary volume, compared to controls $(2,3)$, as do individuals with early prodromal signs and subsequent transition to schizophrenia, compared to those who do not make the transition (1). In samples diagnosed with schizophrenia, an inverse association has been reported between illness duration and pituitary volume (4), although not consistently so (5). In addition, there is evidence for larger pituitary volume in first-degree relatives of patients with schizophrenia (6).

The occurrence of pituitary enlargement in prodromal and antipsychoticnaïve patients as well as in relatives, suggests the enlargement is not due to antipsychotic (AP) medication. On the other hand, cross-sectional studies show positive associations between first-generation (FGA) or prolactin-elevating secondgeneration antipsychotics (SGA) (e.g., risperidone, amisulpiride) and pituitary volume $(2,7)$ in FE patients, although not all studies agree (3). In addition, a longitudinal study reported a dose-response effect of prolactin-sparing SGA (e.g., olanzapine, quetiapine, clozapine) on pituitary volume, higher doses predicting reduced volume (8). The mixed findings possibly reflect the fact that the pituitary gland is a highly dynamic organ, with many factors impacting on its volume over time. For example, studies have shown that women have larger pituitary volumes than men (9), and that both endogenous and exogenous estrogens are associated with pituitary volume (10).

The pituitary gland is a crucial organ involved in the hypothalamus-pituitaryadrenal (HPA)-axis stress response. In depression research, increased pituitary volume is thought to reflect HPA axis hyperfunctioning. Exposure to stress activates the HPA axis through the release of corticotropin releasing hormone $(\mathrm{CRH})$ in the hypothalamus, resulting in secretion of adrenocorticotropic hormone (ACTH) in the pituitary, stimulating the release of cortisol in the adrenal cortex. Cortisol, through a negative feedback mechanism, regulates HPA axis activity. Persistently elevated cortisol levels can impair the negative feedback mechanism (11), resulting in HPA axis hyperactivity. As a result of HPA axis hyperactivity, patients become more sensitive to stressors, referred to as stress sensitization (12).

Increased cortisol levels have been found in FE patients (13) as well as in siblings of patients with schizophrenia (14), and may predict transition to a clinical psychotic 
outcome in young individuals at-risk (15). FE patients in the acute phase also show non-suppression of cortisol secretion in the dexamethasone suppression test and in the dexamethasone/corticotrophin releasing factor test $(16,17)$. Furthermore, there is evidence that patients with schizophrenia are more sensitive to daily life stressors resulting in increased levels of stress-related negative emotions (18) and psychotic experiences (19). Evidence of increased cortisol reactivity to stress has also been detected in people at higher than average genetic risk for schizophrenia (14). However, there is also evidence for a blunted cortisol response to metabolic and psychosocial stressors in patients with schizophrenia $(20,21)$ and in medicationnaive patients (22).

To date, the association between pituitary volumes and stress-reactivity in schizophrenia remains unclear. The present study is the first to examine pituitary volume in relation to cortisol (biological stress-reactivity) and negative affect (emotional stress-reactivity) in the context of daily life stressors, using a genetically sensitive sample (patients at highest genetic risk, siblings of patients at higher than average genetic risk, and controls at average genetic risk). The hypothesis was that patients and, to a lesser extent, siblings would show increased stress-reactivity compared to controls, accompanied by larger pituitary volumes.

\section{Methods and Materials}

\section{Subjects}

Data pertain to baseline measures of an ongoing longitudinal study in Maastricht, the Netherlands. Details on the selection procedures are described in a prior publication (23). The sample consisted of 20 patients with a diagnosis of schizophrenia or related psychotic disorder, 37 siblings of patients with schizophrenia and 32 controls. Inclusion criteria were: (i) age: 16 to 50 years, (ii) diagnosis of non-affective schizophrenia and (iii) good command of Dutch language.

Diagnosis was based on the Diagnostic and Statistical Manual of Mental Disorder-IV (DSM-IV) criteria (24), assessed with the Comprehensive Assessment of Symptoms and History (CASH) interview (25). Patients were diagnosed with: schizophrenia $(n=11)$, schizoaffective disorder $(n=2)$, schizophreniform disorder $(n=1)$, brief psychotic disorder $(n=2)$, and psychotic disorder not otherwise specified $(n=4)$. The CASH was also used to confirm the absence of a diagnosis of non-affective schizophrenia in the siblings, and absence of a lifetime diagnosis of any psychotic 
disorder or any current affective disorder in the healthy controls. Six siblings and seven controls had a history of major depressive disorder, but none presented in a current depressive episode. Prior to MRI acquisition, participants were screened for the following exclusion criteria: (i) brain injury with unconsciousness for over 1 hour, (ii) meningitis or other neurological diseases that might have affected brain structure/function, (iii) cardiac arrhythmia requiring medical treatment (iv), severe claustrophobia. In addition, subjects with metal corpora aliena were excluded from the study, as well as women with intrauterine device status and (suspected) pregnancy. The study was approved by the standing ethics committee, and all the subjects gave written informed consent in accordance with the committee's guidelines.

\section{Measures}

The Positive and Negative Syndrome Scale (PANSS) (26) was used to measure psychotic symptoms over the last two weeks.

Use of antipsychotic medication was determined using reports of the participant's psychiatrist. Best estimate lifetime (cumulative) AP medication use was determined by multiplying the number of days of AP use with the corresponding haloperidol equivalents and summing up these scores for all periods of AP use.

Estrogen exposure was determined by multiplying the number of months of contraceptive medication use with micrograms estrogen (of the corresponding contraceptive) per month.

Substance use was assessed with the Composite International Diagnostic Interview (CIDI) sections B-J-L (27). Use of cannabis and other drugs was assessed as reported frequency of use during the last 12 months, as well as lifetime. Alcohol intake was calculated as the average number of weekly consumptions during the last 12 months and tobacco use as the average number of daily cigarettes during the last 12 months.

\section{Experience Sampling Method (ESM)}

ESM is a random time-sampling self-assessment technique; studies have demonstrated the feasibility, validity, and reliability of ESM in general and patient populations $(28,29)$. Subjects received a digital wristwatch that emitted a signal ten times a day on six consecutive days, at unpredictable moments between 7:30 a.m. and 10:30 p.m. After each 'beep', subjects completed ESM self-assessment 
forms concerning current context, thoughts, emotions, and psychotic experiences. Subjects were instructed to complete their reports immediately after the beep, thus minimizing memory distortions. Reports were considered valid when subjects responded within 15 min after the beep, as determined by comparing the actual beep time with the reported time of completion. For inclusion in the analyses, a valid response to at least one-third of the emitted beeps was required (30).

Stress-reactivity, as described in previous work, was conceptualized as emotional (18) and biological reactivity (14) to minor disturbances in daily life. Measures of stress, mood and cortisol were derived from the experience sampling data as described below.

\section{Salivary cortisol sampling}

After each ESM beep, participants collected a saliva sample with a cotton swab (Salivette; Sarstedt, Etten-Leur, the Netherlands), replaced the swab in the salivette tube, and recorded the exact collection time. Samples were stored in subjects' home freezers until transport to the lab, where uncentrifuged samples were kept at $-20^{\circ} \mathrm{C}$ until analysis. Saliva samples collected more than 15 minutes after the beep were excluded from the analysis.

\section{ESM measures}

In accordance with previous work, two different stress measures were computed: event stress and social stress (18).

Event-stress was assessed as follows: after each beep, the most important event that had happened between the current and the previous report was reported. This event was subsequently rated on a bipolar Likert scale (-3=very unpleasant, $0=$ neutral, $3=$ very pleasant). The responses were recoded to allow high scores to reflect stress $(-3=$ very pleasant, $0=$ neutral, $3=$ very unpleasant).

To measure social stress, subjects were asked to evaluate the social context when other persons were present, by rating on a 7-point Likert scale ( $1=$ not true, $7=$ very true) the item: "I don't like the company" and the subsequent item: "I would rather be alone". The mean of these two items constituted the social stress scale.

\section{Assessment of negative affect}

After each beep, participants were asked to answer questions regarding their mood on 7-point Likert scales ( $1=$ not at all, 7=very). ESM negative affect was assessed with 
6 mood-related adjectives (down, guilty, insecure, lonely, anxious, angry/ irritated) that were reduced to a single measure of the mean Negative Affect [NA](Cronbach's $a=0.86)$.

\section{Salivary cortisol}

Salivary cortisol is a reliable and non-invasive measure of the free, unbound cortisol in blood, which is considered to bethebiologically active hormone. Radioimmunoassays were run in duplicate, using a tracer solution of cortisol-3CMO coupled with 2-[125 I] histamine and specific antibodies raised against cortisol-3CMO-BSA (31) (Dr. J. Sulon, Department of Reproductive Physiology, School of Veterinary Medicine, University of Liège). The lower detection limit of the assay was $0.2 \mathrm{nmol} / \mathrm{L}$. The intra- and interassay coefficients of variation were $<5 \%$ and $<12 \%$, respectively. All samples from an individual were analyzed in the same assay to reduce sources of variability. Samples with cortisol $>44 \mathrm{nmol} / \mathrm{L}(\mathrm{n}=0)$ were considered physiologically abnormal and were excluded from the statistical analysis. As antipsychotic medication may influence cortisol values, cortisol was only measured in siblings and controls.

\section{MRI acquisition and processing}

MRI scans were acquired with a 3T Siemens scanner using the following acquisition parameters: Modified Driven Equilibrium Fourier Transform (MDEFT) sequence: 176 slices, $1 \mathrm{~mm}$ isotropic voxel size, TE $2.4 \mathrm{~ms}$, TR $7.92 \mathrm{~ms}$, flip angle $15^{\circ}$, total acquisition time: 12 min 51s, and the Magnetization Prepared Rapid Acquisition Gradient Echo (MP-RAGE: Alzheimer's Disease Neuroimaging Initiation (ADNI)) sequence: 192 slices, $1 \mathrm{~mm}$ isotropic voxel size, TE $2.6 \mathrm{~ms}$, TR $2250 \mathrm{~ms}$, flip angle $9^{\circ}$, total acquisition time: 7 min 23s. For both sequence the matrix size was $256 \times 256$ and the field of view $256 \times 256 \mathrm{~mm}$. Two sequences were used because of a scanner update during data collection. The MP-RAGE and MDEFT are very similar, but in order to prevent any systematic bias, the total proportion of MP-RAGE scans (27\%) was balanced between the groups.

\section{MRI preprocessing}

Scans were preprocessed with Freesurfer stable release v5.0. Technical details of these procedures are described in prior publications $(32,33)$. 


\section{Volume measures}

Pituitary volumes were obtained after manual tracing using GIANT (General Image ANalysis Tools developed by EHBMG (34), a customised software program that allows tracing of regions of interest in triplanar view and calculation of volumes of interest. All tracings were carried out on the native images. Each pituitary was traced in all coronal slices where it could be visualized, after the protocol that has been described previously (35). Pituitary volume (in $\mathrm{mm} 3$ ) was calculated by summing the areas of the relevant slices and multiplying by the voxel size. All images were traced by the same rater (SB), who was blind to group assignment. The intra-class correlation coefficient of repeated measurements, based on a training set of 15 scans, was $r=0.92$.

\section{Statistical analyses}

ESM and cortisol data were analysed using multilevel regression techniques, thus taking into account the hierarchical structure of the data. Repeated momentary measurements (level 1) were nested in subjects (level 2) who were part of the same family (level 3). Given these three levels, data were analyzed using the XTMIXED multilevel random regression routine in STATA 11.0 (36). The B's are the fixed regression coefficients of the predictors in the multilevel model. Interaction terms were evaluated by Wald tests (37). In case of significant interaction effects, stratified analyses were conducted in order to quantify group differences, using the STATA MARGIN command to calculate the appropriate linear combinations from the model containing the interaction. All analyses were adjusted for the a priori hypothesized confounders age, sex, intracranial volume, estrogen exposure and scan type.

Group differences in pituitary volumes were examined using multiple regression procedures, with pituitary volume as dependent variable and group status (dummy variable: $0=$ controls, $1=$ siblings, 2 =patients) as independent variable.

Group differences in stress-reactivity were assessed by multilevel analyses, with NA as the dependent variable and group, stress (event stress and social stress) and their interactions as the independent variables.

To test the hypothesis that group status modified the association between pituitary volume and stress-reactivity, multilevel regression analyses were conducted with stress, pituitary volume and group as well as their interaction terms as independent variables and $\mathrm{NA}$ as the dependent variable: $\mathrm{NA}=\mathrm{B} 0+\mathrm{B} 1$ (group) $+\mathrm{B} 2$ (stress) 
$+B 3($ volume $)+B 4($ group $\times$ stress $)+B 5($ group $\times$ volume $)+B 6$ (stress $\times$ volume $)+$ $B 7$ (group $\times$ stress $\times$ volume). The group $\times$ stress $\times$ volume interaction was fitted with the control group as the reference category. Pituitary volume was entered both as a linear variable and as dummy variables representing the distribution of volume calculated at the 33th and 66th percentiles of pituitary volume of the controls, allowing visualization of dose-response $(1=\leq 33$ th percentile: low pituitary volume, $2=\geq 33$ th and $<66$ th percentile: medium pituitary volume, $3=\geq 66$ th percentile: high pituitary volume).

The same pattern of analyses as described above were applied to the biological stress measure, the log transformed cortisol values (Incort)) (=dependent variable). Additional confounders were: time of cortisol sample, time2, recent consumption of food or tobacco (i.e. in the approximately 90 minute interval since the previous beep). To test whether mean cortisol level differed between the two groups, a regression model was estimated with Incort as the dependent variable and group status (dummy variable: $0=$ controls, $1=$ siblings) as the independent variable.

The association between pituitary volume and both exogenous estrogen (in women) and lifetime AP (in patients) was investigated using multiple regression analysis.

\section{Power analysis}

Power calculations for the 3-way interaction analyses were carried out by empirical statistical simulation in STATA (www.stata.com/support/faqs/stat/power.html), as described previously (23). Effect sizes were based on previously published work in this area. The effect sizes for the association between group and NA, between stress and NA and the interaction between group and stress were adapted from Myin-Germeys et al., (2001)(18). Similarly, effect sizes in the model of cortisol were adapted from Collip et al., (in press)(14). The effect sizes for the other interactions were not known. Therefore, effect sizes of 0.2 SD (small) were used for the patient versus control simulations, and effect sizes of $0.1 \mathrm{SD}$ were used for the sibling versus control simulations. At an alpha of 0.05 , the 3-way interaction analysis had a power of $56 \%$ to detect a significant difference between patients and controls and a power of $18 \%$ to detect a significant difference between siblings and controls. Therefore, results of the three-way interactions measuring differences between siblings and controls will only be described exploratively in order to generate hypotheses for future research and help generate realistic power calculations based on published effect sizes in these groups. 


\section{Sensitivity analysis}

Studies report an association between pituitary volume and illness duration ((4, 38), with increased pituitary volume for FE patients and decreased pituitary volume for established schizophrenia patients (ESP). Therefore, explorative analyses were carried out separately in patients with an illness duration of $\leq 5$ years $(F E ; n=10)$ and $>5$ years $(E S ; n=10)$.

\section{Results}

\section{Descriptive analyses}

Groups were well matched on most demographic variables (Table 1). Patients smoked more cigarettes and cannabis and used more hard drugs (lifetime) than siblings and controls, with no difference between the latter two groups. Eighteen patients received AP (atypical: $n=2$; typical: $n=16$ ). Furthermore, 3 patients and 2 controls used antidepressants and 1 patient and 1 control used benzodiazepines. Patients reported higher PANSS scores than controls and siblings with no difference between the latter two groups (Table1).

\section{Group differences in pituitary volume and in emotional stress-reactivity}

Mean pituitary volume did not differ between groups (patients: $602.6 \mathrm{mm3}$, SE 23.4; siblings: $624.5 \mathrm{~mm} 3$, SE 17.5; controls: $624.4 \mathrm{~mm} 3$, SE 18.0; $B=5.34, p=0.76$ ). There was a trend significant group $x$ event stress interaction in the model of NA (Table 2 ), indicating that stress-reactivity differed between groups. Stratified analyses revealed that patients had significantly higher levels of stress-reactivity compared to both controls and siblings. For social stress, there was no significant interaction effect with group in the model of NA (Table 2).

\section{Interaction between genetic risk, emotional stress-reactivity and pituitary volume}

In the combined group of patients, siblings and controls, a significant association between volume (linear variable) and stress-reactivity (social stress) $\left(x^{2}=23.03\right.$, $p=0.00$ ) was found. There was a significant group $x$ social stress $x$ volume (linear variable) interaction in the model of NA, indicating that the association between pituitary volume and stress-reactivity differed between groups $\left(x^{2}=20.13, p=0.00\right)$ Stratified analyses showed that, with increasing pituitary volume, stress-reactivity was progressively greater in patients compared to both controls and siblings, 
whereas no difference was apparent between the latter two groups. Visualizing the effect over the three tertile groups of pituitary volume revealed progressively higher stress-reactivity with progressively higher pituitary volume in all three groups, but much more pronounced in the patients compared to siblings and controls (Table 3 ) (Figure 1). Stress-reactivity was significantly higher in the high volume group when compared to the low volume group in controls $\left(x^{2}=7.17, p=0.01\right)$, siblings $\left(x^{2}=5.34\right.$, $p=0.02)$ and in patients $\left(X^{2}=12.72, p=0.00\right)$. In patients, stress-reactivity was also significantly increased in the medium volume group, compared to the low volume group ( $\left.x^{2}=30.62, p=0.00\right)$.

The event stress $x$ volume interaction effect in the model of NA was not significant, nor was the group $x$ event stress $x$ volume (linear variable) interaction $\left(x^{2}=1.15\right.$, $p=0.56$ ) (Table 3 ), however effect sizes were directionally similar to those observed for social stress.

\section{Group differences in cortisol levels and in biological stress-reactivity}

Siblings had significantly higher cortisol levels than controls $(\mathrm{B}=.30, \mathrm{P}=0.00)$. There was no significant association between pituitary volume and cortisol levels in the combined group of siblings and controls $(B=-0.001, P=0.25)$.

The group $\mathrm{x}$ stress interaction in the model of cortisol was significant for neither social nor event-related stress (Table 2 ).

\section{Interaction between genetic risk, biological stress-reactivity and pituitary volume}

The stress $x$ volume interaction and the group $x$ stress $x$ volume interaction in the model of cortisol were not significant for either social $\left(X^{2}=1.04, p=0.31\right)$ or event stress $\left(x^{2}=1.49, p=0.22\right)$ (Table 3$)$.

\section{AP medication use and estrogen exposure in relation to pituitary volume}

Lifetime $A P$ use did not predict pituitary volume (linear variable: $B=1.04, P=0.19$; tertiles: $B=29.32, P=0.51)$, nor did estrogen exposure $(B=0.00, P=0.48)$. There was no significant interaction between group and estrogen exposure in the model of pituitary volume $\left(x^{2}=0.00, p=0.99\right)$.

Women had larger pituitary volumes than men $(B=63.94, P=0.04)$, but no group $x$ gender interaction on pituitary volume was apparent $\left(X^{2}=2.00, P=0.37\right)$. The direction and significance of the results remained the same when estrogen exposure was removed as confounding factor from the analyses (results available upon request). 


\section{Sensitivity analysis}

Although results were not statistically significant, FE patients had higher pituitary volumes (mean: $641.1 \mathrm{~mm} 3, \mathrm{SE}$ 33.79) than controls, and ES patients had lower pituitary volumes (mean: 564mm3, SE 91.08) than controls. Post-hoc analyses revealed that the group $x$ social stress $x$ volume (linear variable) interaction was attributable predominantly to the FE patients $\left(x^{2}=22.66, p=0.00\right)$, whereas in the ES patients this interaction was no longer apparent, although effect sizes were directionally similar $\left(x^{2}=1.65, p=0.44\right)$.

\section{Discussion}

There was no mean difference in pituitary volume among the three groups. Patients with schizophrenia showed higher levels of emotional stress-reactivity compared to siblings and controls. Emotional stress-reactivity was not only moderated by group, but also by pituitary volume. In all three groups, increased emotional stress-reactivity was associated with higher pituitary volume, but this association was much more pronounced in the patient group, suggesting a process of progressive sensitization mediating clinical outcome.

\section{Emotional stress-reactivity}

The finding of increased emotional stress-reactivity in the group at highest genetic risk group (patients) is in line with other studies that have shown that minor stressors in the flow of daily life were associated with an increase in negative emotions in individuals with a diagnosis of schizophrenia $(18,29)$. Although there was no difference in pituitary volume between the groups, emotional stress-reactivity was associated with larger pituitary volume in all three groups, with a much more pronounced increase in the patients than in the other two groups (Table 3). More specifically, each unit increase in stress-reactivity was associated with an increase of pituitary volume of 0.20 SD in the patients. This phenomenon may indicate a mechanism of stress sensitization in the patients and mediate the onset of schizophrenia.

Stress sensitization occurs when early and /or frequent exposures to stressors alter the stress response system, sensitizing individuals to later stress, leading to increased biological and behavioral response to that stressor, even when less severe than the original stressor. Given the fact that many environmental risk factors associated with 
schizophrenia may be linked to stress, stress sensitization may represent a common mechanism linking multiple environmental exposures (12). For example, evidence suggests that patients with schizophrenia, who report more childhood trauma, show increased stress-reactivity (39). Furthermore, previous exposure to stressful life events has been associated with higher sensitivity to small stressors in daily life (40).

Higher pituitary volume may be the result of differential functional states (e.g., increased stress-sensitivity/hypercortisolism) or, vice versa, contribute causally to increased stress-sensitivity. Post-hoc analyses revealed that FE patients had higher and patients with ES lower pituitary volumes than controls, in line with previous studies $(2,5)$. In addition, the association between increased stress-reactivity and pituitary volume was confined to the FE group. These observations are in agreement with the hypothesis of two biologically distinct pathways resulting in mean group differences between (i) type 1 psychotic disorder, characterized by high levels of positive symptoms and an episodic course $(41,42)$, as well as high stress-reactivity and associated larger pituitary volume, and (ii) type 2 psychotic disorder, characterized by high levels of negative symptoms, cognitive impairments and a chronic course (43-46), as well as low stress-sensitivity and smaller pituitary volumes. A larger study sample and a longitudinal design are needed to draw more definitive conclusions about underlying mechanisms and direction of effects.

\section{Biological stress-reactivity}

Mean cortisol levels were higher in siblings than in controls, consistent with another study from our group (14). It has been suggested that elevated cortisol levels in patients with a diagnosis of schizophrenia $(13,47)$ and their siblings reflect disturbances in the negative feedback regulation of the HPA axis (48). A comparable observation in depression is that HPA axis hyperactivity is thought to reflect a lack of negative inhibitory feedback by circulating cortisol on the HPA axis, particularly at the level of pituitary cells producing $A C T H$, leading to an increase in the size and number of these cells. Persistently elevated cortisol secretion could also lead to resistance of the glucocorticoid receptors for cortisol (49).

Cortisol reactivity to daily life stress, however, did not show a significant difference between siblings and controls and therefore does not agree with an earlier study (14). The present analyses, although based on the same cohort as described by Collip and colleagues, were carried out in individuals for whom MRI data were available, 
resulting in a sample size reduction. Thus, statistical power was insufficient to detect small differences in cortisol reactivity to daily life stress between siblings and controls and/or as a function of pituitary volume.

In sum, although some evidence for HPA axis hyperactivity was found (increased mean cortisol values in siblings), cortisol reactivity was not mediated by group status or pituitary volume in this study. However, larger studies are needed before more definitive conclusions can be drawn. Nevertheless, the biological and emotional stress-reactivity pathways seemed to be associated, as similar patterns in both biological and emotional stress-reactivity were apparent in siblings and controls.

\section{Methodological considerations}

Some authors have cast doubt on the reliability and subject compliance in paperand-pencil ESM studies, favouring the use of electronic devices (50). However, in a comparative study, Green et al. (2006) concluded that both methods yielded similar results (51).

Two different scanning sequences were used in this study, which could in theory have influenced the volume measurements. However, it has been shown that withinscanner measurements were reliable for subcortical volumes across scan sessions (52). Furthermore, in our data, no large or significant interaction was found between scan type and group on pituitary volume $(x 2=0.09 \mathrm{p}=0.96)$. Similarly, adjusting the analyses for scanning sequence did not affect direction or significance of the results.

Numerous external factors can influence pituitary volume, such as the use of AP. According to the study by Nicolo et al. (2010) in FE patients, SGA's reduce pituitary gland volume in a dose-dependent manner (8). However, some studies report that prolactin-elevating medication increases pituitary volume in comparison with prolactin-sparing medication $(2,6)$, whereas others do not $(3,4)$. The present study did not find an association between cumulative lifetime exposure to AP medication and pituitary volume, but the groups were too small to examine differential effects of AP group (SGA versus FGA). Furthermore adding lifetime AP as an additional confounder did not change the results (results available upon request). Exogenous estrogen exposure has also been associated with pituitary volume. Reduced pituitary volumes have been found in women taking oral contraceptives (Grams et al., 2010) but, in contrast, elevated pituitary volumes have been found 
in menopausal women using estrogens (53). The present study did not find an association between life-time estrogen exposure and pituitary volume. Larger studies investigating the association between estrogens and pituitary volume longitudinally are warranted. Nevertheless, there was a gender effect, i.e. pituitary volumes were higher in women than in men, possibly reflecting differences in endogenous estrogen levels (9). The role of estrogen in schizophrenia remains unknown. Evidence suggests that estrogens may exert a neuroprotective effect and possibly have antipsychotic properties (54). On the other hand, if estrogen could alsolead to pituitaryenlargement, this may potentially be less beneficial in terms of vulnerability for schizophrenia. It is advisable to take estrogen measures into account when examining pituitary volumes. 


\begin{tabular}{|c|c|c|c|c|}
\hline & Controls & Siblings & Patients & Test statistic + \\
\hline & $(n=32)$ & $(n=37)$ & $(n=20)$ & $\mathrm{p}$-value \\
\hline Age, years: mean (SD) & $31.7(11.4)$ & $28.3(7.8)$ & $29.1(8.0)$ & $F=1.95 P=0.15$ \\
\hline Gender (male:female) & $10: 22$ & $14: 23$ & 11:09 & $X 2=2.97 P=0.23$ \\
\hline Completed education & $5.8(1.8)$ & $5.3(2.2)$ & $4.7(1.8)$ & $F=5.49 P=0.00$ \\
\hline \multicolumn{5}{|l|}{ PANSS Scores } \\
\hline Mean positive scale (SD) & $7.4(1.3)$ & $7.5(1.1)$ & $12.4(5.1)$ & $F=10.00 P=0.00$ \\
\hline Mean negative scale (SD) & $8.0(0.2)$ & $8.2(1.0)$ & $10.8(3.3)$ & $F=9.15 P=0.00$ \\
\hline Mean disorganization scale (SD) & $10.2(0.4)$ & $10.2(0.5)$ & $31.4(4.1)$ & $F=8.65 P=0.00$ \\
\hline Mean excitement scale (SD) & $8.3(0.6)$ & $8.4(1.1)$ & $9.9(2.1)$ & $F=5.38 P=0.00$ \\
\hline Mean emotional distress scale (SD) & $9.5(2.5)$ & $9.9(2.3)$ & $14.2(5.0)$ & $F=7.56 P=0.00$ \\
\hline Mean alcohol use present state (SD) & $6.1(8.7)$ & $7.6(9.2)$ & $4.9(6.6)$ & $F=1.64 P=0.19$ \\
\hline Mean cigarettes use present state (SD) & $1.1(3.9)$ & $1.8(4.6)$ & $12.1(11.9)$ & $F=7.86 P=0.00$ \\
\hline \multicolumn{5}{|l|}{ Cannabis use } \\
\hline Mean cannabis use last 12 months (SD) & $1.6(8.8)$ & $3.4(12.6)$ & $34.3(99.8)$ & $F=1.68 P=0.18$ \\
\hline Mean cannabis use lifetime (SD) & $16.8(34.4)$ & $19.6(35.7)$ & $54.2(48.0)$ & $F=4.49 P=0.00$ \\
\hline \multicolumn{5}{|l|}{ Hard drug use } \\
\hline Mean hard drug use last 12 months (SD) & $1.6(9.2)$ & $0.0(0.0)$ & $5.0(18.2)$ & $F=0.78 P=0.51$ \\
\hline Mean hard drug use life time(SD) & $3.4(13.0)$ & $5.1(15.4)$ & $40.5(73.05)$ & $F=3.48 P=0.02$ \\
\hline \multicolumn{5}{|l|}{ Antipsychotics } \\
\hline Type AP (typical:atypical) & & & $2: 16$ & \\
\hline Mean haloperidolequivalent present state(SD) & & & $2.4(1.9)$ & \\
\hline Mean lifetime AP use in haloperidolequivalent (SD) & & & $48.2(47.1)$ & \\
\hline Mean lifetime estrogen exposure ${ }^{1}$ (SD) & $17589(31700)$ & $18474(29410)$ & $672(2013)$ & $F=9.23 P=0.00$ \\
\hline Scan type (MDEFT:ADNI) & 23:09 & $26: 11$ & $16: 04$ & $X 2=0.7 P=0.72$ \\
\hline
\end{tabular}

Abbreviations: PANSS, Positive and Negative Syndrome Scale; AP, antipsychotic

${ }^{1}$ months use of oral contraceptives multiplied with micrograms estrogen (of the corresponding oral contraceptive) per month $\mathrm{F} / \mathrm{Chi}^{2}$ and $\mathrm{P}$-values refer to between-group differences 
Table 2. Multilevel regression estimates of emotional- and biological stress reactivity

\begin{tabular}{lccc}
\hline & & & \\
& $X 2$ & $P$ & $B$ \\
Biological stress reactivity (cortisol) & & & \\
Group*event stress & 0.22 & 0.64 & \\
Group*social stress & 0.56 & 0.45 & \\
Emotional stress reactivity (NA) & & & \\
Group*event stress & 5.47 & 0.06 & $\mathrm{C}=0.04^{1} ; \mathrm{S}=0.04^{1} ; \mathrm{P}=0.07^{1}$ \\
Group*social stress & 2.48 & 0.29 & \\
& & & \\
\hline
\end{tabular}

${ }^{1} \mathrm{P}<0.05$

The $x^{2}$ and $P$-values represent the results of the Wald test, testing the significance of stratified effects

calculated from the model with the group $x$ stress interaction on respectively cortisol and negative affect

$\mathrm{C}=$ controls; $\mathrm{S}=$ siblings $\mathrm{P}=$ patients

the B's represent the effect sizes of level of stress sensitivity compared to the reference level 


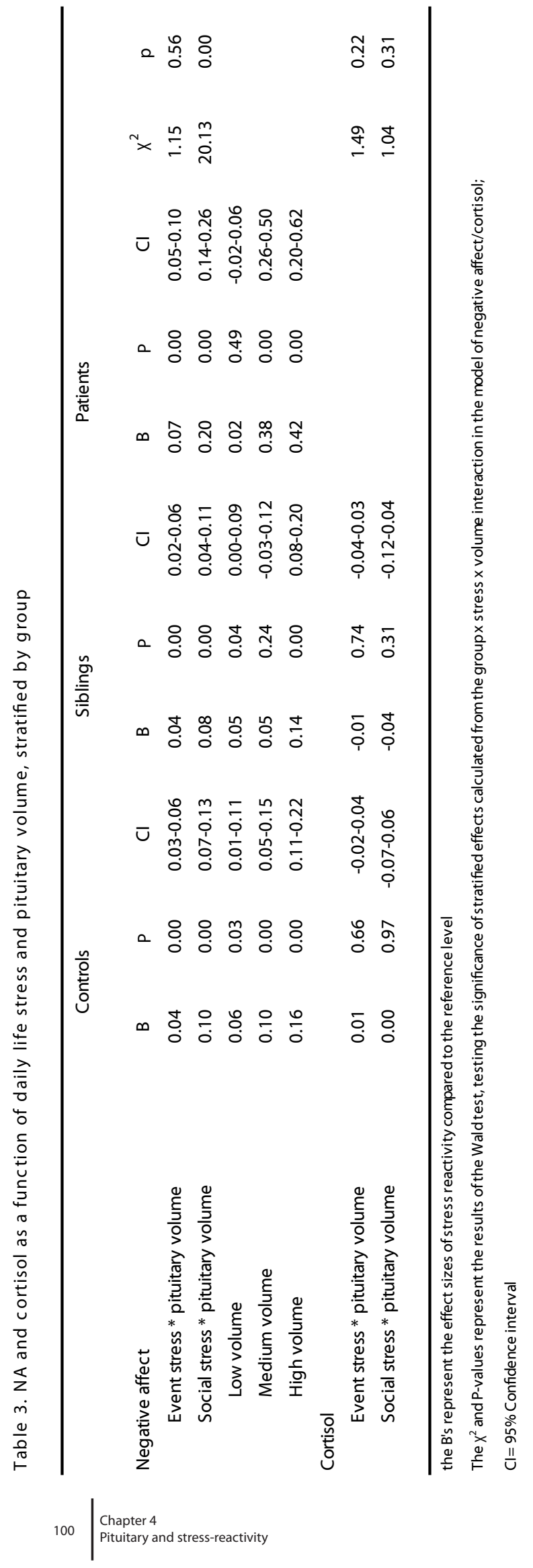




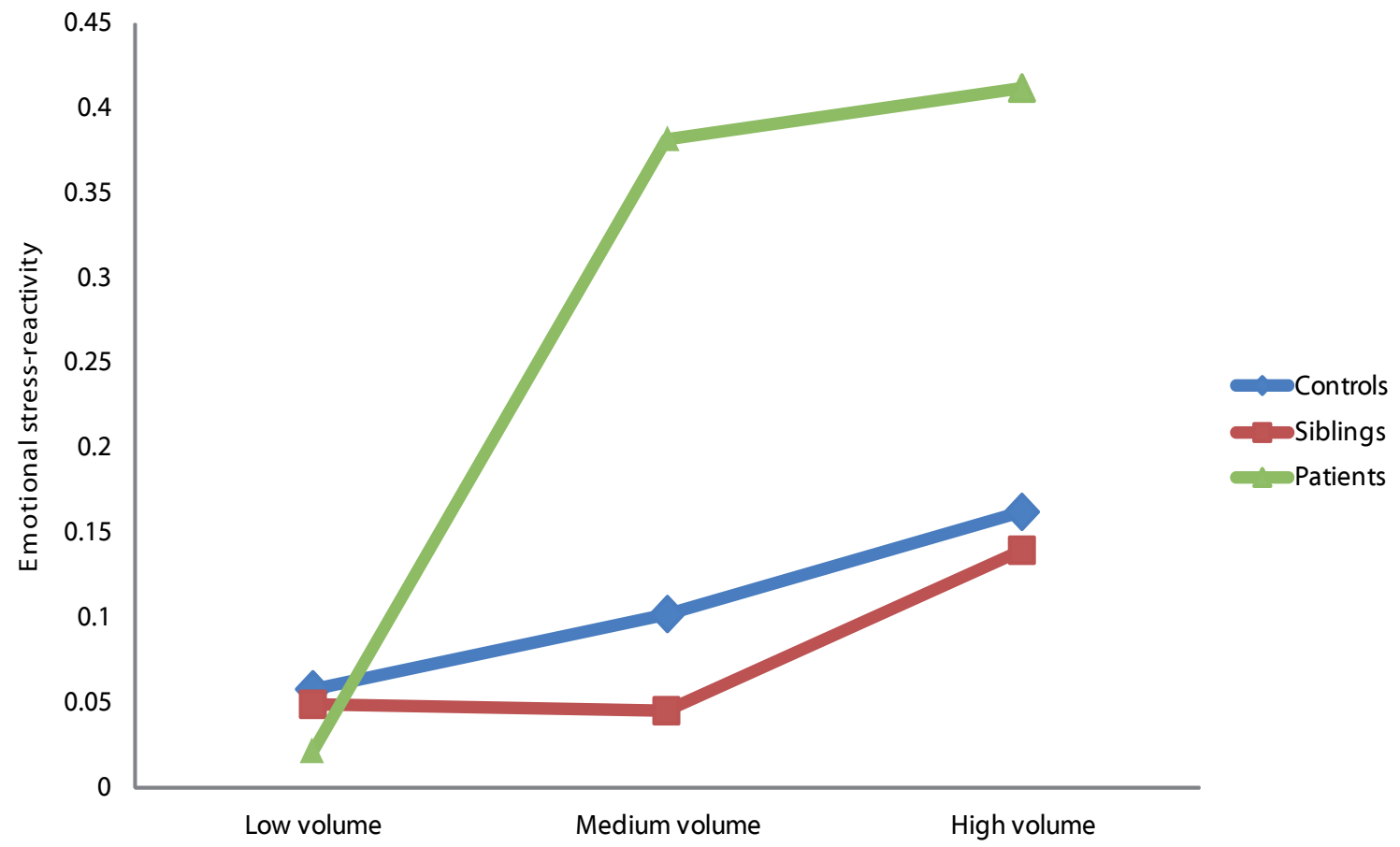

Figure 1. Stress-reactivity as a function of pituitary volume, stratified by group. Stress-reactivity was significantly higher in the high volume group when compared to the low volume in controls $(P=0.01)$, siblings $(P=0.02)$ and in patients $(\mathrm{P}=0.00)$. When comparing middle volume with low volume only patients showed increased stress-reactivity $(P=0.00)$. Patients showed higher stress-reactivity when compared to controls in the medium pituitary volume group $(P=0.00)$ and in the high pituitary volume group $(P=0.02)$. 


\section{References}

1. Garner B, Pariante CM, Wood SJ, Velakoulis D, Phillips L, Soulsby B, et al. (2005): Pituitary volume predicts future transition to psychosis in individuals at ultra-high risk of developing psychosis. Biol Psychiatry 58:417-23.

2. Pariante $C M$, Dazzan $P$, Danese A, Morgan KD, Brudaglio F, Morgan C, et al. (2005): Increased pituitary volume in antipsychotic-free and antipsychotic-treated patients of the AEsop firstonset psychosis study. Neuropsychopharmacolog y30:1923-31.

3. Takahashi T, Suzuki M, Velakoulis D, Lorenzetti V, Soulsby B, Zhou SY, et al. (2009): Increased pituitary volume in schizophrenia spectrum disorders. Schizophr Res 108:114-21.

4. Pariante CM, Vassilopoulou K, Velakoulis D, Phillips L, Soulsby B, Wood SJ, et al. (2004): Pituitary volume in psychosis. Br J Psychiatry 185:5-10.

5. Upadhyaya AR, El-Sheikh $R$, MacMaster FP, Diwadkar VA, and Keshavan MS (2007): Pituitary volume in neuroleptic-naive schizophrenia: a structural MRI study. Schizophr Res 90:266-73.
6. Mondelli V, Dazzan P, Gabilondo A, Tournikioti K, Walshe M, Marshall N, et al. (2008): Pituitary volume in unaffected relatives of patients with schizophrenia and bipolar disorder.

Psychoneuroendocrinolog y33:1004-12.

7. MacMaster FP, El-Sheikh R, Upadhyaya AR, Nutche J, Rosenberg DR, and Keshavan M (2007): Effect of antipsychotics on pituitary gland volume in treatment-naive firstepisode schizophrenia: a pilot study. Schizophr Res 92:207-10.

8. Nicolo JP, Berger GE, Garner BA, Velakoulis D, Markulev C, Kerr M, et al. (2010): The effect of atypical antipsychotics on pituitary gland volume in patients with first-episode psychosis: a longitudinal MRI study. Schizophr Res 116:49-54.

9. Doraiswamy PM, Potts JM, Axelson DA, Husain MM, Lurie SN, Na C, et al. (1992): MR assessment of pituitary gland morphology in healthy volunteers: age- and gender-related differences. AJNR Am J Neuroradiol 13:1295-9.

10. Grams AE, Gempt J, Stahl A, and Forschler A (2010): Female pituitary size in relation to age and hormonal factors. Neuroendocrinology 92:128-32.
11. Walker EF and Diforio D (1997): Schizophrenia: a neural diathesis-stress model. Psychol Rev 104: 667-85.

12. Collip D, Myin-Germeys I, and Van Os J (2008): Does the concept of "sensitization" provide a plausible mechanism for the putative link between the environment and schizophrenia? Schizophr Bull34:220-5.

13. Ryan MC, Sharifi N, Condren $\mathrm{R}$, and Thakore JH (2004): Evidence of basal pituitary-adrenal overactivity in first episode, drug naive patients with schizophrenia. Psychoneuroendocrinolog y 29:1065-70.

14. Collip D, Nicholson NA, Lardinois M, Lataster T, Mengelers R, van Os J, et al. (In press): Stress and cortisol in individuals at risk for psychosis: an experience sampling study. Psychological Medicine.

15. Walker EF, Brennan PA, Esterberg M, Brasfield J, Pearce B, and Compton MT (2010): Longitudinal changes in cortisol secretion and conversion to psychosis in at-risk youth. J Abnorm Psychol 119:401-8. 
16. Herz MI, Fava GA, Molnar G, and Edwards L (1985): The dexamethasone suppression test in newly hospitalized schizophrenic patients. Am J Psychiatry 142:127-9.

17. Lammers $\mathrm{CH}$, GarciaBorreguero D, Schmider J, Gotthardt U, Dettling M, Holsboer F, et al. (1995):

Combined dexamethasone/corticotro pin-releasing hormone test in patients with schizophrenia and in normal controls: II. Biol Psychiatry38:803-7.

18. Myin-Germeys I, van Os J, Schwartz JE, Stone AA, and Delespaul PA (2001): Emotional reactivity to daily life stress in psychosis. Arch Gen Psychiatry 58:1137-44.

19. Myin-Germeys I, Marcelis M, Krabbendam L, Delespaul $P$, and van Os J (2005): Subtle fluctuations in psychotic phenomena as functional states of abnormal dopamine reactivity in individuals at risk. Biol Psychiatry 58:10510.

20. Brenner K, Liu A, Laplante DP, Lupien S, Pruessner JC, Ciampi A, et al. (2009): Cortisol response to a psychosocial stressor in schizophrenia: blunted, delayed, or normal? Psychoneuroendocrinolog y34:859-68.
21. Marcelis M, Cavalier $E$, Gielen J, Delespaul P, and Van Os J (2004): Abnormal response to metabolic stress in schizophrenia: marker of vulnerability or acquired sensitization? Psychol Med34:1103-11.

22. van Venrooij JA, Fluitman SB, Lijmer JG, Kavelaars A, Heijnen CJ, Westenberg $\mathrm{HG}$, et al. (2010): Impaired Neuroendocrine and Immune Response to Acute Stress in MedicationNaive Patients With a First Episode of Psychosis. Schizophr Bull.

23. Habets $P$, Marcelis $M$, Gronenschild E, Drukker M, and Os JV (2011): Reduced Cortical Thickness as an Outcome of Differential Sensitivity to Environmental Risks in Schizophrenia. Biol Psychiatry. 69: 487-494

24. APA (2000): Diagnostic and statistical manual of mental disorders, 4th ed. Washington, DC: American Psychiatric Association.

25. Andreasen NC, Flaum $M$, and Arndt S (1992): The Comprehensive

Assessment of Symptoms and History (CASH). An instrument for assessing diagnosis and psychopathology. Arch Gen Psychiatry 49:615-23.
26. Kay SR, Fiszbein A, and Opler LA (1987): The positive and negative syndrome scale (PANSS) for schizophrenia. Schizophr Bull 13:261-76.

27. WHO (1990): Composite International Diagnostic Interview (CIDI) Geneva: World Health Organization.

28. Csikszentmihalyi M and Larson R (1987): validity and reliability of the expercience-Sampling Method. Journal of Nervous \& Mental Disease 175:526-36.

29. Myin-Germeys I, Oorschot M, Collip D, Lataster J, Delespaul P, and van Os J (2009): Experience sampling research in psychopathology: opening the black box of daily life. Psychol Med 39:1533-47.

30. Delespaul $P$, deVries $M$, and van Os J (2002):

Determinants of occurrence and recovery from hallucinations in daily life. Soc Psychiatry Psychiatr Epidemio/37:97104.

31. Sulon J, Demey-Ponsart $\mathrm{L}$, Beauduin $\mathrm{P}$, and Sodoyez JC (1978): Radioimmunoassay of corticosterone, cortisol and cortisone: their application to human cord and maternal plasma. J Steroid Biochem 9:671-6. 
32. Dale AM, Fischl $B$, and Sereno MI (1999): Cortical surface-based analysis. I.

Segmentation and surface reconstruction.

Neuroimage 9:179-94.

33. Fischl B, Sereno MI, and Dale AM (1999): Cortical surface-based analysis. II: Inflation, flattening, and a surfacebased coordinate system. Neuroimage 9:195-207.

34. Gronenschild EH, Burgmans $S$, Smeets $F$, Vuurman EF, Uylings HB, and Jolles J (2010): A timesaving and facilitating approach for segmentation of anatomically defined cortical regions: MRI volumetry. Psychiatry Res 181:211-8.

35. Sassi RB, Nicoletti $M$, Brambilla P, Harenski K, Mallinger AG, Frank E, et al. (2001): Decreased pituitary volume in patients with bipolar disorder. Biol Psychiatry 50:271-80.

36. StataCorp (2009): Stata Statistical Software:

Release 11. College Station, TX: StataCorp LP.

37. Clayton D and Hills M (1993): Statistical Models in Epidemiology Oxford:

Oxford University Press.

38. Tournikioti $\mathrm{K}$, Tansella M, Perlini C, Rambaldelli G, Cerini R, Versace A, et al. (2007): Normal pituitary volumes in chronic schizophrenia. Psychiatry Res 154:41-8.
39. Lardinois $M$, Lataster $T$, Mengelers R, van Os J, and Myin-Germeys I (2010): Childhood trauma and increased stress-sensitivity in psychosis. Acta Psychiatr Scand.

40. Myin-Germeys I, Krabbendam L, Delespaul PA, and Van Os J (2003): Do life events have their effect on psychosis by influencing the emotional reactivity to daily life stress? Psychol Med 33:327-33.

41. Lataster T, Collip D, Lardinois $\mathrm{M}$, van Os J, and Myin-Germeys I (2010): Evidence for a familial correlation between increased reactivity to stress and positive psychotic symptoms. Acta Psychiatr Scand.

42. Myin-Germeys I and van Os J (2007): Stressreactivity in psychosis: evidence for an affective pathway to psychosis. Clin Psychol Rev 27:409-24.

43. Crow TJ (1980): Molecular pathology of schizophrenia: more than one disease process? $\mathrm{Br}$ Med J280:66-8.

44. Murray RM, O'Callaghan E, Castle DJ, and Lewis SW (1992): A neurodevelopmental approach to the classification of schizophrenia. Schizophr Bull18:319-32.
45. Robins E and Guze SB (1970): Establishment of diagnostic validity in psychiatric illness: its application to schizophrenia. Am J Psychiatry 126:983-7.

46. Van Os J, Gilvarry C, Bale R, Van Horn E, Tattan T, White I, et al. (1999): A comparison of the utility of dimensional and categorical representations of psychosis. UK700 Group. Psychol Med 29:595-606.

47. Mondelli V, Dazzan $P$, Hepgul N, Di Forti M, Aas M, D'Albenzio A, et al. (2010): Abnormal cortisol levels during the day and cortisol awakening response in first-episode psychosis: the role of stress and of antipsychotic treatment. Schizophr Res 116:234-42.

48. Phillips LJ, McGorry PD, Garner B, Thompson KN, Pantelis C, Wood SJ, et al. (2006): Stress, the hippocampus and the hypothalamic-pituitaryadrenal axis: implications for the development of psychotic disorders. Aust N ZJ Psychiatry 40:725-41.

49. Pariante CM (2006): The glucocorticoid receptor: part of the solution or part of the problem? J

Psychopharmaco/20:7984.

50. Stone AA, Shiffman $S$, Schwartz JE, Broderick JE, and Hufford MR (2002): Patient non-compliance with paper diaries. BMJ 324:1193-4. 
51. Green AS, Rafaeli E, Bolger N, Shrout PE, and Reis HT (2006): Paper or plastic? Data equivalence in paper and electronic diaries. Psychol Methods 11:87-105.

52. Jovicich J, Czanner S, Greve D, Haley E, van der Kouwe A, Gollub R, et al. (2006): Reliability in multisite structural MRI studies: effects of gradient nonlinearity correction on phantom and human data. Neuroimage 30:436-43.

53. Abech DD, Moratelli $\mathrm{HB}$, Leite SC, and Oliveira MC (2005): Effects of estrogen replacement therapy on pituitary size, prolactin and thyroidstimulating hormone concentrations in menopausal women. Gynecol Endocrinol 21:223-6.

54. Boerma $M A$, van der Stel JC, van Amelsvoort T, Linszen $\mathrm{DH}$, and de Haan $\mathrm{L}$ (2010): [Women, schizophrenia and oestrogen; neurobiological hypotheses and hormonetherapy studies]. Tijdschr Psychiatr 52:23544. 
1 Dept. of Psychiatry and Psychology, School for Mental Health and Neuroscience, EURON, Maastricht University Medical Center, Maastricht, The Netherlands

2 King's College London, King's Health Partners, Department of Psychosis Studies Institute of Psychiatry, London, United Kingdom 


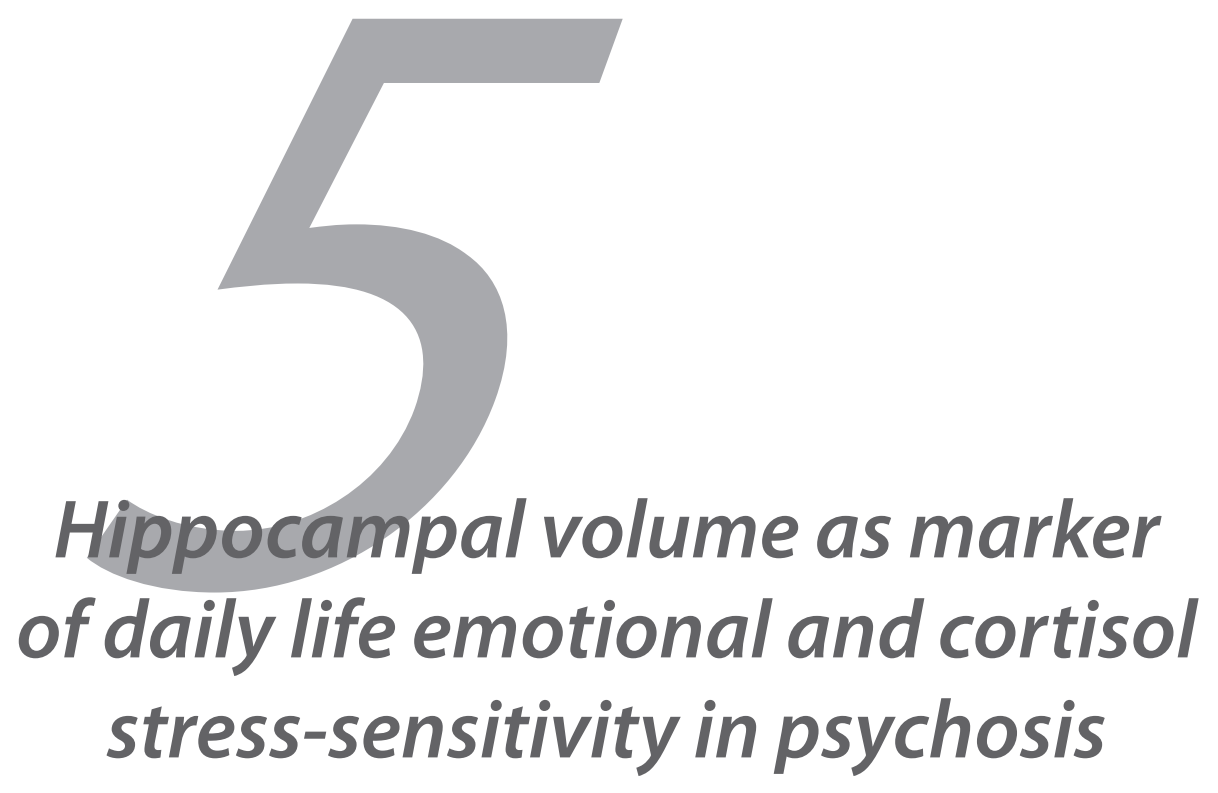

Submitted

Petra Habets ${ }^{1 *}$, Dina Collip ${ }^{1 *}$, Machteld Marcelis ${ }^{1}$, Ed Gronenschild ${ }^{1}$, Tineke Lataster ${ }^{1}$, Mariëlle Lardinois ${ }^{1}$, Nancy A. Nicolson ${ }^{1}$, Jim van Os ${ }^{1,2}$, Inez Myin-Germeys ${ }^{1}$ for G.R.O.U.P.

* Contributed equally 


\section{Abstract}

Background: Reduced hippocampal size and increased stress-sensitivity are associated with genetic risk for psychotic disorder. However, to what degree the hippocampus is implicated in daily life stress-reactivity in psychotic disorder has never been examined. The current study investigated (i) whether hippocampal volume (HV) was associated with emotional and cortisol daily stress-reactivity, and (ii) whether genetic risk (the contrast between controls, patients and siblings of patients) moderated this relationship.

Methods: 1-weighted MRI scans were acquired from 20 patients with schizophrenia, 38 healthy siblings at higher than average genetic risk for schizophrenia and 33 controls. Freesurfer 5.0.0 was used to measure HV. The Experience Sampling Method (ESM; a structured momentary assessment diary technique) was used to assess emotional stress-reactivity (the effect of momentary stress on momentary negative affect (NA)). Cortisol stress-reactivity was assessed using momentary cortisol levels extracted from saliva in the control and sibling groups.

Results: Multilevel linear regression analyses revealed a significant three-way interaction between group, HV, and momentary stress in both the model of NA and the model of cortisol. Increased stress-reactivity was associated with smaller $\mathrm{HV}$ in patients and larger HV in controls. In line with the results in patients, siblings with small HV demonstrated increased cortisol stress-reactivity compared to those with large HV, although there was no association between HV and emotional stressreactivity in siblings.

Conclusions: The findings suggest that HV may index risk and possibly diseaserelated mechanisms underlying daily life emotional and cortisol stress-reactivity in psychotic disorder. 


\section{Introduction}

Patients with psychotic disorder generally display reduced hippocampal size [1-4]. Recent studies have shown that similar alterations in hippocampal volume (HV) may be present in first-degree relatives of patients with schizophrenia [5, 6], suggesting that HV alterations constitute part of the liability to psychosis. The hippocampus plays a pivotal role in regulating emotional responses to stressful stimuli and in the negative feedback mechanism controlling hypothalamic-pituitary-adrenal (HPA) axis activity [7-11]. Because the hippocampus has an inhibitory influence, a smaller HV might be associated with increased HPA axis reactivity to stress. Indeed, in clinical samples, studies have reported an inverse association between HV and cortisol levels. In two studies, hippocampal atrophy was accompanied by hypercortisolemia $[12,13]$. Similarly, in patients with a psychotic disorder, smaller left HV was associated with higher salivary cortisol levels [14].

In contrast, findings in healthy volunteers show mixed results. One study, examining the association between HV and cortisol response to experimental psychological stress as well as awakening [15], found a positive association between $\mathrm{HV}$ and cortisol reactivity in young healthy volunteers, whereas a negative association between HV and the cortisol response to a physiological challenge was found in another sample [16]. These findings indicate that the association between HV and stress-reactivity may be different in healthy and clinical populations.

Familial vulnerability for psychosis has been associated with amplified emotional and cortisol responses to stress in daily life. Patients with a psychotic disorder and their unaffected first-degree relatives have been found to display increased negative emotions and an increase in psychotic experiences [17, 18]. Similarly, a recent study showed that siblings of patients compared to controls respond with increased cortisol secretion to minor everyday stressors (Collip et al., in press). The neural mechanisms underlying this augmented stress-sensitivity, however, have not yet been identified.

The current study investigates whether HV is associated with emotional and cortisol reactivity to daily life stress, as indexed by momentary variation in negative affect and momentary cortisol levels. Given the reported discrepancy between clinical and non-clinical samples in the association between HV and cortisol [19], we examined whether this association was moderated by genetic risk for psychosis. Because some earlier studies suggest that cortisol levels are primarily associated with left 
HV [20 491], analyses also investigated hemispheric differentiation with regard to: differences in the HV stress-reactivity. Analyses thus examined to what degree (i) HV was associated with emotional and cortisol reactivity to daily stress, and (ii) group (control, sibling, patient), moderated the association between (emotional and cortisol) reactivity to stress and HV.

\section{Methods and Materials}

\section{Subjects}

The study sample consisted of patients with a diagnosis of non-affective psychotic disorder, their siblings, and controls from the general population, in the context of the Dutch national GROUP project [21]. In selected representative geographical areas in the Netherlands and Belgium, patients were identified through clinicians whose caseload was screened for inclusion criteria. Subsequently, a group of patients presenting consecutively at these services either as outpatients or inpatients, were recruited for the study. First-degree relatives were recruited through participating patients. Control subjects were recruited from the same population as the patients, through random mailings in the geographic region and advertisements in newspapers. All interviews were conducted by trained psychology graduates. From the wider sampling frame, the following subgroups were selected: 20 patients with a diagnosis of schizophrenia or related psychotic disorder, 37 siblings of patients with a diagnosis of schizophrenia and 32 controls. Inclusion criteria were: (i) age 16 to 50 years, (ii) diagnosis of non-affective psychotic disorder and (iii) good command of the Dutch language. Siblings had to be free of any lifetime non-affective psychotic disorder. For the control subjects, the occurrence of any psychotic disorder in either the subject or any first-degree family member, assessed using the Family Interview for Genetic Studies (FIGS) [22], constituted an exclusion criterion.

Diagnosis was based on the Diagnostic and Statistical Manual of Mental Disorder-IV (DSM-IV) criteria [23], assessed with the Comprehensive Assessment of Symptoms and History (CASH) interview [24]. Patients were diagnosed with: schizophrenia $(n=11)$, schizoaffective disorder $(n=2)$, schizophreniform disorder $(n=1)$, brief psychotic disorder $(n=2)$, and psychotic disorder not otherwise specified $(n=4)$. The $\mathrm{CASH}$ was also used to confirm the absence of a diagnosis of non-affective psychosis in the siblings, and absence of a lifetime diagnosis of any psychotic disorder or any current affective disorder in the healthy controls. Six siblings and seven controls had 
a history of major depressive disorder, but none presented in a current depressive episode.

Prior to MRI acquisition, participants were screened for the following exclusion criteria: (i) brain injury with unconsciousness for over 1 hour, (ii) meningitis or other neurological diseases that might have affected brain structure/function, (iii) cardiac arrhythmia requiring medical treatment and (iv) severe claustrophobia. In addition, subjects with metal corpora aliena were excluded from the study, as well as women with an intrauterine device or (suspected) pregnancy. The study was approved by the standing ethics committee, and all the subjects gave written informed consent in accordance with the committee's guidelines.

\section{Measures}

The Positive and Negative Syndrome Scale (PANSS) [25] was used to measure psychotic symptoms over the last two weeks.

Antipsychotic medication was determined from reports of the participant's psychiatrist. Best estimate lifetime (cumulative) antipsychotic medication (AP) use was determined by multiplying the number of days of AP use with the corresponding haloperidol equivalents and summing up these scores for all periods of AP use [26].

Estrogen exposure was estimated by multiplying the number of months of oral contraceptive use with micrograms estrogen (of the corresponding oral contraceptive) per month.

Substance use was assessed using the Composite International Diagnostic Interview (CIDI) sections B-J-L [27]. Cannabis use and other drug use (stimulants, sedatives, opiates, cocaine, PCP, psychedelics, inhalants, or other (e.g., XTC, poppers)) was assessed as reported frequency of use (i) during the last 12 months, and (ii) lifetime. Alcohol and tobacco use was defined as the reported number of weekly consumptions during the last 12 months.

\section{Experience Sampling Method (ESM)}

The Experience Sampling Method is a random time-sampling self-assessment technique; studies have demonstrated the feasibility, validity, and reliability of ESM in general and patient populations $[28,29]$. Subjects received a digital wristwatch that emitted a signal ten times a day on six consecutive days, at unpredictable moments between 7:30 a.m. and 10:30 p.m. After each 'beep', subjects completed ESM self- 
assessment forms concerning current context, thoughts, emotions, and psychotic experiences. Subjects were instructed to complete their reports immediately after the beep, thus minimizing memory distortions. Reports were considered valid when subjects responded within 15 min after the beep, as determined by comparing the actual beep time with the reported time of completion. For inclusion in the analyses, participants had to have provided valid responses to at least one-third of the emitted beeps [30].

Stress-reactivity, as described in previous work, was conceptualized as emotional [18] and cortisol reactivity (Collip et al., in press)[31] to minor disturbances in daily life. Momentary measures of stress, negative affect (NA) and cortisol were derived from the experience sampling data as described below.

\section{ESM measures}

Event stress. In accordance with previous work, stress was conceptualized as the subjectively appraised unpleasantness of distinctive events [18]. After each beep, participants were asked to report the most important event that had happened between the current and the previous report and then to rate this event on a 7point scale $(-3=$ very unpleasant, $0=$ neutral, $3=$ very pleasant $)$. The responses were recoded to allow high scores to reflect stress $(-3=$ very pleasant, $0=$ neutral, $3=$ very unpleasant).

Negative affect. In line with previous reports [18] ESM NA was assessed as the mean score on 6 ESM items, rated on 7-point Likert scales ( 1 = not at all to 7 = very): "I feel insecure", "I feel lonely", "I feel anxious", "I feel down", "I feel guilty" and "I feel angry/ irritated" (Cronbach's $a=.84)$.

\section{Salivary cortisol sampling}

After each ESM beep, participants (siblings, controls) collected a saliva sample with a cotton swab (Salivette; Sarstedt, Etten-Leur, the Netherlands), replaced the swab in the salivette tube, and recorded the exact collection time. Samples were stored in subjects' home freezers until transport to the lab, where uncentrifuged samples were kept at $-20^{\circ} \mathrm{C}$ until analysis. Saliva samples collected more than 15 minutes after the beep were excluded from the analysis. 


\section{Salivary cortisol}

Salivary cortisol is a reliable and non-invasive measure of the free, unbound cortisol in plasma, the biologically active hormone. Radioimmunoassays were run in duplicate, using a tracer solution of cortisol-3CMO coupled with 2-[125 I] histamine and specific antibodies raised against cortisol-3CMO-BSA [33] (Dr. J. Sulon, Department of Reproductive Physiology, School of Veterinary Medicine, University of Liège). The lower detection limit of the assay was $0.2 \mathrm{nmol} / \mathrm{L}$. The intra- and interassay coefficients of variation were $<5 \%$ and $<12 \%$, respectively. All samples from an individual were analyzed in the same assay to reduce sources of variability. All samples were within the normal physiological range $(<44 \mathrm{nmol} / \mathrm{L})$. Cortisol was not measured in the patients with a psychotic disorder, as they usually receive antipsychotic medication, which can affect cortisol levels.

\section{MRI acquisition and processing}

MRI scans were acquired using a 3T Siemens scanner and the following acquisition parameters: Modified Driven Equilibrium Fourier Transform (MDEFT) sequence: 176 slices, $1 \mathrm{~mm}$ isotropic voxel size, TE $2.4 \mathrm{~ms}$, TR $7.92 \mathrm{~ms}$, flip angle $15^{\circ}$, total acquisition time: 12 min 51s, and for the Magnetization Prepared Rapid Acquisition Gradient Echo(MP-RAGE): Alzheimer's Disease Neuroimaging Initiation (ADNI) sequence: 192 slices, $1 \mathrm{~mm}$ isotropic voxel size, TE $2.6 \mathrm{~ms}$, TR $2250 \mathrm{~ms}$, flip angle $9^{\circ}$, total acquisition time: $7 \mathrm{~min} 23 \mathrm{~s}$. For both sequences the matrix size and field of view were $256 \times 256$. Two sequences were used because of a scanner update during data collection. The MP-RAGE and MDEFT are very similar, but to prevent any systematic bias, the total proportion of MP-RAGE scans (around 1/3) was balanced between the groups.

\section{MRI preprocessing}

Scans were processed and analyzed using Freesurfer stable release v5.0.0. Technical details of these procedures are described in prior publications [34-40]. Data were automatically transformed into Talairach standard space.

\section{Volume measures}

The automated procedures for volumetric measures of the different brain structures are described by Fischl et al. [36]. This procedure automatically assigns a neuroanatomical label to each voxel in an MRI volume based on probabilistic information automatically estimated from a manually labelled training set. The 
training set included both healthy persons in the age range 18-87 years and a group of Alzheimer's disease patients in the age range 60-87 years, and the classification technique employs a registration procedure that is robust to anatomical variability, including the ventricular enlargement typically associated with neurological diseases and aging. The technique has previously been shown to be comparable in accuracy to manual labelling. The segmentations were visually inspected for accuracy.

\section{Statistical analyses}

ESM and cortisol data were analysed using multilevel regression techniques, which take the hierarchical structure of the data into account. In the current study, repeated momentary measurements (level 1) were nested in subjects (level 2) who were part of the same family (level 3). Data were analyzed using the XTMIXED multilevel random regression routine in STATA 11.0 [41]. Effect sizes from predictors in the multilevel model were expressed as $B$, representing the unstandardized fixed regression coefficient. Interactions were assessed by Wald test. The size of the moderator effects was calculated by applying and testing the appropriate linear combinations using the STATA MARGIN command. Raw cortisol values were log transformed to reduce skewness of distribution, generating the variable Incort. The variable time was centered around the grand mean for all samples. To model the cortisol diurnal curve, the variable time was included as a predictor in all analyses with Incort as dependent variable; addition of higher order polynomial terms did not improve model fit. Analyses were adjusted for the a priori selected confounders age, sex, intracranial volume, and scan type. Moreover, analyses were re-run including estrogen exposure and AP [14, 42], respectively.

\section{Group differences in hippocampal volume and cortisol}

To test whether HV or mean cortisol level differed between groups, a regression was estimated with $\mathrm{HV}$ and Incort respectively as the dependent variable and the categorical variable group ( $0=$ controls, $1=$ siblings, $2=$ =patients; for cortisol, controls and siblings only) as independent variable. 


\section{Interaction between group, stress-reactivity and volume}

In order to test whether HV was associated with emotional stress-reactivity, and whether this was moderated by group, regression analyses were conducted with event stress, $H V$ and group (entered as linear three-level variable of patients, siblings and controls $=$ reference) as well as their interaction terms as independent variables and $\mathrm{NA}$ as the dependent variable $\mathrm{NA}=B_{0}+B_{1}$ (group) $+B_{2}$ (stress) $+B_{3}$ (volume) + $B_{4}$ (group $\times$ stress $)+B_{5}($ group $\times$ volume $)+B_{6}$ (stress $\times$ volume $)+B_{7}($ group $\times$ stress $\times$ volume).

In separate analyses, HV was entered either as a linear variable or as dummy variable representing the distribution of volume calculated at the $33^{\text {rd }}$ and $66^{\text {th }}$ percentiles of $\mathrm{HV}$ of the controls, allowing visualization of dose-response $\left(1=<33^{\text {th }}\right.$ percentile: low HV, $2=>33^{\text {th }}$ and $<66^{\text {th }}$ percentile: middle HV, $3=>66^{\text {th }}$ percentile: high HV). To ensure that definitions for small, medium and large HV were the same for all groups, patients and siblings were allocated to hippocampal group on the basis of the criteria for the control group.

In order to test the hypothesis that controls and siblings differed in their association between HV and cortisol stress-reactivity, the same model as described above was applied to cortisol (Incort) as the dependent variable. Additional confounders for all cortisol analyses were: time of cortisol sample, estrogen exposure and recent consumption of food or tobacco (i.e., in the approximately 90 minutes interval since the previous beep).

\section{Results}

\section{Descriptive analyses}

Groups were well matched on most demographic variables (Table 1). Patients smoked more cigarettes and cannabis than siblings and controls and had more lifetime hard drug use than siblings and controls, with no significant differences between the latter two groups. Eighteen patients received AP (atypical: $n=2$; typical: $\mathrm{n}=16$ ). Furthermore, three patients used an antidepressant and one patient used a benzodiazepine. Two controls used an antidepressant, and one control used a benzodiazepine. Patients reported higher total, positive, and negative PANSS scores than controls and siblings, with no differences between the latter two groups (Table1). 


\section{Group differences in hippocampal volume, cortisol and stress-reactivity}

There was a significant association between group and HV. Patients $(B=-247.6,95 \%$ $\mathrm{Cl}-415.1,-80.01 ; p=0.01)$ and siblings $(B=-148.6,95 \% \mathrm{Cl}-292.66,-4.47 ; p=0.04)$ had smaller $\mathrm{HV}$ than controls. Patients and siblings did not differ $(\mathrm{B}=99.0,95 \% \mathrm{Cl}-57.63$, $255.61 ; p=0.22$ ).

Siblings had significantly higher cortisol levels than controls $(B=0.28,95 \% \mathrm{Cl} 0.11$, $0.45 ; p=0.001)$. However, no significant association between cortisol levels and total HV $(B=-186.2,95 \% C l$-398.16, 25.76; $p=0.085)$, left HV ( $B=-157.1,95 \% \mathrm{Cl}-393.72$, 79.62; $p=0.19)$ or right $H V(B=-215.4,95 \% C l-452.63,21.94 ; p=0.075)$ was found in the combined group of siblings and controls and no significant interaction between cortisol and group (siblings and controls) was found for total HV $\left(x^{2}(1)=0.00 ; p=\right.$ $0.99)$, left $H V\left(X^{2}(1)=0.03 ; p=0.85\right)$ or right $H V\left(X^{2}(1)=0.03 ; p=0.86\right)$.

There was a significant group $\mathrm{x}$ event stress interaction in the model $N A$, indicating that emotional stress-reactivity differed between groups $\left(X^{2}(2)=10.05, p=0.01\right)$. Stratified analyses revealed that patients had significantly higher stress-reactivity $(B=0.08,95 \% C l 0.054,0.097 ; p=0.00)$ compared to both controls $(B=0.05,95 \% C l$ $0.054,0.097 ; p=0.00)$ and siblings $(B=0.04,95 \% C l 0.024,0.056 ; p=0.00)$. For cortisol, no significant interaction was found between group (siblings and controls) and event stress $\left(x^{2}(1)=0.24 ; p=0.62\right)$.

\section{Emotional stress-reactivity contingent on hippocampal volume and genetic risk}

A significant group $\mathrm{x}$ event stress $\mathrm{x}$ total HV interaction was found in the model of $N A$ $\left(X^{2}(2)=5.88, p=0.05\right)$. Differentiation by hemisphere revealed that the interaction with left $H V\left(X^{2}(2)=8.04, p=0.02\right)$, but not with right $H V\left(x^{2}(2)=3.24, p=0.20\right)$, was significant. Thus, the association between left $H V$ and stress-reactivity differed between groups (Figure 1). Stratified analyses revealed increased emotional stress-reactivity in controls with larger left HV in comparison to controls with medium $\left(X^{2}(1)=5.28\right.$, $\mathrm{p}=0.02)$ or small left $\mathrm{HV}\left(\mathrm{x}^{2}(1)=9.85, \mathrm{p}=0.01\right)$. In siblings, no significant differences in stress-reactivity were found between siblings with small, medium or large HV (medium vs. high: $X^{2}(1)=2.93, p=0.09$; low vs. medium: $X^{2}(1)=2.95, p=0.09$; low vs. high: $\left.X^{2}(1)=0.02, p=0.89\right)$. Patients with small and medium HV were significantly more stress-reactive than patients with large HV $\left(X^{2}(1)=21.17, p<0.01 ; X^{2}(1)=19.65\right.$, $p<0.01$, respectively). Emotional stress-reactivity in patients differed from that of controls and siblings at all three levels of left HV. There was a trend difference in emotional stress-reactivity between controls and siblings with large left $H V\left(X^{2}(1)=\right.$ 


\section{Analysis controlled for antipsychotic medication \& estrogen exposure}

The association between group and left HV decreased slightly after controlling for AP use $\left(x^{2}(2)=5.92 ; p=0.05\right)$, but remained after controlling for estrogen exposure $\left(x^{2}(2)=6.80 ; p=0.03\right)$. The interaction between group $x$ event stress $x$ left HV on NA remained significant after controlling for use of antipsychotic medication or estrogen levels, $\left(\mathrm{X}^{2}(2)=6.08, \mathrm{p}=0.05 ; \mathrm{X}^{2}(2)=6.89, \mathrm{p}=0.03\right.$, respectively).

\section{Cortisol stress-reactivity contingent on hippocampal volume and genetic risk}

There was a significant group $\mathrm{x}$ event stress $\mathrm{x}$ total HV interaction in the model of cortisol $\left(X^{2}(1)=3.77, p=0.05\right)$. Differentiation by hemisphere revealed that the interaction was significant for left $H V\left(X^{2}(1)=4.11, p=0.04\right)$, but not for right $H V\left(x^{2}\right.$ $(1)=2.65, p=0.10)$, suggesting that the association between left HV and cortisol reactivity to stress differed between the control and sibling group. For the control group, stratified analyses revealed no significant differences in cortisol response to daily stress between the hippocampal groups. In the sibling group, however, left HV moderated the effect of stress on cortisol, with small compared to large HV being associated with increased cortisol responses to stress $\left(X^{2}(1)=9.66, p=0.002\right)$. Regarding differences between the control and sibling group, a non-significant trend difference was found for large left HV only $\left(x^{2}(1)=2.89, p=0.09\right)$.

\section{Discussion}

To our knowledge, this is the first study to examine the association between stresssensitivity, indicators of HPA axis activity, and HV in a sample with different levels of genetic risk for psychosis. Results show that the immediate effect of daily stress on negative affect and cortisol was not only conditional on HV, but also on genetic risk for psychosis. Patients with a small and medium left HV reported a larger increase in emotional stress-reactivity compared to patients with large HV. In line with the results in patients, siblings with small HV demonstrated increased cortisol reactivity to stress compared to those with large HV, although there was no association between HV and emotional stress-reactivity in this group. In contrast, controls with a large HV were more emotionally stress reactive than controls with small HV, 
although this was not the case for cortisol reactivity.

\section{Hippocampal Volume and overall diurnal cortisol}

In line with a substantial amount of (meta-analytic) evidence [3, 4], HV in the patient group was smaller than that of control participants. Similarly, decreased HV in the siblings of patients with a psychotic disorder was found, which corresponds with findings from a recent meta-analysis $[5,6]$, as does the finding of absence of differences in HV between patients and their non-psychotic relatives [43].

There was no association between overall diurnal cortisol levels and HV, which is in line with a previous study that found no association between HV and cortisol in first episode psychosis [44]. Another study, however, that differentiated between left and right $\mathrm{HV}$, found that baseline cortisol levels were associated with smaller left HV in first-episode psychosis, but not in controls [20]. Although we investigated left and right HV separately, no association between HV and cortisol level was apparent in siblings and controls, combined or in interaction. Nevertheless, there was a nonsignificant trend in the direction of a negative association between $\mathrm{HV}$ and diurnal cortisol levels, which is in line with the results of Mondelli and colleagues (2010b).

\section{Stress-reactivity and Hippocampal Volume in patients with psychotic disorder}

In patients with a psychotic disorder, smaller HV was associated with increased emotional stress-reactivity, while larger HV was associated with a diminished emotional response to stress. Thus, patients with a psychotic disorder were not only more likely to have a small hippocampus, but those with a decreased HV were also more likely to experience augmented stress-reactivity. These findings support the evidence that the hippocampus has an inhibitory role on the human stress response, extending findings to the realm of daily life.

We found differences in stress-reactivity within the group of patients with psychotic disorder that could be traced to differences in HV, i.e. patients with smaller HV were most responsive to the environment. This finding underscores the notion that there are different pathways to psychotic disorder [45], stress-reactivity being associated particularly with positive symptoms and a better prognosis $[45,46]$. For example, patients with smaller HV may have experienced childhood trauma, impacting on cumulative glucocorticoid exposure and HV. The HV in turn, as shown in the current study, influences stress-reactivity. On the other hand, lower stress-reactivity may predict more negative symptoms. Unfortunately, the current patient group was too 
small to explore clinical differences as a function of HV.

It is important to note that the direction of the association between HV and stressreactivity is unresolved. The question of whether heightened cortisol reactivity may ultimately cause hippocampal volume changes or whether alterations in HV, possibly through decreased inhibitory functioning of the hippocampus, are responsible for increased stress-reactivity, should be answered in longitudinal studies.

\section{Stress-reactivity and Hippocampal Volume in subjects at increased genetic risk for psychotic disorder}

Similar to the findings in patients, siblings with smaller HV exhibited increased cortisol stress-reactivity, while larger HV in the siblings was associated with decreased cortisol response to stress. Interestingly, however, this was not found at the emotional level. Buchanan and colleagues (2009) suggest that the hippocampus may be a crucial element of a network involved in producing an integrated response to psychosocial stress (indexed by behavior and HPA activity). We found a decreased cortisol response to stress in siblings with larger HV and in patients a large HV was associated with reduced emotional response to stress. It may be that these represent markers for reduced integration of the stress response in those at increased risk for psychosis. In other words, decreased cortisol concentrations in the siblings with larger HV reflect suboptimal HPA axis functioning, resulting in increased liability for psychosis. Another possibility is that the blunted cortisol stress response in siblings with larger HV represents a protective factor against illness expression, given increased background vulnerability. It may also indicate that, even given suboptimal cortisol reactivity, siblings manage to cope better with stress and/or have higher resilience and therefore show relatively "healthy" emotional stress-reactivity.

\section{Stress-reactivity and Hippocampal Volume in healthy controls}

In controls, we found the reverse pattern, with smaller HV associated with reduced emotional stress-reactivity, and larger HV associated with increased emotional stress-reactivity. Cortisol reactivity to small daily hassles, however, did not differ as a function of HV in the control group.

These findings contradict another study in healthy adults that report evidence for an association between stress level and smaller anterior HV. However, the stress measure used comprised retrospective summary information. In contrast, the current study measures emotional stress-reactivity in daily life [47]. Our findings at the emotional 
level do correspond with a study by Pruessner and colleagues (2007), who found that larger HV in healthy young participants was associated with increased cortisol response to awakening (CAR) and to an experimental stressor [19]. Pruessner and co-workers (2007) speculated that a larger hippocampus may require increased cortisol concentrations for optimal functioning. However, we found no association between $\mathrm{HV}$ and cortisol stress-reactivity in the control group. Differences in cortisol measures between the current study and the study by Pruessner and colleagues may constitute one explanation for the discrepant findings. Cortisol responses to laboratory stress and to awakening may affect different aspects of HPA axis reactivity than the reactivity to everyday hassles, which are likely more subtle stimuli. Nevertheless, the control participants with larger HV reported elevated emotional stress-reactivity to naturally occurring stressors compared to those with smaller $\mathrm{HV}$, which corresponds to the cortisol reactivity findings reported by Pruessner and colleagues (2007).

\section{Strength and weaknesses}

This study has several limitations. First, use of ESM booklets instead of electronic devices means that the exact timing of participants' self- reports and saliva samples cannot be firmly established [48]. However, results of a study comparing self-reported and electronically monitored saliva collection times, with the same intensive, semirandom time-sampling protocol used in the current study, indicated that saliva was generally collected very close to the prescribed time and that self-reported collection times corresponded well with the electronic time-stamps [49]. Another comparative study concluded that paper and electronic diaries yield similar results [50]. Second, no saliva samples were taken at the time of awakening, so that the current dataset does not allow examination of the CAR, a measure of HPA axis activity that appears to be blunted in first-episode psychosis [14] and may be associated with HV [19].

The current study also had some specific strengths. In particular, the repeated sampling of salivary cortisol over 6 days takes into account the well-known but often ignored unreliability of cortisol measures obtained at infrequent intervals [51]. Multiple cortisol measures per person were complemented by a relatively large number of participants. Use of multilevel modeling allowed assessment of withinperson associations between cortisol and subjective experience in real time and real-life contexts, as moderated by HV. Although cortisol measures were within the normal range, intensive sampling revealed different patterns of HPA activity with 
different HVs. Moreover, we combined measures of emotional and cortisol stresssensitivity with HV size, allowing a more comprehensive examination of HPA axis functioning. 
Table 1. Subject demographics

\begin{tabular}{|c|c|c|c|c|}
\hline & Controls & Siblings & Patients & Test statistic + \\
\hline & $(n=32)$ & $(n=37)$ & $(n=20)$ & $\mathrm{p}$-value \\
\hline Age, years: mean (SD) & $31.7(11.4)$ & $28.3(7.8)$ & $29.1(8.0)$ & $\mathrm{F}=1.95 \mathrm{P}=0.15$ \\
\hline Gender (male:female) & $10: 22$ & $14: 23$ & 11:09 & $X 2=2.97 P=0.23$ \\
\hline Completed education & $5.8(1.8)$ & $5.3(2.2)$ & $4.7(1.8)$ & $F=5.49 P=0.00$ \\
\hline \multicolumn{5}{|l|}{ PANSS Scores } \\
\hline Mean positive scale (SD) & $7.4(1.3)$ & $7.5(1.1)$ & $12.4(5.1)$ & $F=10.00 P=0.00$ \\
\hline Mean negative scale (SD) & $8.0(0.2)$ & $8.2(1.0)$ & $10.8(3.3)$ & $F=9.15 P=0.00$ \\
\hline Mean disorganization scale (SD) & $10.2(0.4)$ & $10.2(0.5)$ & $31.4(4.1)$ & $F=8.65 P=0.00$ \\
\hline Mean excitement scale (SD) & $8.3(0.6)$ & $8.4(1.1)$ & $9.9(2.1)$ & $F=5.38 P=0.00$ \\
\hline Mean emotional distress scale (SD) & $9.5(2.5)$ & $9.9(2.3)$ & $14.2(5.0)$ & $\mathrm{F}=7.56 \mathrm{P}=0.00$ \\
\hline Mean alcohol use present state (SD) & $6.1(8.7)$ & $7.6(9.2)$ & $4.9(6.6)$ & $F=1.64 P=0.19$ \\
\hline Mean cigarettes use present state (SD) & $1.1(3.9)$ & $1.8(4.6)$ & $12.1(11.9)$ & $F=7.86 P=0.00$ \\
\hline \multicolumn{5}{|l|}{ Cannabis use } \\
\hline Mean cannabis use last 12 months (SD) & $1.6(8.8)$ & $3.4(12.6)$ & $34.3(99.8)$ & $\mathrm{F}=1.68 \mathrm{P}=0.18$ \\
\hline Mean cannabis use lifetime (SD) & $16.8(34.4)$ & $19.6(35.7)$ & $54.2(48.0)$ & $\mathrm{F}=4.49 \mathrm{P}=0.00$ \\
\hline \multicolumn{5}{|l|}{ Hard drug use } \\
\hline Mean hard drug use last 12 months (SD) & $1.6(9.2)$ & $0.0(0.0)$ & $5.0(18.2)$ & $F=0.78 P=0.51$ \\
\hline Mean hard drug use life time(SD) & $3.4(13.0)$ & $5.1(15.4)$ & $40.5(73.05)$ & $\mathrm{F}=3.48 \mathrm{P}=0.02$ \\
\hline \multicolumn{5}{|l|}{ Antipsychotics } \\
\hline Type AP (typical:atypical) & & & $2: 16$ & \\
\hline Mean haloperidolequivalent present state(SD) & & & $2.4(1.9)$ & \\
\hline Mean lifetime AP use in haloperidolequivalent (SD) & & & $48.2(47.1)$ & \\
\hline Mean lifetime estrogen exposure ${ }^{1}$ (SD) & $17589(31700)$ & $18474(29410)$ & $672(2013)$ & $F=9.23 P=0.00$ \\
\hline Scan type (MDEFT:ADNI) & 23:09 & $26: 11$ & $16: 04$ & $X 2=0.7 P=0.72$ \\
\hline
\end{tabular}

Abbreviations: PANSS, Positive and Negative Syndrome Scale; AP, antipsychotic

${ }^{1}$ months use of oral contraceptives multiplied with micrograms estrogen (of the corresponding oral contraceptive) per month

$\mathrm{F} / \mathrm{Chi}^{2}$ and $\mathrm{P}$-values refer to between-group differences 


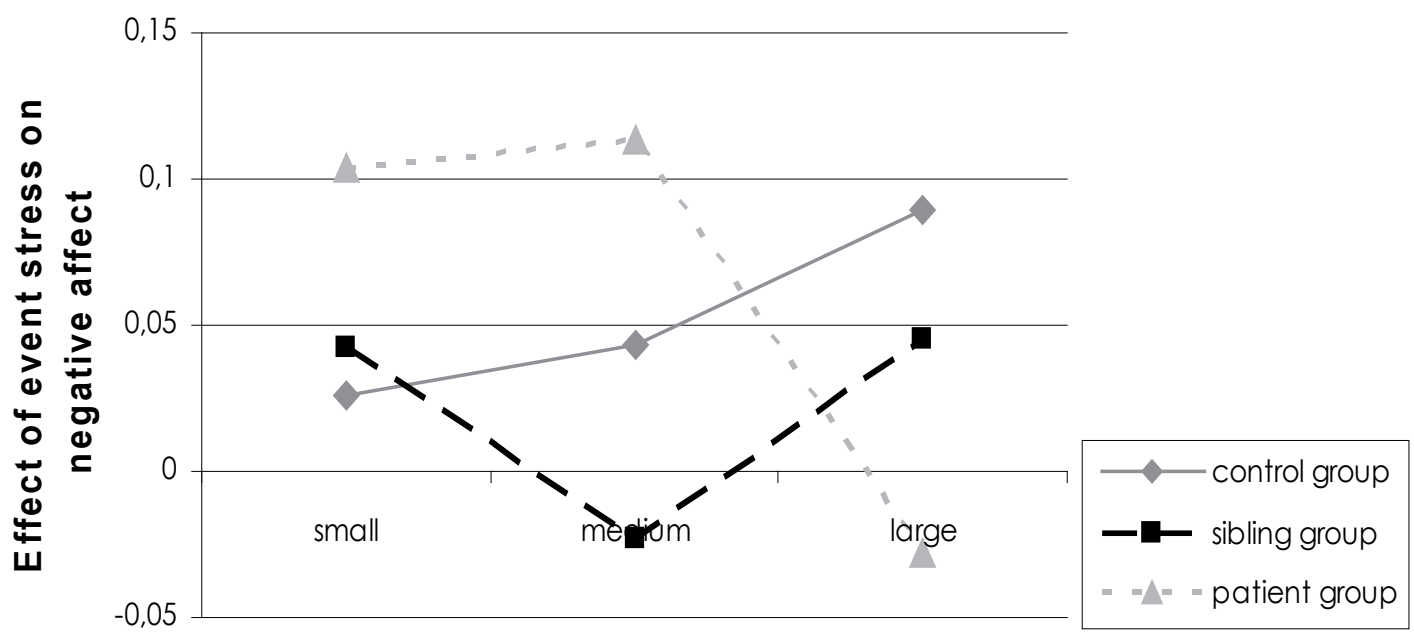

Left Hippocampal Volume Size

Figure 1. Emotional stress-reactivity stratified by hippocampal volume, in control, sibling and patient groups: Multilevel estimates of the effects of daily events on negative affect. The models control for age, gender, intracranial volume and scan type. Effects are unstandardized regression coefficients. 


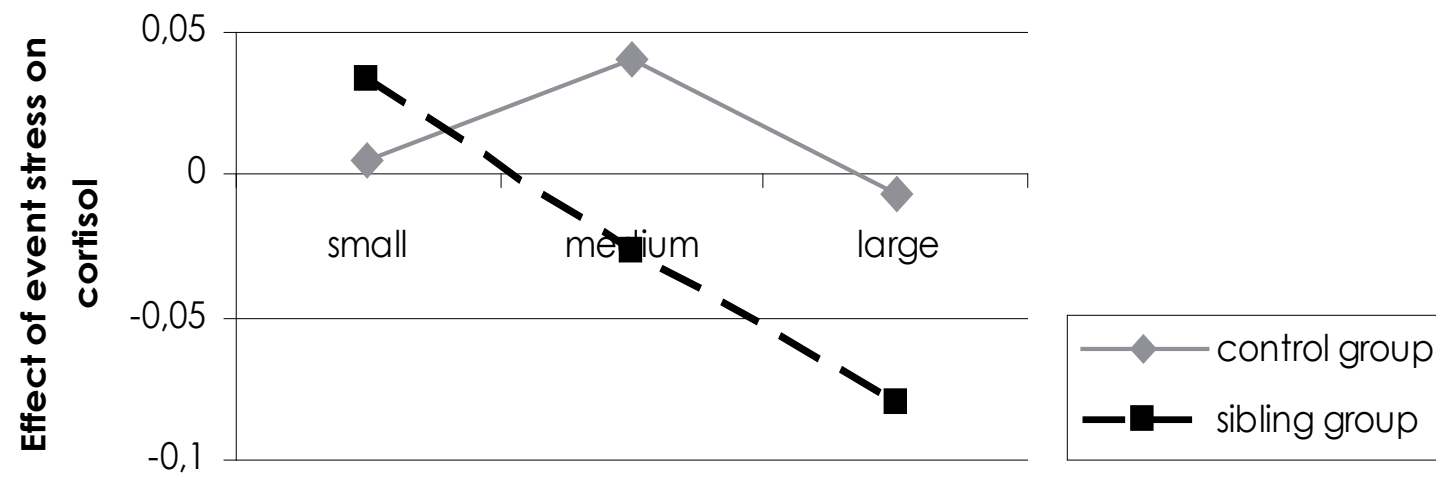

\section{Left Hippocampal Volume Size}

Figure 2. Biological stress-reactivity stratified by hippocampal volume, in sibling and control groups: Multilevel estimates of the effects of daily events on cortisol. The dependent variable is log-transformed cortisol (Incort). The models control for time, age, gender, oral estrogen exposure, recent food intake, recent smoking and intracranial volume, and scantype. Effects are unstandardized regression coefficients. 


\section{References}

1. Geuze, E., E. Vermetten, and J.D. Bremner, MR-based in vivo hippocampal volumetrics: 2. Findings in neuropsychiatric disorders. Mol Psychiatry, 2005. 10(2): p. 160-84.

2. Steen, R.G., et al., Brain volume in first-episode schizophrenia: systematic review and meta-analysis of magnetic resonance imaging studies. Br J Psychiatry, 2006. 188: p. 510-8.

3. Wright, I.C., et al., Metaanalysis of regional brain volumes in schizophrenia. Am J Psychiatry, 2000. 157(1): p. 16-25.

4. Vita, A., et al., Brain morphology in first-episode schizophrenia: a meta-analysis of quantitative magnetic resonance imaging studies. Schizophr Res, 2006. 82(1): p. 75-88.

5. Lawrie, S.M., et al., Brain structure and function changes during the development of schizophrenia: the evidence from studies of subjects at increased genetic risk. Schizophr Bull, 2008. 34(2): p. 330-40.

6. Boos, H., et al., Brain volumes in relatives of patients with schizophrenia: a meta-analysis. 2007, Am Med Assoc. p. 297.

7. Corcoran, C., et al., The stress cascade and schizophrenia: etiology and onset. Schizophrenia Bulletin, 2003. 29(4): p. 671-92.
8. O'Brien, J.T.,

The'glucocorticoid

cascade'hypothesis in man:

prolonged stress may cause permanent brain damage.

1997, Maney. p. 199-201.

9. Sapolsky, R.M., Glucocorticoids and hippocampal atrophy in neuropsychiatric disorders. 2000, Am Med Assoc. p. 925.

10. Buchanan, T.W., D. Tranel, and C. Kirschbaum, Hippocampal damage abolishes the cortisol response to psychosocial stress in humans. Horm Behav, 2009. 56(1): p. 44-50.

11. Jacobson, L. and R. Sapolsky, The role of the hippocampus in feedback regulation of the hypothalamic-pituitaryadrenocortical axis. Endocr Rev, 1991. 12(2): p. 118-34.

12. Lupien, S.J., et al., Cortisol levels during human aging predict hippocampal atrophy and memory deficits. 1998, Nature Publishing Group. p. 69-73.

13. Knoops, A.J.G., et al., Basal Hypothalamic Pituitary Adrenal Axis Activity and Hippocampal Volumes: The SMART-Medea Study. 2011, Elsevier.

14. Mondelli, $\mathrm{V}_{\text {., }}$ et al. Abnormal cortisol levels during the day and cortisol awakening response in firstepisode psychosis: the role of stress and of antipsychotic treatment. Schizophr Res, 2010. 116(2-3): p. 234-42.
15. Pruessner, J.C., et al., Stress regulation in the central nervous system: evidence from structural and functional neuroimaging studies in human populations - 2008 Curt Richter Award Winner. Psychoneuroendocrinology, 2008. 35(1): p. 179-91.

16. Tessner, K.D., et al., The relation of cortisol levels with hippocampus volumes under baseline and challenge conditions. 2007, Elsevier. p. 70-78.

17. Myin-Germeys, I., P. Delespaul, and J. van Os, Behavioural sensitization to daily life stress in psychosis. Psychological Medicine, 2005. 35(5): p. 733-41.

18. Myin-Germeys, l., et al., Emotional reactivity to daily life stress in psychosis. Archives of General Psychiatry, 2001. 58(12): p. 1137-44.

19. Pruessner, M., et al., The associations among hippocampal volume, cortisol reactivity, and memory performance in healthy young men. Psychiatry Res, 2007. 155(1): p. 1-10.

20. Mondelli, V., et al., Higher cortisol levels are associated with smaller left hippocampal volume in first-episode psychosis. Schizophr Res, 2010. 119(1-3): p. 75-78.

21. G.R.O.U.P., Evidence that Familial Liability for Psychosis is Expressed as Differential Sensitivity to Cannabis: an Analysis of Patient-Sibling and Sibling-Control Pairs. Archives of General Psychiatry, 2011. in press. 
22. Maxwell, M.E., Family Interview for Genetic Studies (FIGS): Manual For FIGS. 1992, Clinical Neurogenetics Branch, Intramural Research Program, National Institute of Mental Health, Bethesda, MD.

23. APA, Diagnostic and statistical manual of mental disorders. 4th ed. 2000, Washington, DC: American Psychiatric Association.

24. Andreasen, N.C., M. Flaum, and S. Arndt, The

Comprehensive Assessment of Symptoms and History (CASH). An instrument for assessing diagnosis and psychopathology. Arch Gen Psychiatry, 1992. 49(8): p. 61523.

25. Kay, S.R., A. Fiszbein, and L.A. Opler, The positive and negative syndrome scale (PANSS) for schizophrenia. Schizophrenia Bulletin, 1987. 13(2): p. 261-76.

26. Cahn, W., et al., Brain volume changes in firstepisode schizophrenia: a 1year follow-up study. Arch Gen Psychiatry, 2002. 59(11): p. 1002-10.

27. WHO, Composite International Diagnostic Interview (CIDI). 1990, World Health Organization: Geneva.

28. Csikszentmihalyi, M. and R. Larson, Validity and reliability of the Experience-Sampling Method. Journal of Nervous and Mental Disease, 1987. 175(9): p. 526-36.
29. Myin-Germeys, l., et al., Experience sampling research in psychopathology: opening the black box of daily life. Psychological Medicine, 2009. 39(9): p. 1533-47.

30. Delespaul, P., M. deVries, and J. van Os, Determinants of occurrence and recovery from hallucinations in daily life. Social Psychiatry and Psychiatric Epidemiology, 2002. 37(3): p. 97-104.

31. Jacobs, N., et al., $A$ momentary assessment study of the relationship between affective and adrenocortical stress responses in daily life. Biol Psychol, 2007. 74(1): p. 606.

32. Jacobs, N., et al., $A$ momentary assessment study of the relationship between affective and adrenocortical stress responses in daily life. Biological Psychology, 2007. 74(1): p. 60-6.

33. Sulon, J., et al., Radioimmunoassay of corticosterone, cortisol and cortisone: their application to human cord and maternal plasma. J Steroid Biochem, 1978. 9(7): p. 671-6.

34. Dale, A.M., B. Fischl, and M.I. Sereno, Cortical surface-based analysis. I. Segmentation and surface reconstruction. Neuroimage, 1999. 9(2): p. 179-94.

35. Fischl, B. and A.M. Dale, Measuring the thickness of the human cerebral cortex from magnetic resonance images. Proc Natl Acad Sci U S A, 2000. 97(20): p. 11050-5.
36. Fischl, B., et al., Whole brain segmentation: automated labeling of neuroanatomical structures in the human brain. Neuron, 2002. 33(3): p. 341-55.

37. Fischl, B., M.I. Sereno, and A.M. Dale, Cortical surfacebased analysis. Il: Inflation, flattening, and a surfacebased coordinate system. Neuroimage, 1999. 9(2): p. 195-207.

38. Han, X., et al., Reliability of MRI-derived measurements of human cerebral cortical thickness: the effects of field strength, scanner upgrade and manufacturer. Neuroimage, 2006. 32(1): p. 180-94.

39. Jovicich, J., et al., Reliability in multi-site structural MRI studies: effects of gradient non-linearity correction on phantom and human data. Neuroimage, 2006. 30(2): p. 436-43.

40. Segonne, F., et al., A hybrid approach to the skull stripping problem in MRI. Neuroimage, 2004. 22(3): p. 1060-75.

\section{StataCorp, STATA/SE} statistical software, release 11 . 2009, Texas: College Station.

42. Meador-Woodruff, J.H. and J.F. Greden, Effects of psychotropic medications on hypothalamic-pituitaryadrenal regulation. 1988. p. 225. 
43. Seidman, L.J., et al., Left hippocampal volume as a vulnerability indicator for schizophrenia: a magnetic resonance imaging morphometric study of nonpsychotic first-degree relatives. 2002, Am Med Assoc. p. 839.

44. Gunduz-Bruce, H., et al., Cortisol levels in relation to hippocampal sub-regions in subjects with first episode schizophrenia. 2007, Elsevier. p. 281-287.

45. Myin-Germeys, I. and J. van Os, Stress-reactivity in psychosis: evidence for an affective pathway to psychosis. Clinical Psychology Review, 2007. 27(4): p. 409-24.

46. Lataster, T., et al., Evidence for a familial correlation between increased reactivity to stress and positive psychotic symptoms. Acta Psychiatr Scand, 2010. 122(5): p. 395-404.

47. Szeszko, P.R., et al., Increased stress and smaller anterior hippocampal volume. Neuroreport, 2006. 17(17): p. 1825-8.

48. Stone, A.A., et al., Patient non-compliance with paper diaries. Bmj, 2002. 324(7347): p. 1193-4.

49. Jacobs, N., et al., Electronic monitoring of salivary cortisol sampling compliance in daily life. Life Sciences 2005. 76(21): p. 2431-43.

50. Green, A.S., et al., Paper or plastic? Data equivalence in paper and electronic diaries. Psychological Methods, 2006. 11(1): p. 87-
51. Hruschka, D.J., B.A. Kohrt, and C.M. Worthman,

Estimating between-and within-individual variation in cortisol levels using multilevel models.

Psychoneuroendocrinology, 2005. 30(7): p. 698-714. 



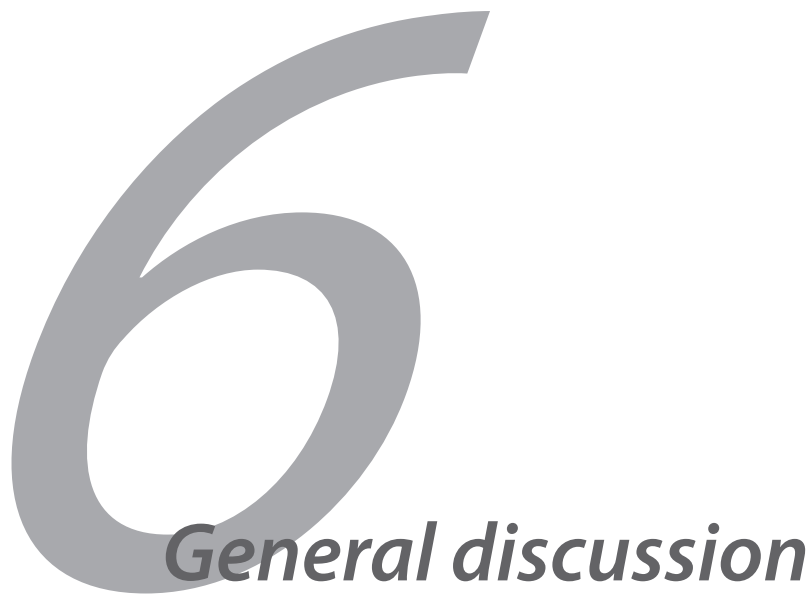


Psychotic disorder is a highly heterogeneous disorder of which the aetiology remains elusive. Childhood trauma, cannabis use and stress are known environmental risk factors that increase the risk for developing a psychotic disorder. However, the impact of these environmental risk factors is less than the risk related to having a first-degree relative (1). Using twin and adoption studies, researchers have found that $80 \%$ of the liability for psychotic disorder has a genetic origin $(2,3)$ although consistent evidence for genes involved in psychotic disorder is still lacking. With regard to genetic effects on the brain in individuals with psychotic disorder, there is evidence for both indirect and direct genetic effects. In this respect, environmental factors are assumed to contribute to brain alterations in psychotic disorder, and genetic effects could be misinterpreted when not taking environmental factors into account (4). For example, the pathway to psychotic disorder may involve gene-environment interactions influencing pathological processes of early brain development, such as neuronal loss and synaptic pruning, which continue to unfold as the brain matures during adolescence. These neurodevelopmental abnormalities may lead to the activation of pathological neural circuits and consequently to the emergence of symptoms in response to cumulative genetic and environmental interplay (5). In other words, the brain may be differentially sensitive to certain environments due to genetic vulnerability associated with the risk for psychotic disorder (i.e., gene-environment interaction). Alternatively, it may be that genes contribute to the tendency of individuals to expose themselves to adverse environments, which, in turn, may lead to an indirect genetic, causal effect of the environment on brain alterations associated with the illness phenotype (i.e., geneenvironment correlation).

In summary, it is likely that the interplay between genes and environment is related to brain phenotypes in psychotic disorder. However, this association is customarily ignored in neuroimaging studies. The studies described in this thesis aimed at identifying genetic and environmental factors that are associated with brain alterations in psychotic disorder using a genetically sensitive study sample.

\section{STRUCTURAL CEREBRAL INTERMEDIATE PHENOTYPE}

\section{Cortical thickness}

Investigating genetic effects without measuring genes directly can be done using the intermediate phenotype approach. The rationale behind this is to find phenotypes 
with a simpler genetic basis than the genetically complex and etiologically heterogeneous psychotic disorder genotype. Before a biological marker can be defined as an intermediate phenotype, several definitions have to be fulfilled: the intermediate phenotype (1) should be associated with psychotic disorder, (2) should be heritable, (3) should be present even when the illness is not active, (4) should cosegregate with psychotic disorder within families, (5) should be present at higher rates in unaffected family members when compared to the general population (6). In chapter 2, a family study design was used to examine the influence of different genetic risk levels for psychotic disorder on surface-based cortical thickness measures. Analyses showed some decreases in overlapping regions in patients with psychotic disorder and their healthy siblings. Shared cortical decrements were found in frontal, temporal, parietal and occipital regions in the two groups at higher than average genetic risk for psychosis. These regions, which may be potential intermediate phenotypes, were part of two different brain networks: i) the heteromodal association cortical regions and ii) the network involved in sensory gating. The heteromodal association cortex is involved in the integration of sensory, motor and behavioural activities with drive and mood, resulting in an integrated network critically important for attention, language, working memory and executive function $(7,8)$. Whereas the heteromodal association cortex is involved in integration, sensory gating reflects the ability to filter out redundant and/or distracting sensory information, thus allowing the brain to focus on a (first) stimulus preventing overstimulation or distraction by other stimuli. Delusions and hallucinations may, consequently, arise from an individual's response to an erroneous attribution of salience to external and internal stimuli. In short, the widespread cortical alterations in patients and siblings provides further evidence for the suggestion that psychotic disorder is not a disorder of a single brain area but rather a disorder of several brain regions being part of various networks $(9,10)$. In the highest genetic risk group, alterations were much more pronounced and widespread than in the sibling group, possibly reflecting a more dysfunctional brain network. Siblings shared some of the cortical thickness decrements with their ill family member and, additionally, showed some specific alterations though they have not expressed the clinical phenotype. It could be hypothesised that brain networks are flexible and able to compensate for certain failures up to a certain threshold. When the threshold is exceeded, failures in one or more networks may result in altered information processing and the expression of overt psychotic symptoms. Accordingly, smaller failures in the network 
may contribute to the development of symptoms on a subclinical level.

The finding that siblings shared some brain alterations with their ill family member suggests a genetic influence, which is in accordance with twin studies reporting grey matter volume reductions in twins discordant for schizophrenia and showing that the greatest similarity in affected brain areas was present in monozygotic twins as compared to dizygotic twins $(11,12)$,. It can be hypothesised that with lower genetic loading, brain alterations become more subtle. The brain alterations in siblings were indeed subtle and some of the variation in cortical thickness could be explained by cannabis use (as was also the case in patients), which was demonstrated by the association between cannabis use and cortical thickness and by the fact that the group-specific thinning in siblings disappeared after correction for cannabis use. Upon correction, the shared regions between patients and siblings remained significant, suggesting that these alterations are not fully conditional on this environmental influence and may be caused by shared genetic factors in the patients and siblings.

In summary, the genetic vulnerability for psychotic disorder may be associated with cortical thinning in regions involved in brain networks associated with several cognitive functions and with psychotic symptomatology. In addition to the shared genetic vulnerability that may influence cortical thickness in certain brain areas, environmental factors, specific (epi)genetic effects or gene-environment interactions may be determinants of patient- or sibling-specific cortical thinning in other areas.

\section{DIFFERENTIAL SENSITIVITY TO THE ENVIRONMENT}

\section{Childhood trauma and cortical thickness}

There is accumulated evidence for an association between psychotic disorder and childhood trauma (13-15), but studies investigating this relationship are prone to bias. For example, patients with psychotic disorder may report more childhood trauma because of their illness. However, if indeed a reporting bias would be the basis of the association between psychotic disorder and childhood trauma, this could not explain why a difference in cortical thickness between exposed and non-exposed patients (and particularly siblings) is greater than between exposed and non-exposed controls. Therefore, in an attempt to circumvent bias, the study presented in chapter $\mathbf{3}$ used an objective biological measure (i.e., cortical thickness) as an outcome measure instead of the usual illness phenotype. It was examined 
whether the effect of trauma on cortical thickness was conditional on genetic risk for psychotic disorder. The analyses revealed that patients exposed to higher levels of trauma in childhood had significantly lower cortical thickness values. This was not found in the controls. Siblings (although not significantly different from controls) displayed increased cortical thickness with increasing childhood trauma levels. This directionally opposite finding in siblings may represent chance or noise. Alternatively, siblings and controls may differ from patients in that the effect of exposure to traumatic experiences on cortical thickness may be neutral (controls) or even trophic (siblings). The existence of differential sensitivity to trauma is likely not the only moderator of the outcome. Differences in psychological adaptation, resilience and coping styles may be important mitigators of the risk for later psychotic outcomes.

Moreover, as siblings in this study experienced less childhood trauma compared to their ill relatives, mediation (i.e., genetically influenced differential exposure to the environment) may constitute part of the underlying mechanisms leading to psychosis. Research has shown that harsh parental behaviours directed at one person in the family may have protective effects for the other children in the family, a phenomenon called the sibling barricade (16), suggesting that, given shared genetic liability, differential exposure to trauma may result in illness in only one sib of the sibling pair (17). As mentioned before, patients reported more childhood trauma than controls and siblings with no difference in childhood trauma exposure between the latter two groups. Therefore, no definite conclusions can be drawn regarding the exact mechanism, but as mediation does not exclude moderation and vice versa, the difference in clinical expression between patients and siblings may well be due to a combination of both mechanisms (differential exposure and sensitivity to the environment).

Lastly, the findings may reflect genetic plasticity (64), indicating that the same gene may confer positive sensitivity to an exposure in some environments but negative sensitivity in others. For example, research has shown that a polymorphism in FKBP5, a modulator of glucocorticoid receptor (GR) sensitivity, influences the association between childhood trauma and later development of posttraumatic stress. FKBP5 showed reduced expression in PTSD, consistent with enhanced GR responsiveness, but only in interaction with developmental trauma (18). FKBP5 is located on chromosome 6p21, a chromosomal region associated with psychotic disorder (19) and, therefore, a candidate gene to use in the investigation of the relation between 
developmental trauma and psychotic disorder. It could be argued that differences in FKBP5 aggravate or diminish the effects of childhood trauma on the stress hormone system, thereby altering HPA axis sensitivity and risk for psychotic disorder.

\section{Cannabis use and cortical thickness}

Cannabis use has been linked to the development of psychosis (20), but the role of cannabis use in brain alterations evidenced in psychotic disorder is not clear. In chapter 3, it was examined whether there was an effect of cannabis use on cortical thickness and, in addition, whether this was conditional on a genetic risk for psychotic disorder. The results showed that exposure to cannabis was associated with cerebral cortical thinning in individuals at high (patients) and intermediate (siblings) genetic risk for psychotic disorder whereas this was not the case for those at low genetic risk (controls). Furthermore, there was a suggestion of a similar pattern of regional thinning in the frontal and parahippocampal regions in patient and sibling cannabis users. The finding that cannabis use had a differential impact on cortical thickness not only in patients but also in siblings extended earlier findings, indicating that gene-environment interactions may underlie the association between cannabis use and psychosis (21-24). For example, evidence for a gene-environment interaction between psychosis and cannabis use has been found for the cathechol-Omethyltransferase (COMT) VAL ${ }^{158}$ Met gene. Val allele carriers of the COMT gene are more prone to develop psychotic symptoms or later psychotic disorder with cannabis use than carriers of the MET allele $(21,23)$. Furthermore, a recent study provided evidence for the involvement of AKT1 in the association between psychosis and cannabis use (25). Genetic variation in AKT1 moderated the relationship between recent cannabis use and the level of schizotypy in siblings of patients with psychotic disorder. Also, increased risk allele loading in patients was associated with increased sensitivity to lifetime cannabis use. In healthy individuals, the AKT1 A allele was found to be associated with lower grey matter volume in the prefrontal lobe. In addition, evidence was found for gene-gene (epistatic) interaction in that subjects with both the COMT Val allele and the AKT1 A allele had lower prefrontal grey matter volumes than subjects with only the AKT1 A allele, relating the AKT1 polymorphism to mechanisms that may influence altered dopamine signalling (26).] 


\section{Stress-sensitivity and volumetric proxy measures for HPA axis}

\section{functioning}

Previous research suggests that patients with psychotic disorder and their siblings demonstrate greater increases in negative affect as a response to daily life stressors than healthy control subjects, suggesting that increased reactivity to stress is associated with a genetic risk for psychotic disorder $(27,28)$. Altered volumes of the pituitary gland have also been associated with stress and with increased vulnerability for psychotic disorder; for example, increased pituitary volumes have been found in patients with psychotic disorder (29), siblings of patients with psychotic disorder (30) and in subjects at ultra-high risk (31). The pituitary gland is a crucial organ involved in the HPA axis stress response and regulates cortisol secretion in response to stressful events (Figure 1A). Persistently elevated cortisol levels can decrease the activity of the negative feedback mechanism on the HPA axis, controlled by the hippocampus (32), resulting in a sensitised state of HPA axis hyperactivity (Figure 1B). Pituitary volume can, therefore, be viewed as a proxy measure for HPA axis functioning. As a result of HPA axis hyperactivity, patients become more sensitive to stressors, a phenomenon called stress-sensitisation (33). Stress-sensitisation occurs when early and/or frequent exposures to stressors alter the stress response system, sensitising individuals to later stress and leading to increased biological and behavioural responses to that stressor even when less severe than the original stressor (33). Given the fact that many environmental risk factors associated with psychotic disorder may reflect certain types of stressors (trauma, life events and daily life stressors, discrimination, migration, urbanicity), stress-sensitisation possibly represents a common underlying mechanism (33). Nevertheless, stress-reactivity has never been directly examined in relation to HPA axis functioning in psychotic disorder. In chapter 4, the relationship between biological (cortisol) and emotional stress-reactivity and pituitary volume was examined as a function of genetic risk for psychotic disorder. Cortisol measures were only available for siblings and controls. Although pituitary volume was not significantly different between the groups, higher pituitary volume was significantly associated with increased emotional stress-reactivity in all three groups (patients with psychotic disorder, siblings and controls). This association was significantly stronger in the patient group than in the siblings and controls, suggesting a process of progressive sensitisation mediating the clinical outcome. The siblings did not differ from controls with regard to cortisol reactivity nor was there an interaction between group status and pituitary volume in the model of 
biological stress-reactivity. Emotional and biological stress-reactivity in siblings appeared to be associated and showed a similar pattern as in controls although baseline cortisol measures were higher in siblings than in controls. It should be noted that power issues may have led to type II errors in the sibling analyses.

Higher pituitary volume may be the result of differential functional states, such as increased stress-sensitivity/hypercortisolism or, vice versa, pituitary volume may contribute causally to increased stress-sensitivity. If the latter were true, it can be hypothesised that pre-existing individual differences in regional brain morphology partly increase vulnerability to (or decrease resiliency against) life stressors. These individual differences may emerge early in life, resulting from a combination of genetic and developmental influences (34).

Another proxy for HPA axis functioning may be the hippocampal volume as the hippocampus plays an essential role in regulating emotional responses to stressful stimuli and has an important role in the negative feedback mechanisms on the HPA axis (35-37). However, repeated heightened cortisol levels can decrease the activity of the negative feedback mechanism from the hippocampus on the hypothalamus (38), which may result in a sensitised state of HPA axis hyperactivity (Figure 1B). In humans, hippocampal atrophy is cross-sectionally accompanied by hyperactivity of the HPA axis and elevated levels of cortisol (39). Furthermore, reduced hippocampal size has been well established in patients with a psychotic disorder (40-43), and recent studies have shown that similar brain abnormalities in hippocampal volume reduction are present in first-degree relatives of patients with psychotic disorder (44, 45), suggesting that hippocampal volume changes may constitute part of the liability for psychosis. However, the association of hippocampal volume with biological and emotional real life stress-reactivity has never been examined. In chapter $\mathbf{5}$, it was hypothesised that increased stress-reactivity could be associated with lower hippocampal volume and that this association would be moderated by the genetic risk for psychotic disorder. Results indicated that patients with smaller hippocampal volume had a greater increase in negative affect in reaction to stress, which was not found in siblings. With regard to biological stress-reactivity, siblings with reduced hippocampal volume exhibited increased cortisol reactivity. This discrepancy between the emotional and biological stress-reactivity pattern in siblings might suggest that, even with an increased biological reactivity, siblings manage to cope better with stress and/or have higher resilience and, consequently, display a 
relatively healthy emotional stress-reactivity. Although no definite conclusion can be drawn on the direction of this association using a cross-sectional study, studies in mice have shown that repeated exposure to stress and associated glucocorticoid excess can alter hippocampal neurons or induce changes in the gross morphology of the hippocampus (46). It could be hypothesised that repeated stress can alter hippocampal morphology, which, in turn, may lead to a malfunctioning negative feedback mechanism resulting in HPA axis hyperfunctioning

In short, lower hippocampal volume was associated with increased emotional reactivity in patients and increased cortisol reactivity in siblings, suggestive of a genetic influence. The lack of emotional reactivity in siblings may be a true effect, thus reflecting better coping styles or higher resilience, or it may be a false negative finding.

The studies described in chapters $\mathbf{4}$ and $\mathbf{5}$ provide further evidence for a malfunctioning of the HPA axis in patients with psychotic disorder assuming hippocampal volume, pituitary volume and elevated cortisol levels can be considered proxy measures for HPA axis functioning. Integrating the results from both chapters, that is higher pituitary volume and lower hippocampal volume associated with increased stress-reactivity at the behavioural level in patients with psychotic disorder, it may be concluded that the neural diathesis-stress model of stress-induced HPA axis hyperactivity $(32,38)$ (Figure 1 B) can also be applied to daily life stressors. A comparable observation in depression is that HPA axis hyperactivity is thought to reflect a lack of negative inhibitory feedback by circulating cortisol on the HPA axis, especially at the level where pituitary cells produce ACTH, leading to an increase in the size and number of these cells (47). In siblings, increased stressreactivity (at the endocrinological level) was associated with lower hippocampal volumes. This finding was consistent with the results on the behavioural level (emotional stress-reactivity) in patients. However, with regard to pituitary volume, there was no interaction between group and pituitary volume on cortisol reactivity. The only evidence for HPA axis hyperactivity was higher baseline cortisol levels in siblings than in controls. It cannot, therefore, be concluded at this stage whether emotional stress-reactivity patterns in siblings and patients are associated and qualitatively different from controls or dissociated from each other. In both studies, however, there was evidence for certain biological differences in siblings that may fit the altered (emotional) stress-reactivity pattern in patients, indicating genetically 
influenced HPA axis hyperactivity in psychotic disorder.

One could speculate in two ways about the direction of the effect: do smaller hippocampal volume and, consequently, a disruption of the negative feedback lead to increased pituitary volume or does larger pituitary volume lead to an excess of cortisol, causing a toxic effect on the hippocampus, reflected by smaller volumes? Although the start of the sensitisation process might not be clear, both brain structures are part of a functional brain circuitry, likely affecting each other. Evidence suggests that alterations in both structures are present before the onset of the disease $(31,48)$, but detailed information about the timing of these structural alterations during development is lacking. There are studies, however, suggesting that the morphology of the two structures may change over time. For example, FEP patients have shown increased pituitary volumes whereas patients with a chronic psychotic disorder have shown decreased pituitary volume (29). Similarly, hippocampal volumes may change over time, (49) and hippocampal deficits may be reversed after antidepressant therapy (50), suggesting that various processes influence the plasticity of brain structures over time.

Taken together, the studies described in chapters $\mathbf{4}$ and $\mathbf{5}$ indicate that volumetric alterations in brain structures involved in HPA axis functioning are associated with increased stress-reactivity in patients with psychotic disorder and, to a certain extent, in siblings of these patients. The association between altered brain structures involved in the HPA axis and increased reactivity to stress extends the neural diathesis-stress model of psychotic disorder to small daily life stressors. 


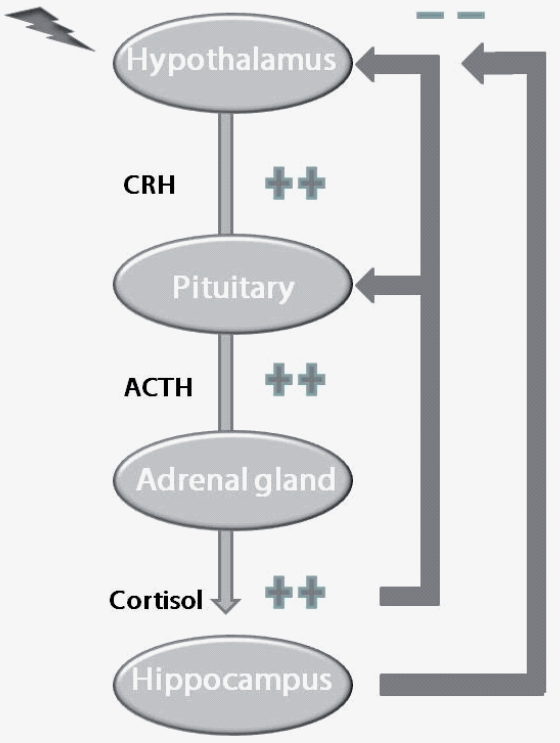

Normal HPA-axis functioning
STRESS

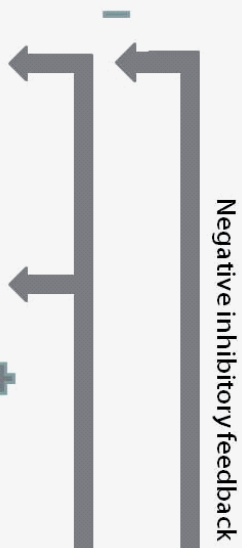

HPA-axis hyperfunctioning

Figure 1. Exposure to stress activates the HPA axis through the release of corticotropin releasing hormone $(\mathrm{CRH})$ in the hypothalamus, resulting in secretion of adrenocorticotropic hormone $(\mathrm{ACTH})$ in the pituitary, stimulating the release of cortisol in the adrenal gland. Cortisol, through a negative feedback mechanism (via the hippocampus, hypothalamus and pituitary) regulates HPA axis activity (A). One theory could be that persistently elevated cortisol levels associated with increased pituitary volume, may lead to smaller hippocampi and consequently to a diminished negative feedback, resulting in a sensitised state of HPA axis hyperactivity (B). 
The studies in this thesis provide evidence for associations between brain alterations and environmental risk factors such as childhood trauma, cannabis use, and daily life stress. This relationship could inherently result in positive psychotic symptoms through a common mechanism, that is, dopamine sensitisation $(1,51-53)$. Bearing in mind that an oversimplification is made of very complex mechanisms, such as psychosis, in which several neurotransmitter systems are involved, dopamine dysregulation may be a final step in a complex developmental cascade that starts early in life and ends with the onset of full-blown psychotic disorder at the adolescent or adult age (Figure 2). Taking cannabis use as an example, this exposure may ultimately impact dopamine sensitisation. In this thesis, cannabis-associated regional cortical thinning was found in individuals at high compared to low genetic risk for psychotic disorder with preliminary evidence for alterations in the frontal pole, entorhinal cortex and parahippocampal gyrus. It could be hypothesised that genetically determined frontal sensitivity to cannabis may affect the stressbuffering system, implying less top-down control, with subsequently increased subcortical dopamine levels. This, in combination with a direct effect of delta-9tetrahydrocannabinol $(\delta-9-\mathrm{THC})$, the active ingredient of cannabis, on dopamine transmission in the ventral tegmental area (VTA) and striatum (54), may eventually induce dopamine sensitisation from which psychotic symptoms arise. In addition, hippocampal alterations may be at the origin of striatal dopamine alterations $(55,56)$. Recent animal studies have suggested that altered activity of the ventral hippocampus may induce an increase in the number of spontaneously firing dopamine neurons in the VTA, which, in turn, may lead to pathological high levels of dopamine release in the limbic striatum (57). To date, it remains unclear whether the cannabis-associated alterations in cortical thickness reflect neuronal or glial loss, reduction in synaptic density or a change in cell size, all of which have been reported in rodent studies investigating the hippocampus $(58,59)$. In addition, glutamatergic effects of $\delta$-9-THC may affect grey matter volume and, possibly, cortical thickness through a mechanism of neurotoxicity $(60,61)$.

The pathway from stress to psychotic symptoms may also involve dopamine sensitisation. As mentioned before, altered frontal cortical alterations may affect the stress-buffering system, resulting in increased dopamine release in the limbic striatum. (62-64). In line with this hypothesis, it has been reported that patients with 
psychotic disorder show higher dopamine metabolite increases during metabolic stress than controls, and this dopamine metabolite increase was associated with lower (prefrontal) grey matter volume (65-67). In a recent PET study, subjects at increased psychometric risk for psychotic disorder had increased dopamine release compared to controls following a social stress task (68). Not only has current psychological stress been found to be associated with increased striatal dopamine release, but adverse early life experiences may moderate this association (69). Developmental trauma or other types of (chronic) adversity may alter HPA axis functioning (70) through hypersensitive glucocorticoid release or abnormalities in glucocorticoid receptors (47). In addition, studies in this thesis suggested that proxy measures for HPA axis hyperfunctioning (higher pituitary and lower hippocampal volume) are associated with increased reactivity to daily life stress in patients with psychotic disorder. As there is evidence for a synergistic relation between the activation of the HPA axis and the activation of dopaminergic circuits, increased glucocorticoid secretion may lead to increased dopamine activity in certain brain regions such as the ventral striatum and amygdala (64). In addition, some brain regions, such as the hippocampus or the prefrontal lobe, may be particularly sensitive to stressors (46, $64,71)$, possibly aggravating the effects by inducing dopamine sensitisation. In summary, although the exact mechanisms need to be elucidated, dopamine release in the limbic system can be increased by stress and cannabis exposure (72). Repeated exposure to these environmental factors may lead to prolonged changes in the functioning of the dopamine system and, eventually, to dopamine sensitisation (73). As subcortical dopamine systems are involved in incentive or motivational salience and reward prediction (74-76), dopamine sensitisation may lead to an aberrant assignment of salience to innocent stimuli $(75,77,78)$. Delusions and hallucinations could consequently arise from an individual's response to erroneous attribution of salience to external and internal stimuli (79). 


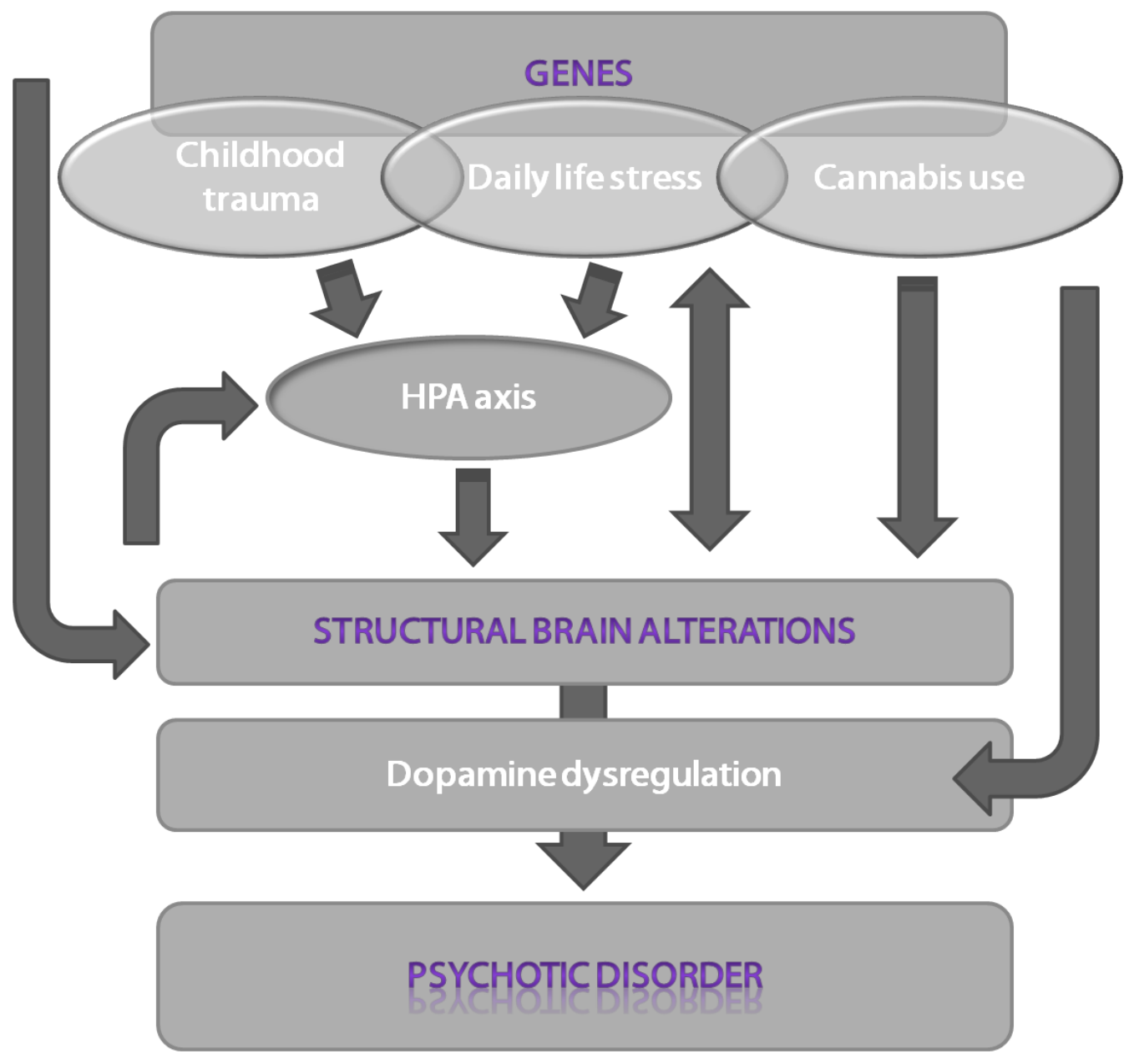

Figure 2 Pathways towards psychotic disorder

\section{THE PROBLEM OF HETEROGENEITY}

A significant amount of structural neuroimaging studies investigating brain alterations in psychotic disorder have become available over the last decade. This literature suggests that brain alterations related to psychotic disorder are smaller and more subtle than researchers originally believed would be the case. Furthermore, no specific brain alteration has been found to be pathognomonic for psychotic disorder. For instance, ventricle enlargement, which is reported in approximately $80 \%$ of the studies, is also observed in Alzheimer's disease (80) and bipolar disorder (81). Many, if not all, brain structures have been described in relation to schizophrenia. Reviews and meta-analyses provided evidence for decreased volume in the hippocampus 
in psychotic disorder, together with moderate evidence for frontal and temporal reductions $(9,41,42,82-85)$. The lack of consistency in 'group differences' in cortical and subcortical phenotypes among individual studies is likely the result of great variety in structural imaging processing and analysing techniques, available in a wide range of different software packages, applied to a highly heterogeneous phenotype. Thus, there not only is much heterogeneity in imaging methods but also there exists great variance in the clinical expression of psychotic disorder. Psychotic disorder is, according to the DSM-IV classification system, a categorical defined set of symptoms, suggesting qualitative differences between an ill and healthy individual. However, an extensive amount of epidemiological data have shown that (subclinical) psychotic symptoms are also present in the general population and that there is not only phenomenological continuity but also etiologic continuity (86). In other words, the factors associated with these minor psychotic symptoms are the same as those associated with the risk for psychotic disorder, that is, male, poor education, ethnic minority, and cannabis use (87). Therefore, suggestions have been made to drop the syndrome-oriented categorical representation and replace it with a symptom-oriented continuum representation of psychotic disorder $(86,88)$. Measuring differences in cortical thickness or other brain measurements between illness groups based on a dimensional classification rather than the classical categorical approach may increase consistency between results and may facilitate detection of etiologic overlap between disorders. To date, an interesting outcome of GWAS data analyses is that there appears to be a considerable genetic overlap between schizophrenia and bipolar disorder, consistent with the idea that the two disorders exist on a clinical continuum with overlapping symptom dimensions (89). Similarly, genes such as DISC1(90), NRG1(91) and ANK3(92) are associated with both psychotic disorder and bipolar disorder. A comparable genetic overlap may also exist with autism spectrum disorders, for which deletions in the neurexin 1 gene have been associated with both autism and psychotic disorder (93). The demonstration of shared structural deficits in psychotic disorder and bipolar disorder has provided further support to this etiologic overlap between two, as yet categorically, defined illnesses $(81,94,95)$. 
Using structural MRI measurements as a diagnostic tool or clinical guidance is still a future perspective. Structural brain images lack specificity although considerable predictive power has been reported for subgroups (96). Despite the absence of (as yet) clinical applications of MRI scanning, investigating gene-environment relationships associated with brain phenotypes may help to further elucidate the aetiology of psychotic disorder and lead to the development of more targeted treatments to avert relapse. For example, as daily life stress has been associated with HPA axis dysfunction, the potential for drugs acting upon glucocorticoid systems (e.g., $\mathrm{CRH}$ antagonists) and thereby intervening at a more upstream level in the brain than at the traditional postsynaptic dopamine receptor level could become a target of further investigation.

Siblings of patients with psychotic disorder showed evidence of higher cortical thickness values when exposed to trauma during childhood than siblings not exposed to childhood trauma. Furthermore, it was determined that siblings of patients do show increased biological response to stressors whereas this increased stress response was not apparent at the behavioural level. These differences between patients and siblings may reflect the importance of protective factors resulting from different coping and/or attributional styles, increasing their resilience. Therefore, delivering psychoeducation for patients and individuals at a higher than average genetic risk for psychotic disorder and focusing on different coping strategies in dealing with stress and stress-related symptoms are essential strategies in preventing relapse or transition to psychosis.

Furthermore, replications on brain alterations deriving from differential sensitivity to certain environmental factors, such as cannabis use, are urgently needed as this knowledge may further guide early intervention and prevention programs. This may include the development of awareness campaigns and psycho-education for young people at risk for psychotic disorder who are or who are not (yet) in contact with mental health services. Moreover, as a result of better insight into the pathways to psychotic disorder, stigma and self-stigma can be potentially reduced.

With the above mentioned potential implications in mind, future research on brain alterations and mechanisms in psychosis should make use of symptom dimensions besides categorical illness phenotypes and further elucidate differential sensitivities to environmental factors as these areas, to date, are far from being explored. New 
multivariate methods can be used to investigate the association between complex brain phenotypes and a large number of single nucleotide polymorphisms (SNPs)(97). Investigating SNPs of COMT, AKT1 and FKBP5 are interesting because of their relationship with environmental risk factors such as cannabis use and stress $(18,25)$.

In summary, although it will be a difficult task, integrating genetic and environmental data with brain imaging data, and thereby using relevant dimensional symptom profiles instead of traditional diagnostic constructs, is the challenge and could be the future for personalised medicine in terms of tailor-made treatments and prevention strategies.

\section{CONCLUDING REMARKS}

This thesis examined potential genetic and environmental determinants of brain alterations in psychotic disorder. It was found that regional cortical thickness alterations may be an indicator of genetic risk for psychotic disorder. Furthermore, cannabis use was associated with cortical thinning in patients with psychotic disorder and their siblings, suggestive of underlying gene-environment interactions associated with psychotic disorder. With regard to trauma, increased levels of childhood trauma were associated with decreased cortical thinning in patients, but not in siblings and controls, possibly reflecting specific disease-related processes. In addition, volumetric alterations of the pituitary and hippocampus, structures that are involved in the HPA axis stress response were associated with stress-reactivity in patients with psychotic disorder and, to a certain extent, in their siblings.

The findings have deepened the relationship between neural substrates and various environmental factors in individuals at high genetic risk for psychotic disorder. It was shown that combining research fields such as neuroimaging and genetic epidemiology is feasible and that neuroimaging phenotypes play an important role in identifying gene-environment relationships in psychotic disorders. 


\section{References}

1. Howes OD, McDonald C, Cannon M, Arseneault L, Boydell J, and Murray RM (2004): Pathways to schizophrenia: the impact of environmental factors. Int J

Neuropsychopharmacol 7 Suppl 1:S7-S13.

2. Gottesman I and Shields J (1982):

Schizophrenia: The Epigenetic Puzzle. New York: NY: Cambridge University Press

3. Sullivan PF, Kendler KS, and Neale MC (2003): Schizophrenia as a complex trait: evidence from a meta-analysis of twin studies. Arch Gen Psychiatry60:1187-92.

4. van Os J, Kenis G, and Rutten BP (2010): The environment and schizophrenia. Nature 468:203-12.

5. Deutch AY (1993): Prefrontal cortical dopamine systems and the elaboration of functional corticostriatal circuits: implications for schizophrenia and Parkinson's disease. $J$ Neural Transm Gen Sect 91:197-221.

6. Gottesman, II and Gould TD (2003): The endophenotype concept in psychiatry: etymology and strategic intentions. Am J Psychiatry 160:63645.
7. Mesulam MM

(1990): Large-scale neurocognitive networks and distributed processing for attention, language, and memory. Ann Neuro/28:597-613.

8. Pearlson GD, Petty RG, Ross CA, and Tien AY (1996):

Schizophrenia: a disease of heteromodal association cortex? Neuropsychopharmacolog y14:1-17.

9. Glahn DC, Laird AR, Ellison-Wright I, Thelen SM, Robinson JL, Lancaster JL, et al. (2008): Meta-analysis of gray matter anomalies in schizophrenia: application of anatomic likelihood estimation and network analysis. Biol Psychiatry 64:774-81.

10. Goldman AL, Pezawas L, Mattay VS, Fischl B, Verchinski BA, Chen Q, et al. (2009): Widespread reductions of cortical thickness in schizophrenia and spectrum disorders and evidence of heritability. Arch Gen Psychiatry 66:467-77.
11. Hulshoff Pol HE, Schnack HG, Mandl RC, Brans RG, van Haren NE, Baare WF, et al. (2006): Gray and white matter density changes in monozygotic and samesex dizygotic twins discordant for schizophrenia using voxelbased morphometry. Neuroimage 31:482-8.

12. Baare WF, van Oel CJ, Hulshoff Pol HE, Schnack HG, Durston S, Sitskoorn MM, et al. (2001): Volumes of brain structures in twins discordant for schizophrenia. Arch Gen Psychiatry 58:33-40.

13. Bendall $S$, Jackson $\mathrm{HJ}$, Hulbert CA, and McGorry PD (2008): Childhood trauma and psychotic disorders: a systematic, critical review of the evidence. Schizophr Bull34:568-79.

14. Read J, van Os J, Morrison AP, and Ross CA (2005): Childhood trauma, psychosis and schizophrenia: a literature review with theoretical and clinical implications. Acta Psychiatr Scand 112:330-50.

15. Spauwen J, Krabbendam L, Lieb R, Wittchen $\mathrm{HU}$, and van Os $J$ (2006): Impact of psychological trauma on the development of psychotic symptoms: relationship with psychosis proneness. $\mathrm{Br} \mathrm{J}$ Psychiatry 188:527-33. 
16. Feinberg $M E$,

Neiderhiser JM, Simmens

$S$, Reiss D, and

Hetherington EM (2000):

Sibling comparison of

differential parental

treatment in adolescence:

gender, self-esteem, and

emotionality as mediators

of the parenting-

adjustment association.

Child Dev 71:1611-28.

17. Pfeifer $S$,

Krabbendam L, Myin-

Germeys I, and al. e

(2010): A cognitive intermediate phenotype study confirming possible gene-early adversity interaction in psychosis outcome: A general population twin study. Psychosis1-11.

18. Binder $E B$, Bradley RG, Liu W, Epstein MP, Deveau TC, Mercer KB, et al. (2008): Association of FKBP5 polymorphisms and childhood abuse with risk of posttraumatic stress disorder symptoms in adults. JAMA 299:1291305.

19. Cheng $\mathrm{R}$, Juo $\mathrm{SH}$, Loth JE, Nee J, lossifov I, Blumenthal R, et al. (2006): Genome-wide linkage scan in a large bipolar disorder sample from the National Institute of Mental Health genetics initiative suggests putative loci for bipolar disorder, psychosis, suicide, and panic disorder. Mol Psychiatry 11:252-60.
20. Hall $W$ and

Degenhardt L (2008):

Cannabis use and the risk

of developing a psychotic

disorder. World

Psychiatry 7:68-71.

21. Caspi A, Moffitt

TE, Cannon M, McClay J,

Murray $\mathrm{R}$, Harrington $\mathrm{H}$,

et al. (2005): Moderation

of the effect of

adolescent-onset

cannabis use on adult

psychosis by a functional

polymorphism in the

catechol-O-

methyltransferase gene:

longitudinal evidence of a

gene $\mathrm{X}$ environment

interaction. Biol

Psychiatry 57:1117-27.

22. Henquet $C$, Murray R, Linszen D, and van Os J (2005): The environment and schizophrenia: the role of cannabis use. Schizophr Bull31:608-12.

23. Henquet $C$, Rosa A, Delespaul P, Papiol S, Fananas L, van Os J, et al. (2009): COMT ValMet moderation of cannabisinduced psychosis: a momentary assessment study of 'switching on' hallucinations in the flow of daily life. Acta Psychiatr Scand 119:15660.

24. Verdoux $\mathrm{H}$, Gindre C, Sorbara F, Tournier $\mathrm{M}$, and Swendsen JD (2003): Effects of cannabis and psychosis vulnerability in daily life: an experience sampling test study. Psychol Med 33:23-32.
25. van Winkel $R$ (2010): Family-Based Analysis of Genetic Variation Underlying Psychosis-Inducing Effects of Cannabis: Sibling Analysis and Proband Follow-up. Arch Gen Psychiatry.

26. Tan HY, Nicodemus KK, Chen Q, Li Z, Brooke JK, Honea R, et al. (2008): Genetic variation in AKT1 is linked to dopamine-associated prefrontal cortical structure and function in humans. J Clin Invest 118:2200-8.

27. Myin-Germeys I, van Os J, Schwartz JE, Stone AA, and Delespaul PA (2001): Emotional reactivity to daily life stress in psychosis. Arch Gen Psychiatry 58:113744.

28. Oorschot $M$, Kwapil T, Delespaul P, and Myin-Germeys I (2009): Momentary assessment research in psychosis. Psychol Assess 21:498505.

29. Pariante $\mathrm{CM}$ (2008): Pituitary volume in psychosis: the first review of the evidence. $J$ Psychopharmacol22:7681. 
30. Mondelli V,

Dazzan P, Gabilondo A,

Tournikioti K, Walshe M,

Marshall N, et al. (2008):

Pituitary volume in

unaffected relatives of

patients with

schizophrenia and bipolar

disorder.

Psychoneuroendocrinolog

y33:1004-12.

31. Garner B,

Pariante CM, Wood SJ,

Velakoulis D, Phillips $\mathrm{L}$,

Soulsby B, et al. (2005):

Pituitary volume predicts

future transition to

psychosis in individuals at

ultra-high risk of

developing psychosis. Biol

Psychiatry 58:417-23.

32. Walker EF and

Diforio D (1997):

Schizophrenia: a neural

diathesis-stress model.

Psychol Rev 104:667-85.

33. Collip D, Myin-

Germeys I, and Van Os J

(2008): Does the concept

of "sensitization" provide

a plausible mechanism for

the putative link between

the environment and

schizophrenia? Schizophr

Bull34:220-5.

34. McEwen BS and

Gianaros PJ (2010):

Central role of the brain

in stress and adaptation:

links to socioeconomic

status, health, and

disease. Ann N Y Acad Sci

1186:190-222.
35. O'Brien JT,

The'glucocorticoid

cascade'hypothesis in

man: prolonged stress

may cause permanent

brain damage. 1997,

Maney. p. 199-201.

36. Sapolsky RM,

Romero LM, and Munck

AU, How do

glucocorticoids influence

stress responses?

Integrating permissive,

suppressive, stimulatory,

and preparative actions.

2000, Endocrine Soc. p.

55 .

37. Corcoran C, Walker E, Huot R, Mittal

$V$, Tessner K, Kestler L, et

al. (2003): The stress

cascade and

schizophrenia: etiology

and onset. Schizophr. Bull.

29:671-92.

38. Walker E, Mittal

$\mathrm{V}$, and Tessner K (2008):

Stress and the

hypothalamic pituitary

adrenal axis in the

developmental course of

schizophrenia. Annu Rev

Clin Psychol4:189-216.

39. Lupien SJ, de

Leon M, De Santi S, Convit

A, Tarshish C, Nair NPV, et

al., Cortisol levels during

human aging predict

hippocampal atrophy and

memory deficits. 1998,

Nature Publishing Group.

p. 69-73.
40. Geuze $\mathrm{E}$,

Vermetten $\mathrm{E}$, and

Bremner JD (2005): MR-

based in vivo

hippocampal volumetrics:

2. Findings in

neuropsychiatric

disorders. Mol. Psychiatry

10:160-84.

41. Steen RG, Mull C, McClure R, Hamer RM, and Lieberman JA (2006):

Brain volume in first-

episode schizophrenia:

systematic review and

meta-analysis of magnetic

resonance imaging

studies. Br J Psychiatry

188:510-8.

42. Wright IC, Rabe-

Hesketh S, Woodruff PW,

David AS, Murray RM, and

Bullmore ET (2000):

Meta-analysis of regional

brain volumes in

schizophrenia. Am. J.

Psychiatry 157:16-25.

43. Vita A, De Peri L,

Silenzi $C$, and Dieci $M$

(2006): Brain morphology

in first-episode

schizophrenia: a meta-

analysis of quantitative

magnetic resonance

imaging studies.

Schizophr. Res. 82:75-88.

44. Lawrie SM, Mclntosh AM, Hall J, Owens DG, and Johnstone EC (2008): Brain structure and function changes during the development of schizophrenia: the evidence from studies of subjects at increased genetic risk. Schizophr. Bull. 34:330-40. 
45. Boos $\mathrm{H}$, Aleman

A, Cahn W, Pol HH, and Kahn RS, Brain volumes in relatives of patients with schizophrenia: a metaanalysis. 2007, Am Med Assoc. p. 297.

46. Lucassen PJ, Heine VM, Muller $M B$, van der Beek EM, Wiegant VM, De Kloet ER, et al. (2006): Stress, depression and hippocampal apoptosis. CNS Neurol Disord Drug Targets 5:531-46.

47. Pariante $C M$ (2006): The glucocorticoid receptor: part of the solution or part of the problem? J Psychopharmaco/20:7984.

48. Buehlmann $\mathrm{E}$, Berger GE, Aston J, Gschwandtner U, Pflueger MO, Borgwardt SJ, et al. Hippocampus abnormalities in at risk mental states for psychosis? A crosssectional high resolution region of interest magnetic resonance imaging study. J Psychiatr Res 44:447-53.
49. Velakoulis D, Wood SJ, Wong MT, McGorry PD, Yung A, Phillips L, et al. (2006): Hippocampal and amygdala volumes according to psychosis stage and diagnosis: a magnetic resonance imaging study of chronic schizophrenia, firstepisode psychosis, and ultra-high-risk individuals. Arch Gen Psychiatry 63:139-49.

50. McEwen BS (2005): Glucocorticoids, depression, and mood disorders: structural remodeling in the brain. Metabolism 54:20-3.

51. Laruelle M (2000): The role of endogenous sensitization in the pathophysiology of schizophrenia: implications from recent brain imaging studies. Brain Res Brain Res Rev 31:371-84.

52. Di Forti M, Lappin JM, and Murray RM (2007): Risk factors for schizophrenia--all roads lead to dopamine. Eur Neuropsychopharmacol 17 Suppl 2:S101-7.

53. Murray RM, Lappin J, and Di Forti M (2008): Schizophrenia: from developmental deviance to dopamine dysregulation. Eur Neuropsychopharmacol 18 Suppl 3:S129-34.
54. Kuepper R, Morrison PD, van Os J, Murray RM, Kenis G, and Henquet C (2010): Does dopamine mediate the psychosis-inducing effects of cannabis? A review and integration of findings across disciplines. Schizophr Res 121:107-17.

55. Lodge DJ and Grace AA (2008): Hippocampal dysfunction and disruption of dopamine system regulation in an animal model of schizophrenia. Neurotox Res 14:97-104.

56. Lodge DJ and Grace AA (2007): Aberrant hippocampal activity underlies the dopamine dysregulation in an animal model of schizophrenia. JNeurosci 27:11424-30.

57. Lodge DJ and Grace AA Developmental pathology, dopamine, stress and schizophrenia. Int J Dev Neurosci.

58. Chan GC, Hinds TR, Impey S, and Storm DR (1998): Hippocampal neurotoxicity of Delta9tetrahydrocannabinol. $J$ Neurosci 18:5322-32.

59. Lawston J, Borella A, Robinson JK, and Whitaker-Azmitia PM (2000): Changes in hippocampal morphology following chronic treatment with the synthetic cannabinoid WIN 55,212-2. Brain Res 877:407-10. 
60. Gaspar PA,

Bustamante ML, Silva $\mathrm{H}$, and Aboitiz F (2009):

Molecular mechanisms underlying glutamatergic dysfunction in schizophrenia: therapeutic implications. J Neurochem 111:891-900.

61. Stone JM, Day F, Tsagaraki $\mathrm{H}$, Valli I, McLean MA, Lythgoe DJ, et al. (2009): Glutamate dysfunction in people with prodromal symptoms of psychosis: relationship to gray matter volume. Biol Psychiatry 66:533-9.

62. Czyrak A, Mackowiak M, Chocyk A, Fijal K, and Wedzony $\mathrm{K}$ (2003): Role of glucocorticoids in the regulation of dopaminergic neurotransmission. Pol $\mathrm{J}$ Pharmacol55:667-74.

63. Dallman MF, Akana SF, Strack AM, Scribner KS, Pecoraro N, La Fleur SE, et al. (2004): Chronic stress-induced effects of corticosterone on brain: direct and indirect. Ann N Y Acad Sci1018:141-50.

64. Moghaddam B (2002): Stress activation of glutamate neurotransmission in the prefrontal cortex: implications for dopamine-associated psychiatric disorders. Biol Psychiatry 51:775-87.
65. Breier A, Davis

OR, Buchanan RW, Moricle LA, and Munson RC (1993): Effects of metabolic perturbation on plasma homovanillic acid in schizophrenia. Relationship to prefrontal cortex volume. Arch Gen Psychiatry 50:541-50.

66. Marcelis M, Cavalier E, Gielen J, Delespaul P, and Van Os J (2004): Abnormal response to metabolic stress in schizophrenia: marker of vulnerability or acquired sensitization? PsycholMed 34:1103-11.

67. Marcelis $M$, Suckling J, Hofman P, Woodruff P, Bullmore E, and van Os J (2006):

Evidence that brain tissue volumes are associated with HVA reactivity to metabolic stress in schizophrenia. Schizophr Res 86:45-53.

68. Soliman $A$, O'Driscoll GA, Pruessner J, Holahan AL, Boileau I, Gagnon D, et al. (2008): Stress-induced dopamine release in humans at risk of psychosis: a

[11C]raclopride PET study.

Neuropsychopharmacolog y33:2033-41.
69. Pruessner JC, Champagne F, Meaney MJ, and Dagher A (2004): Dopamine release in response to a psychological stress in humans and its relationship to early life maternal care: a positron emission tomography study using [11C]raclopride. J Neurosci24:2825-31.

70. Bremner JD (2003): Long-term effects of childhood abuse on brain and neurobiology. Child Adolesc Psychiatr Clin N Am 12:271-92.

71. Bremner JD (2005): Effects of traumatic stress on brain structure and function: relevance to early responses to trauma. $J$ Trauma Dissociation 6:5168.

72. Cheer JF, Wassum KM, Heien ML, Phillips PE, and Wightman RM (2004): Cannabinoids enhance subsecond dopamine release in the nucleus accumbens of awake rats. $J$ Neurosci 24:4393-400.

73. Henquet $C$, Krabbendam L, Spauwen J, Kaplan C, Lieb R, Wittchen HU, et al. (2005): Prospective cohort study of cannabis use, predisposition for psychosis, and psychotic symptoms in young people. Bmj330:11. 
74. Schultz W, Dayan

$P$, and Montague PR

(1997): A neural substrate

of prediction and reward.

Science 275:1593-9.

75. Berridge KC and

Robinson TE (1998): What is the role of dopamine in reward: hedonic impact, reward learning, or incentive salience? Brain Res Brain Res Rev 28:30969.

76. Robbins TW and Everitt BJ (1996): Neurobehavioural mechanisms of reward and motivation. Curr Opin Neurobio/6:228-36.

77. Kapur S (2003):

Psychosis as a state of aberrant salience: a framework linking biology, phenomenology, and pharmacology in schizophrenia. Am J Psychiatry 160:13-23.

78. Waelti $P$, Dickinson A, and Schultz W (2001): Dopamine responses comply with basic assumptions of formal learning theory. Nature 412:43-8.

79. Howes OD and Kapur S (2009): The dopamine hypothesis of schizophrenia: version III--the final common pathway. Schizophr Bull 35:549-62.
80. Nestor SM,

Rupsingh $\mathrm{R}$, Borrie $\mathrm{M}$, Smith M, Accomazzi V, Wells JL, et al. (2008): Ventricular enlargement as a possible measure of Alzheimer's disease progression validated using the Alzheimer's disease neuroimaging initiative database. Brain 131:2443-54.

81. Kempton MJ, Geddes JR, Ettinger U, Williams SC, and Grasby PM (2008): Meta-analysis, database, and metaregression of 98 structural imaging studies in bipolar disorder. Arch Gen Psychiatry 65:101732.

82. Harrison PJ (1999): The neuropathology of schizophrenia. A critical review of the data and their interpretation. Brain 122 ( Pt 4):593-624.

83. Harrison PJ (2004): The hippocampus in schizophrenia: a review of the neuropathological evidence and its pathophysiological implications.

\section{Psychopharmacology} (Berl) 174:151-62.

84. Honea R, Crow TJ, Passingham $D$, and Mackay CE (2005): Regional deficits in brain volume in schizophrenia: a meta-analysis of voxelbased morphometry studies. Am J Psychiatry 162:2233-45.
85. Shenton ME, Dickey CC, Frumin $M$, and McCarley RW (2001): A review of $M R I$ findings in schizophrenia. Schizophr Res 49:1-52.

86. van Os J, Linscott RJ, Myin-Germeys I, Delespaul P, and Krabbendam L (2009): A systematic review and meta-analysis of the psychosis continuum: evidence for a psychosis proneness-persistenceimpairment model of psychotic disorder. Psychol Med1-17.

87. Johns LC, Cannon $M$, Singleton N, Murray RM, Farrell M, Brugha T, et al. (2004): Prevalence and correlates of selfreported psychotic symptoms in the British population. $\mathrm{Br} \mathrm{J}$ Psychiatry 185:298-305.

88. Kaymaz $\mathrm{N}$ and van Os J (2010): Extended psychosis phenotype yes: single continuum unlikely. Psychol Med 40:1963-6.

89. van Os J and Kapur S (2009): Schizophrenia. Lancet 374:635-45.

90. Owen MJ, Craddock N, and Jablensky A (2007): The genetic deconstruction of psychosis. Schizophr Bull 33:905-11. 
91. Green EK,

Raybould R, Macgregor S, Gordon-Smith K, Heron J, Hyde S, et al. (2005):

Operation of the schizophrenia susceptibility gene, neuregulin 1, across traditional diagnostic boundaries to increase risk for bipolar disorder. Arch Gen Psychiatry 62:642-8.

92. Athanasiu $\mathrm{L}$, Mattingsdal M, Kahler AK, Brown A, Gustafsson O, Agartz l, et al. (2010): Gene variants associated with schizophrenia in a Norwegian genome-wide study are replicated in a large European cohort. $J$ Psychiatr Res 44:748-53.

93. Stefansson $\mathrm{H}$, Rujescu D, Cichon S, Pietilainen OP, Ingason A, Steinberg S, et al. (2008): Large recurrent microdeletions associated with schizophrenia.

Nature 455:232-6.

94. Mamah D, Wang L, Csernansky JG, Rice JP, Smith $M$, and Barch DM Morphometry of the hippocampus and amygdala in bipolar disorder and schizophrenia. Bipolar Disord 12:341-3.
95. McDonald C, Bullmore ET, Sham PC, Chitnis $\mathrm{X}$, Wickham $\mathrm{H}$, Bramon $\mathrm{E}$, et al. (2004): Association of genetic risks for schizophrenia and bipolar disorder with specific and generic brain structural endophenotypes. Arch Gen Psychiatry 61:974-84.

96. Koutsouleris N, Schmitt GJ, Gaser C, Bottlender R, Scheuerecker J, McGuire $P$, et al. (2009):

Neuroanatomical correlates of different vulnerability states for psychosis and their clinical outcomes. $\mathrm{Br} \mathrm{J}$ Psychiatry 195:218-26.

97. MeyerLindenberg A (2010):

From maps to mechanisms through neuroimaging of schizophrenia. Nature 468:194-202. 




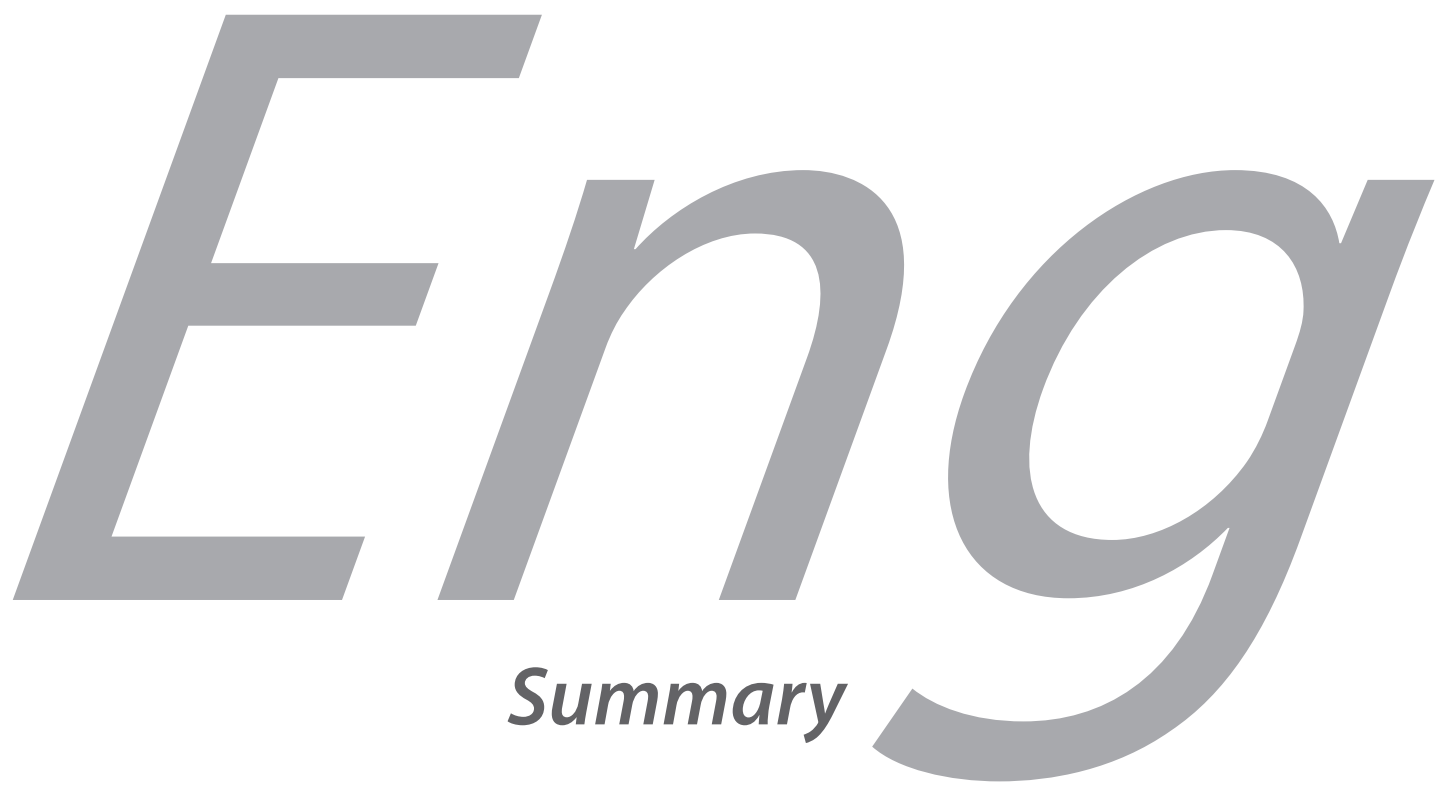


Thefield of geneticepidemiologyand neuroimaging has mainly consisted of disparate research fields. In other words, the integration of findings from epidemiologic and neuroimaging studies on psychotic disorder has not received much attention to date. As both genetic and environmental factors are assumed to play a role in the development of certain brain alterations that may contribute to the risk of developing a psychotic disorder, this thesis "The role of neuroimaging phenotypes in ecogenetic studies of psychotic disorder", attempted to combine both fields. Genetic risk levels, environmental factors and their interactions were analysed in relation to different brain phenotypes. The study samples used in this thesis consisted of patients with psychotic disorder (highest genetic risk group), siblings of patients with psychotic disorder (higher than average genetic risk group), and controls (average genetic risk group).

In chapter 2, cortical thickness was investigated in relation to genetic riskfor psychotic disorder. The goal of this study was to identify biological markers of genetic risk such as intermediate phenotypes. Previous studies have provided some evidence for a cortical thickness intermediate phenotype whereas more extensive and more recent studies have failed to confirm this. The study described in chapter $\mathbf{2}$ indicated that patients and their siblings had cortical thickness reductions in overlapping areas, in the frontal, temporal, parietal and occipital regions combined with patient-specific alterations and some sibling-specific alterations. After controlling for cannabis use, the number of significant clusters was reduced in siblings and patients, but most shared cortical thickness alterations between siblings and patients remained significant. In summary, the results suggest that a cortical thickness intermediate phenotype may exist in psychotic disorder. In addition, we concluded that some of the cortical changes may be influenced by environmental factors such as cannabis use.

In chapter 3, the relationship between cortical thickness and two environmental risk factors, cannabis use and childhood trauma, was investigated using the same genetically sensitive sample. The aetiology of schizophrenia is thought to involve differential - likely genetically mediated - sensitivity to environmental exposures. However, examination of differential sensitivity in models of psychopathological constructs is subject to bias as psychopathology itself may distort exposure assessment. The use of neuroimaging phenotypes may provide unbiased evidence 
for differential sensitivity to environmental exposures. In chapter 3, an association was found between reduced cortical thickness and higher levels of cannabis use in patients with psychotic disorder and their siblings, but not in controls, which extends earlier findings indicating that gene-environment interactions may underlie the association between cannabis use and psychotic disorder. Patients who reported higher levels of childhood trauma also showed cortical thinning, which was not found in controls or siblings with a history of childhood trauma. Siblings and controls may differ from patients in that the effect of exposure to traumatic experiences may be neutral (controls) or even trophic (siblings). To the degree that the effects of trauma on the brain are mediated by long-term psychological adaptation, resilience and coping may moderate the outcome of traumatic experiences over time, possibly mitigating the risk for later psychotic outcomes.

In chapters 4 and 5, we examined whether volumes of specific brain structures related to HPA axis functioning and stress-reactivity were associated and whether this association was influenced by the genetic risk for psychotic disorder. The pituitary and the hippocampus are involved in regulating the stress response in the HPA axis. Exposure to stress activates the HPA axis through the release of CRH in the hypothalamus, resulting in the secretion of the ACTH in the pituitary, thus stimulating the release of cortisol in the adrenal gland. Cortisol, through a negative feedback mechanism, regulates HPA axis activity. Persistently elevated cortisol levels can decrease the activity of the negative feedback mechanism, resulting in a sensitised state of HPA axis hyperactivity. As a result of HPA axis hyperactivity, patients become more sensitive to stressors, a phenomenon called stress-sensitisation. Stress-sensitisation has been hypothesised to be the underlying process related to increased stress-reactivity in individuals with (increased risk for) psychotic disorder. However, whether stress-reactivity is related to structural brain volumes associated with HPA axis functioning (i.e., pituitary and hippocampal volume) has never been examined. In chapter 4, pituitary volume was used as an index for HPA axis functioning. It was shown that an enlarged pituitary volume was associated with increased negative emotions as a response to daily life stressors in patients with psychotic disorder, their siblings and controls. This association was significantly stronger in patients when compared to controls, indicating a process of progressive sensitisation resulting in a clinical phenotype. Although baseline cortisol measures were higher in siblings than controls, biological stress-reactivity in siblings did not 
differ from controls nor was there an interaction between group status and pituitary volume in the model of biological stress-reactivity. However, power issues may have led to type II errors in the sibling analyses. The study described in chapter $\mathbf{5}$ used hippocampal volume as a proxy for HPA axis functioning, and it was found that lower hippocampal volume was associated with increased emotional reactivity in patients but not in siblings and controls. Siblings did show that lower hippocampal volume was associated with increased cortisol reactivity. This discrepancy between the emotional and biological stress-reactivity pattern might suggest that, even with an increased biological reactivity, siblings manage to cope better with stress or have higher resilience and, consequently, demonstrate a relatively healthy emotional stress-reactivity.

In chapter 6, the results of the different chapters were discussed and integrated into a wider context. The studies in this thesis provided evidence for associations between brain alterations in individuals at high genetic risk for psychotic disorder and environmental risk factors such as cannabis use, childhood trauma and daily life stress. Although the exact mechanisms need to be elucidated, it is attractive to speculate that differential sensitivity to the environment may be expressed in structural brain alterations impacting dopamine pathways and resulting in the emergence of psychotic symptoms. We have concluded that the neuroimaging phenotype is an important variable in identifying gene-environment relationships in schizophrenia, and this new paradigm is likely to lead to future clinical valorisation of which examples have been provided. 




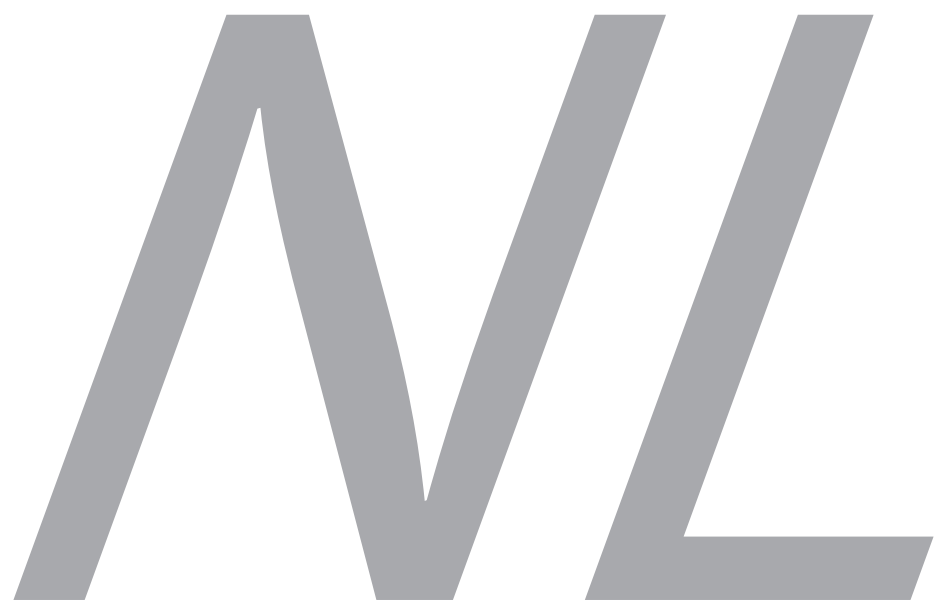

Samenvatting 
Genetische epidemiologie en neuroimaging zijn twee afzonderlijke onderzoeksgebieden en de integratie van de bevindingen van beide onderzoeksvelden op het gebied van psychotische stoornissen heeft tot op heden weinig aandacht gekregen. Omdat zowel genetische als omgevingsfactoren een rol spelen in de ontwikkeling van bepaalde veranderingen in de hersenen die geassocieerd zijn met een verhoogd risico voor het ontwikkelen van een psychotische stoornis zijn in dit proefschrift "The role of neuroimaging phenotypes in ecogenetic studies of psychotic disorder", de twee bovengenoemde onderzoeksgebieden gecombineerd. Verschillen in genetisch risico, omgevingsfactoren en hun interacties werden onderzocht in relatie tot verschillende brein fenotypes. Er werden drie groepen onderzocht verschillend in mate van genetische kwetsbaarheid: een groep patiënten met een psychotische stoornis (hoogste genetische kwetsbaarheid), een groep broers en/of zussen van patiënten met een psychotische stoornis (hoger dan gemiddeld genetische kwetsbaarheid) en een groep gezonde controles (gemiddelde genetische kwetsbaarheid).

In hoofdstuk 2 werden regionale verschillen in corticale dikte in relatie tot het genetisch risico voor psychotische stoornis onderzocht. Het doel van deze studie was om biologische markers voor genetisch risico, zoals intermediaire fenotypes, te identificeren. Eerdere studies hebben bewijs geleverd voor een corticaal intermediair fenotype, maar er zijn ook enkele grote, recente studies die het bestaan van een corticale dikte fenotype niet kunnen ondersteunen. De studie beschreven in hoofdstuk 2 vond dat patiënten en hun familieleden corticale veranderingen vertoonden in frontale, temporale, parietale en occipitale regio's van het brein. Daarnaast werden corticale dikte veranderingen gevonden die specifiek waren voor de patiënten alsmede enkele veranderingen die specifiek waren voor de familieleden. Na controle voor cannabisgebruik, verminderde het aantal significante clusters, maar de meeste gedeelde brein veranderingen bleven tussen patiënten en familieleden echter bestaan. Deze resultaten suggereren dat corticale dikte een potentiële intermediair fenotype is en dat een gedeelte van de corticale dikte veranderingen mogelijk beïnvloed wordt door omgevingsfactoren zoals cannabisgebruik.

In hoofdstuk 3 werd de relatie tussen corticale dikte en twee omgevingsfactoren, cannabisgebruik en trauma in de kindertijd, onderzocht gebruik makende 
van hetzelfde familiestudie design. De etiologie van psychotische stoornis is gerelateerd aan differentiële -waarschijnlijk genetisch gemedieerde- gevoeligheid voor omgevingsfactoren. Onderzoek naar deze differentiële gevoeligheid in psychopathologische populaties is echter aan bias onderworpen, omdat de psychopathologie zelf de uitkomstmaten kan verstoren. Door gebruik te maken van een MRI fenotype als uitkomstmaat, kan er mogelijk onvertekend bewijs voor differentiële gevoeligheid voor omgevingsfactoren gevonden worden. In hoofdstuk 3 werd een associatie gevonden tussen een dunnere cortex en een hogere mate van cannabisgebruik bij zowel patiënten met psychotische stoornis als hun familieleden. Dit geeft additioneel bewijs voor de al eerder gevonden relatie tussen cannabis en kwetsbaarheid voor psychotische stoornis. Patiënten die veel trauma in de kindertijd rapporteren vertoonden ook een lagere corticale dikte ten opzichte van hun gezonde broers/zussen en controlepersonen met vergelijkbare traumatische ervaringen. Het is mogelijk dat familieleden en controles verschillen van patiënten op zo een manier dat het effect van blootstelling aan traumatische ervaringen neutraal kan zijn (controles) of zelfs trofisch (familieleden). Er vanuit gaande dat de effecten van trauma op het brein gemedieerd worden door psychologische adaptatie op de lange termijn, zijn veerkracht en coping mogelijke mechanismen die de consequenties van traumatische ervaringen over de tijd kunnen beinvloeden, door het risico op een psychotische stoornis te verminderen.

In hoofdstuk $\mathbf{4}$ en $\mathbf{5}$ werd onderzocht of de volumes van specifieke hersenstructuren die gerelateerd zijn aan het functioneren van de HPA as geassocieerd waren met stressreactiviteit en of deze relatie beïnvloed werd door verschillen in genetische kwetsbaarheid voor psychotische stoornis. De hypofyse en hippocampus zijn betrokken bij de stressreactie van de HPA as. Blootstelling aan stress activeert de HPA as: de hypothalamus produceert $\mathrm{CRH}$. Dit stimuleert de hypofyse tot de aanmaak van ACTH. ACTH stimuleert daarna de bijnier tot de aanmaak van cortisol. Cortisol remt vervolgens de hypothalamus en dehypofyse in de aanmaakvan CRH en ACTHenzorgt zo voor een negatieve feedback op de HPA as. Continue verhoogde cortisolwaarden kan de activiteit van het negatieve feedback systeem verminderen, wat resulteert in een hyperactieve HPA as. Hierdoor kan het zijn dat patiënten gevoeliger zijn voor stressoren, ook wel stress-sensitisatie genoemd. Stress-sensitisatie wordt gezien als het onderliggende mechanisme gerelateerd aan de verhoogde stress-reactiviteit gezien in individuen met (verhoogd risico op) psychotische stoornis. Het is nog niet 
onderzocht of stress-reactiviteit geassocieerd is met de hersenstructuren (hypofyse en hippocampus) van de HPA as. De studie beschreven in hoofdstuk 4 gebruikte hypofyse volume als een proxy voor het functioneren van de HPA as. De studie toonde aan dat verhoogde hypofysevolumes geassocieerd zijn met verhoogde stress-reactiviteit in patiënten met psychotische stoornis, hun gezonde broers en zussen en controles. Deze associatie was significant sterker bij de patiënten, wat een indicatie is voor een proces van progressieve sensitisatie resulterend in het klinisch fenotype. Ondanks het feit dat baseline cortisolwaarden hoger lagen voor de siblings dan voor de controles, was er geen verschil in biologische stress-reactiviteit tussen siblings en controles. Ook was er geen interactie tussen groep status en hypofyse volume in het model van biologische stress-reactiviteit. Het kan zijn dat power problemen geresulteerd hebben tot type II fouten in de analyse van de siblings. De studie beschreven in hoofdstuk 5 gebruikte hippocampus volume als een proxy voor HPA functioneren en vond dat een lager hippocampusvolume geassocieerd was met verhoogde emotionele reactiviteit in patiënten maar niet in siblings en controles. Siblings hadden wel een hogere cortisol reactiviteit die geassocieerd was met lagere hippocampus volumes. Deze discrepantie tussen emotionele en biologische stress-reactiviteit patronen kunnen wijzen op het feit dat zelfs met een verhoogde biologische stress-reactiviteit, siblings beter omgaan met stress of een betere weerstand hebben tegen stress en dientengevolge een relatieve 'gezonde' emotionele stress-reactiviteit vertonen.

In hoofdstuk $\mathbf{6}$ werden de resultaten van de verschillende hoofdstukken besproken en geïntegreerd in een bredere context. De studies in deze thesis hebben bewijs geleverd voor associaties tussen veranderingen in het brein in individuen met een hoog genetisch risico voor psychotische stoornis en omgevingsfactoren zoals cannabisgebruik, trauma in de kindertijd en dagelijkse stress. Ondanks het feit dat de exacte onderliggende mechanismen nog niet bekend zijn, is het aantrekkelijk om te speculeren dat verschillen in gevoeligheid voor de omgeving zich uiten in structurele veranderingen in het brein die invloed hebben op de transmissie van dopamine, met het ontwikkelen van psychotische symptomen tot gevolg. We hebben geconcludeerd dat het neuroimaging fenotype een belangrijke rol speelt bij het identificeren van gen-omgevings interacties in schizofrenie en dat dit nieuwe paradigma kansen biedt voor toekomstige klinische valorisatie, waarvan enkele voorbeelden werden gegeven. 


Thanks to... 


\section{Seneca}

In elke fase van mijn leven hebben veel mensen mij gesteund en mede dankzij hun is dit proefschrift tot stand gekomen.

Allereerst wil ik graag mijn promotor Prof. Dr. Jim van Os bedanken. Uw ongetemde enthousiasme naar de wetenschap toe is aanstekelijk. E-mails worden beantwoord zelfs vanuit verre vakantieoorden waarvan ik dacht dat er geen internet kan zijn. Heer en meester van STATA en de soeverein van het sociale kapitaal van de afdeling, $u$ doet het allemaal zo eenvoudig lijken.

Mijn co-promotor Dr. Machteld Marcelis. Machteld, ik heb zoveel van u geleerd! Uw kennis, oog voor detail en uw indrukwekkend geheugen laten keer op keer een enorm indruk op me achter. Ondanks uw drukke agenda en chaotische AiO's was er altijd wel tijd voor een 'gewone' babbel en de vergaderingen zijn nooit voorbijgegaan zonder een paar lachbuien. De spannende momenten zal ik ook niet snel vergeten: scheurend over de Belgische snelwegen in uw VW polo en op het vliegtuig met 'gewapende' terroristen. Ik ben enorm dankbaar dat ik op uw project AiO mocht zijn.

Daarnaast wil ik ook graag alle collega's van het MRI team bedanken voor de fijne samenwerking. Ed Gronenschild, bedankt om mij te loodsen door de verwarrende wereld van imaging software en om een super kamergenootje te zijn. Sanne Peeters we hebben het echt met je getroffen. Sven gijsen, jij hebt mij leren scannen. Ik ging met een geruster hartje scannen als ik wist dat jij over mijn schouder mee keek. Merci dat ik u af en toe van uw werk mocht houden met mijn gebabbel. Paul Hofman, hypofyses tekenen is niet simpel, maar dankzij uw deskundige begeleiding hebben we het toch tot een goed einde gebracht. Inez en Dina, ik had nooit gedacht dat ik ESM onderzoek ging doen, nee ik ging hardcore 'biologische' wetenschap doen. Of zoals mijn zus het noemt: ECHTE wetenschap. Amai, wat ben ik terug moeten komen op mijn woorden (en mijn zus ook). ESM is gewoon cool. Het zegt iets over de dagdagelijkse dingen en daar draait het uiteindelijk toch allemaal om. Inez en Dina, ik heb genoten van onze samenwerking en ik hoop dat we het nog vaker gaan doen. Martin van Boxtel. Martin, bij $\mathrm{u}$ is het allemaal begonnen. $U$ heeft me laten zien hoe intrigerend wetenschap wel niet kan zijn. 
Prof. Dr. John Suckling, I am grateful that I had the opportunity to work with such a brilliant researcher. John I truly enjoyed my visit in Cambridge mostly because of your enthusiasm and hospitality and I hope that our collaboration plans will be implemented in the future. I also want to thank you for being part of the advisory committee and the Supervisory Committee.

Ook wil ik graag de andere leden van de leescommissie en van de corona bedanken.

Onderzoeksassistenten, bedankt dat ik steeds welkom ben in het 'kiekenkot', maar vooral bedankt voor de luisterende oortjes en de goede raad. Ron, Truda en de secretaresses, in tijden van crisis staan jullie altijd paraat! Leni, ik vind het super hoe jij altijd de keuken opfleurt met versieringen en versnaperingen. Collega's van SP en KP en de andere divisies, bedankt voor de fijne samenwerking, alle gezellige uitjes, congresbezoekjes en lunchtijden.

Debora, Miriam en Nicole, jullie hebben mij opgevangen toen ik pas bij SP kwam werken. Debora, ik denk nog vaak aan de tijd dat we samen in de auto naar de proefpersonen gingen luid meezingend met de Pussycat Dolls. We hebben ons toch goed geamuseerd. Miriam, jij bent samen met mij aan dit project begonnen. Jij stond mij bij als ik weer met klamme handjes een proefpersoon in de scanner moest 'duwen' en samen hebben we vele uurtjes versleten op het bankje bij de receptie. Nicole, ondanks dat je nog aan het rouwen was vanwege het verlies van je vorige kamergenoot was je voor mij een super kamergenootje.

Margriet, mijn nieuwe en oude kamergenootje! Samen hebben we stage gelopen bij Martin van Boxtel en deelde we dus het stagehok (met nadruk op hok). Ik was daarom dus heel blij dat ik hoorde dat jij bij SP kwam werken als AiO, want (op z'n Vlaams): gij waart/zijt een toffe! Jij bent pespi fan ik coca-cola - jij hebt Henk en Betty, ik heb Dai en Face - jij bent 'echte' cultuur, ik ben popcultuur en zo kan ik nog wel even doorgaan. Maar ondanks (of dankzij) onze tegenstellingen kunnen we het super met elkaar vinden. Tijdens de congresbezoeken waren we ook roomies en heb ik dankzij raad van jouw vader (geniet en verbaas je) kunnen genieten van de hostel in SD. Ik mis je. Veel succes in Amsterdam! Stagiaires Irene, Myriam, Suzanne, Laura bedankt voor de lange uren achter de computer en om samen met mij te wachten op het bankje op de proefpersonen. 
Bedankt aan iedereen van GROUP die zo hard gewerkt hebben om dit prachtige project op te starten. Dit proefschrift was nooit tot stand gekomen zonder de inzet van de proefpersonen en daarvoor mijn dank. Deze mensen hebben me echt verbaasd, er waren zelfs personen die niet alleen met de GROUP studie mee deden maar ook nog eens ESM, MRI, EEG en MindSpeech ondergingen. Proefpersonen die de aller-vroegste trein namen zodat ze na 3 uur reizen bij ons in de kelder onder de scanner konden (en dan maar hopen dat de scanner het niet afliet).

Vrienden en (schoon)familie, ik had graag iedereen apart willen bedanken maar dan zou mijn boekje dubbel zo dik worden. Dus via deze manier: merci voor alles.

Ilse en David. Ilse, bedankt dat je mijn paranimf wilde zijn. We kennen elkaar nog niet heel erg lang maar toch voelt het aan alsof we elkaar altijd al gekend hebben. Onze vriendschap voelt zo vertrouwd aan en ik ben blij dat ge bij SP zijt komen werken. David, ik ben vereerd dat ik uw werk heb mogen gebruiken voor de cover van mijn proefschrift. Ongelofelijk wat gij allemaal al hebt gemaakt, een magnifieke kunstenaar.

Ankie, Olga en Patricia dankzij jullie heb ik een super studententijd gehad en ook al is iedereen nu zijn eigen weg gegaan, de vriendschap is even sterk. Ankie, spinnen of steenmarters verdrijven was niet onze sterkste kant, maar wat hadden we een toffe tijd daar op ons kleine kot. Olga, we konden ons toch goed amuseren met onze series. Ook konden we altijd goed stoom aflaten wanneer de examens voorbij waren: gewoon de cd van Rammstein op in de auto en cruisen. Patricia, gij liet/laat me altijd dingen zien vanuit een ander perspectief, dat is een prachtige gave die je altijd moet blijven koesteren. Onze reis naar NY en Boston was geweldig! Zo kregen we onbetaalbare raad van een 'native': " just stand there and bitch!", werden ratten voor eekhoorns aangezien (of was het omgekeerd), little old ladies werden omvergeblazen, sliepen we met het licht aan voor de kakkerlakken en werden we de West Side Twins.

Chantal, bij het afstuderen van de middelbare school schreef je me nog dat we niet uit elkaar moesten groeien en nu bijna 12 jaar is onze vriendschap nog altijd als vroeger. Je hebt me vaak bijgestaan in de 'moeilijke' momenten en ik weet dat je dat zonder aarzelen altijd voor mij zal blijven doen. Zo'n vriendschap is zeldzaam en ik ben je daarvoor ook erg dankbaar! 
Nadia, van CDSCA tot in Mergozzo, van griezelen in de tent tot griezelen op de slaapkamer, van Anderlecht (remember de enge Standard fans??) tot Schumacher... zoveel mooie herinneringen (en meer) die ik nog steeds koester. Cindy, mijn gekke Cindy! Wat mis ik mijn gekke Cindy toch! Gij hebt er voor gezorgd dat ik ook dingen probeerde die buiten mijn 'comfort zone' lagen, met alle gevolgen van dien! Verdwaalt raken in hartje Brussel, in de moshpit op Werchter, spookrijden op weg naar de Ikea. Maar vooral heb je me gesteund, getroost en gezelschap gehouden wanneer het nodig was. Ge beseft het waarschijnlijk niet, maar ik heb veel van u geleerd!

Bomma, uw knuffels zijn van de beste ter wereld! Van bommakoek tot konijn dat niet echt konijn is, van de verhalen over de mattenklopper tot witte billen zoals die van een beerke, de kleinkinderen hebben altijd een super tijd gehad bij $u$. Kim en ik zelfs nog wat meer want wij mochten altijd bij u komen eten als we bij papa waren. Tijd brengt raad zegt $u$ altijd, en jammer genoeg heeft $u$ zelf vaak veel geduld moeten hebben. $U$ bent mijn schattebout!

Hoe moeilijk de taak van uw ouders is besef je pas wanneer je zelf ouder bent. Dus bedankt mama en papa om los te laten wanneer het nodig was. Papa, ik mis je elke dag een klein beetje meer.

Kim mijn grote zus en hartsvriendin, fiere mama van mijn petekindje Nick. We kennen elkaar zo goed, we hoeven zelfs niet te praten om elkaar te begrijpen. Gij zijt zelfs vaak de enige die mijn humor snapt. Zo verschillend dat we zijn, zoveel lijken we op elkaar. Merci voor alle goede raad en voor de hotline die we hadden tijdens het layouten van het proefschrift. Maar ook bedankt voor al die keren dat ge me tegen hebt gehouden om over te steken bij een rood licht.

Roberto gij zijt mijn droomvent. Gij steunt, motiveert en geeft me een duwke in de rug wanneer ik het nodig heb. Mensen goed te laten voelen daar geniet ge van en dat zegt veel over uw persoonlijkheid. Nore, jij bent mijn alles. Dankzij jou geniet ik eens zo veel van het leven. Mama houdt van je! 



\section{Curriculum Vitae}

Petra An Marietje Habets werd op 10 mei 1981 geboren in Maaseik, Belgie. Na voltooien van het hoger secundair onderwijs aan het Koninklijk Atheneum in Maaseik in 2000, behaalde ze in 2005 haar diploma van Doctorandus in de psychologie, specialisatie neuropsychologie aan de Universiteit van Maastricht. Van 2004 tot 2005 was ze werkzaam als onderzoeksassistent bij de universiteit van Maastricht, eerst bij de afdeling Cognitive \& Clinical Neuroscience daarna bij de afdeling Forensic Psychology. Van september 2005 tot maart 2011 heeft zij als assistent in opleiding het in dit proefschrift beschreven onderzoek uitgevoerd aan de School for Mental Health and Neuroscience afdeling Mental Health onder leiding van prof. Jim van Os en dr. Machteld Marcelis. Tijdens haar AiO-periode verbleef ze een tijdje in Cambridge, waar ze als onderzoeker verbonden was aan de University of Cambridge. Tevens werkte zij als case manager binnen een Assertive Community Treatment team van Psycope, een transmuraal zorgprogramma voor mensen met een psychotische aandoening. Sinds 1 juni 2011 is ze aangesteld als post-doctoraal onderzoeker bij de afdeling Mental Health van de School for Mental Health and Neuroscience.

Petra is getrouwd met Roberto Romano en samen hebben ze een dochter Nore. 



\section{List of publications}

\section{International refereed journals}

Geraerts E, Merckelbach H, Jelicic M, and Habets P (2007):

Suppression of intrusive thoughts and working memory capacity in repressive coping. Am J Psychol 120: 205-18.

Habets $\mathbf{P}$, Krabbendam L, Hofman P, Suckling J, Oderwald F, Bullmore E, Woodruff P, van Os J, Marcelis M. (2008): Cognitive performance and grey matter density in psychosis: functional relevance of a structural endophenotype. Neuropsychobiology 58: 128-37.

Habets P, Marcelis M, Gronenschild E, Drukker M, van Os J. (2011):

Reduced cortical thickness as an outcome of differential sensitivity to environmental risks in schizophrenia. Biological Psychiatry, 69: 487-494.

\section{Submitted papers}

Habets P, Collip D, Myin-Germeys I, Gronenschild E, van Bronswijk S, Hofman P, Lataster T, Lardinois M, Nicolson N A, van Os J, Marcelis M for G.R.O.U.P.: Pituitary volume, stress-reactivity and genetic risk for psychotic disorder.

Habets P, Collip D, Marcelis M, Gronenschild E, Lataster T, Lardinois M, Nicolson N A, van Os J , Myin-Germeys I for G.R.O.U.P.: Hippocampal volume as marker of daily life emotional and cortisol stress-sensitivity in psychosis.

Habets P, van Os J, Gronenschild E, Weltens I, Marcelis M for G.R.O.U.P.:

Cortical thickness alterations and risk for psychotic disorder: evidence for an intermediate phenotype.

Gronenschild E, Habets P, Jacobs H, Mengelers R, Roozendaal N, Marcelis, M: How reliable and accurate is FreeSurfer? The effects of FreeSurfer version, workstation type and Mac OS version on neuroanatomical volume and cortical thickness measurements.

\section{Contributions to books}

Marcelis M, Habets P (2011) Hoofdstuk 15c Biologische risicofactoren;

Obstetrische complicaties, in (Eds Cahn W, Krabbendam L, Myin-Germeys I., Bruggeman R., de Haan, L.) Handboek schizofrenie. Uitgeverij De Tijdstroom. 


\section{Conference presentations}

\section{National}

Habets P, Weltens I, Domen P, van Os J, Marcelis M. Cortical thickness in psychosis: indicator of genetic liability? Tijdschrift voor de psychiatrie 2007; 49: po-40.

Habets P, Weltens I, Goebel R, van Os J, Marcelis M. Verminderde corticale dikte bij patiënten met psychose en hun familieleden. Tijdschrift voor de Psychiatrie 2008; 50: s31.

Habets P, Weltens I, van Os J, Goebel R, Marcelis M. Cortical thickness alterations in patients with psychotic disorder and their siblings: evidence for an intermediate phenotype? 2009; Research day School for Mental Health and Neuroscience.

Habets P, Collip D, Gronenschild E, van Bronswijk S, van Os J, Myin-Germeys I, Marcelis M. Stress sensitiviteit en brein veranderingen in psychose: Bewijs voor verstoorde functie van de Hypothalamus-Hypofyse-Bijnieras? 2010; Schizofreniecongres Zwolle.

Habets P, Collip D, Gronenschild E, van Bronswijk S, van Os J, Myin-Germeys I, Marcelis M. Stress sensitivity and brain alterations in psychotic disorder: evidence for disrupted functioning of the HPA-axis? 2011; Research day School for Mental Health and Neuroscience.

\section{International}

Habets P, Krabbendam L, van Os J, Hofman P, Suckling J, Bullmore E, Woodruff $P$, Marcelis $M$. The cognitive relevance of a structural endophenotype in psychosis. Schizophrenia Research 2006; 81: 158.

Habets P, van Os J, Hofman P, Goebel R, Marcelis M. Cortical thickness and psychosis: a family study. Schizophrenia Bulletin 2007; 33: 334.

Habets P, Weltens I, van Os J, Goebel R, Marcelis M. Cortical thickness in psychosis: A family study. Schizophrenia Research 2008; 102: 70.

Habets P, Weltens I, van Os J, Goebel R, Marcelis M. Cortical thinning in the posterior cingulate gyrus: an endophenotype for schizophrenia? Schizophrenia Bulletin 2009; 35: 220. 
Habets P, van Os J, Goebel R, Marcelis, M. Microstructural brain alterations and working memory in psychosis: relationship with genetic liability? Cognitive Neuroscience Society 2009. Annual Meeting program.

Habets $\mathbf{P}$, Marcelis M, Gronenschild E, Drukker M, van Os J. Seeing is believing: a structural neuroimaging paradigm of gene-environment interactions in schizophrenia. Schizophrenia Research 2010; 117: 155.

Habets $\mathbf{P}$, Gronenschild E, van Os J, Marcelis $M$. The deficit syndrome in schizophrenia: associations with hippocampal volume and prefrontal cortical thickness. Schizophrenia Research 2010; 117: 226.

Habets P, Gronenschild E, van Os J, Marcelis M. Reduced cortical thickness as an outcome of differential sensitivity to environmental risks in schizophrenia. Early Intervention in Psychiatry 2010; 4 (Suppl. 1): 36.

Habets P, Collip D, Myin-Germeys I, Gronenschild E, Lardinois M, Lataster T, van Bronswijk S, van Os J, Marcelis M. Pituitary volume, stress-reactivity and genetic risk for psychotic disorder. Schizophrenia Bulletin 2011; 37:166. Marcelis M, Habets P, Roebroeck A, Goebel R, van Os J. Cerebral connectivity, schizophrenia and genetic liability: a diffusion tensor imaging study. Schizophrenia Bulletin 2007; 33: 345.

Marcelis $\mathrm{M}$, Habets $\mathbf{P}$, van Kroonenburg $\mathrm{M}$, Domen $\mathrm{P}$, van Os J. Bone mineral density in patients with psychosis and non-psychotic siblings Schizophrenia Bulletin 2009; 35: 39.

Marcelis M, Habets P, Weltens I ,Gronenschild E, van Os J. Widespread, heritable, brain alterations in individuals with schizophrenia and individuals 'at risk': evidence for a cortical thickness intermediate phenotype. Schizophrenia Research 2010; 117: 339-340.

Collip D, Habets P, Marcelis M, Gronenschild E, Lardinois M, Lataster T, van Os J, Myin-Germeys I. Hippocampal volumes predicting emotional and biological stress-reactivity in psychosis. Schizophrenia Bulletin 2011; 37:161. 

